\title{
Los procesos de incorporación de las TIC en escuelas secundarias de Rio Gallegos. Efectos, avances y problemas
}

\section{The processes of incorporation of TIC in secondary schools in Rio Gallegos. Effects, advances and problems}

\author{
Federico Jorge Laje, Alejandro Gasel \\ flaje@uarg.unpa.edu.ar,agasel@uarg.unpa.edu.ar \\ Unidad Académica Rio Gallegos - Universidad Nacional de la Patagonia Austral \\ Av. Lisandro de la Torre 860 - Río Gallegos - Santa Cruz - Argentina
}

Recibido: 11/03/2019. Aceptado: 25/09/2019

\section{RESUMEN}

La educación es parte del conjunto de un entramado más amplio y complejo como lo es la sociedad donde las tecnologías de la información y comunicación (TIC) comenzaron a tener un lugar ponderado en la cotidianidad. Sin embargo, las tecnologías no operan por sí misma, sino que son los sujetos y los contextos los que otorgan el sentido a las prácticas que acontecen.

El presente trabajo se enmarca en la línea de estudios que intentan abordar la incidencia, los efectos y avances de los programas de integración de las TIC en establecimientos educativos. Dichas líneas de investigación se instalan en la necesidad de conocer cómo las comunidades educativas van incorporando y apropiándose de las nuevas configuraciones pedagógicas que supone el trabajo con las TIC.

En una primera fase se trabajó en la conformación de un estudio exploratorio descriptivo, a través del diseño de un instrumento de encuesta validado por expertos, destinado a docentes de escuelas secundarias de Rio Gallegos. Esta instancia del trabajo nos permitió tener un primer acercamiento para identificar algunos rasgos sobre los usos y prácticas pedagógicas con TIC en el contexto de las escuelas, caracterizando la población de profesores del nivel medio de nuestra localidad. En una segunda fase de profundización, se realizaron entrevistas en profundidad, seleccionando a docentes para documentar sus testimonios respecto a su práctica pedagógica en las escuelas de nuestra comunidad local. Las entrevistas en profundidad priorizaron la particularización de la experiencia del profesorado, preservando "las realidades múltiples, las visiones diversas y procesos situados de lo que sucede". (R. Stake, 2005), a partir de la práctica que supone la enseñanza enriquecida con tic. Este tratamiento y abordaje metodológico de estudio nos posibilitó hacer un análisis comparativo entre las unidades estudiadas, centrándose en los aspectos más relevantes del problema analizado para poder extraer conclusiones.

Palabras clave: Alfabetización Digital; Integración de las TIC; Modelo 1 a 1.

\begin{abstract}
Education is part of a broader and more complex framework, such as the society in which information and communication technologies (ICTs) began to have a weighted place in
\end{abstract}


everyday life. However, technologies do not operate by themselves, but it is the subjects and contexts that give meaning to the practices that take place.

This work is part of the line of studies that attempt to address the impact, effects and advances of ICT integration programs in educational establishments. These lines of research are based on the need to know how educational communities are incorporating and appropriating the new pedagogical configurations involved in working with ICTs.

In the first phase, work was done on the creation of a descriptive exploratory study, through the design of a survey instrument validated by experts, aimed at secondary school teachers in Rio Gallegos. This instance of the work allowed us to have a first approach to identify some features about the uses and pedagogical practices with ICT in the context of the schools, characterizing the population of teachers of the middle level of our locality. In a second phase of deepening, in-depth interviews were conducted, selecting teachers to document their testimonies regarding their pedagogical practice in the schools of our local community. The in-depth interviews prioritized the particularization of the teachers' experience, preserving "the multiple realities, the diverse visions and situated processes of what happens". (R. Stake, 2005), starting from the practice of teaching enriched with tic. This treatment and methodological approach of study made it possible for us to make a comparative analysis between the units studied, focusing on the most relevant aspects of the problem analysed in order to draw conclusions.

Key words: Digital Literacy; ICT Integration; Model 1 to 1.

\section{1.- INTRODUCCIÓN}

La educación es parte del conjunto de un entramado más amplio y complejo como lo es la sociedad donde las tecnologías de la información y comunicación (TIC) comenzaron a tener un lugar ponderado en la cotidianidad. Sin embargo, las tecnologías no operan por sí misma, sino que son los sujetos y los contextos los que otorgan el sentido a las prácticas que acontecen.

En esta sociedad de la información interconectada, en donde las fronteras y delimitaciones espaciales y temporales se entremezclan, el alcance de los cambios y trasformaciones que se suceden aún no cuenta con suficientes certezas ni anclajes consolidadas o como diría Harvey (1990:393) “(...) se logra la plenitud de su comprensión a través del devenir (...)”.Sin embargo, es compartido el asombro e impacto que las TIC están teniendo en todas las esferas sociales y campos del saber. Con frecuencia, la velocidad y vértigo con que aumenta el nivel de circulación del conocimiento y la información, se adelante incluso a la formalidad de normas legales y se imponen las propias lógicas de esta dinámica tecno cultural que nos habita.

En las coordenadas del campo político educativo, en los últimos años han sido claves en el contexto mundial y regional el horizonte de la inclusión digital. Una expresión de esta clave epocal, fue en 2010 cuando en Argentina sucede la creación del Programa Conectar Igualdad, que promovió no solo una agenda prioritaria a nivel federal, en particular en el nivel secundario, sino que enfatizó:

“(...) se propone trabajar para lograr una sociedad alfabetizada en las nuevas Tecnologías de la Información y la Comunicación (TIC), con posibilidades de un acceso democrático a recursos tecnológicos e información sin distinción de grupo social, económico ni de las más diversas geografías, tanto rurales como urbanas." (Decreto No 459/10).

El presente trabajo se enmarca en la línea de estudios que intentan abordar la incidencia, los 
efectos y avances de los programas de integración de las TIC en establecimientos educativos. Dichas líneas de investigación se instalan en la necesidad de conocer cómo las comunidades educativas van incorporando y apropiándose de las nuevas configuraciones pedagógicas que supone el trabajo con las TIC.

En el marco de esta investigación nos proponemos indagar en los procesos de incorporación de las TIC en escuelas secundarias de la ciudad de Río Gallegos, en la Patagonia Austral Argentina, indagando sobre las prácticas pedagógicas que realizan los docentes a partir de los nuevos escenarios de alta disposición tecnológicas que habitan en las aulas

De este modo nos planteamos como objetivo general:

Analizar las tendencias de los docentes de nivel medio en la Patagonia Austral, en cuanto al uso e integración de las TIC en la práctica pedagógica, identificando las posibilidades reales de uso, los obstáculos percibidos que genera la implementación y uso de tecnología en la clase.

Asimismo como objetivos específicos buscamos:

Determinar el conocimiento y uso de las TIC en las prácticas pedagógicas de los docentes de nivel secundario.

Reconocer las variables que promueven una inclusión genuina de las TIC en escenarios de alta disposición tecnológica en las aulas.

Establecer las estrategias que están implementando en propuestas pedagógico didácticas en clase y conocer los posibles problemas asociados a la práctica pedagógica mediada por TIC. Identificar el grado de apropiación de las TIC por parte de los docentes y su relación con el logro de objetivos planteados en sus prácticas pedagógicas áulicas.

Dado que este trabajo constituye una investigación educativa, las metodologías que se seleccionan pretenden estudiar de manera significativa hechos referentes a las prácticas pedagógicas con TIC de los docentes en escuelas secundarias: su trabajo de enseñanza, sus historias de formación, sus opiniones y representaciones acerca de la inclusión digital en los escenarios de alta disposición tecnológica en las aulas.

Con este horizonte, se considera un tratamiento metodológico que integraría dos momentos:

En una primera fase se optará por la conformación de un estudio exploratorio descriptivo, a través del diseño de un instrumento de encuesta validado por expertos, destinado a docentes de escuelas secundarias de Rio Gallegos. Esta instancia del trabajo nos permitiría tener un primer acercamiento para identificar algunos rasgos sobre los usos y prácticas pedagógicas con TIC en el contexto de las escuelas, caracterizando la población de profesores del nivel medio de nuestra localidad.

En una segunda fase de profundización, se realizaría una estrategia de análisis, a través de entrevistas en profundidad, seleccionando a docentes para recoger su testimonio respecto a su práctica pedagógica en las escuelas de nuestra comunidad local. Las entrevistas en profundidad priorizaría la particularización de la experiencia de los docentes, preservando "las realidades múltiples, las visiones diversas y procesos situados de lo que sucede". (R. Stake, 2005), realizando un análisis de las diferentes configuraciones didácticas que supone la enseñanza enriquecida con tecnología.

Finalmente este tratamiento y abordaje metodológico de estudio posibilitaría hacer un análisis comparativo entre las unidades estudiadas, centrándose en los aspectos más relevantes del problema analizado para poder extraer conclusiones.

Algunas de las preguntas que orientan la investigación, han sido las siguientes: ¿De qué modo los docentes de la localidad de Rio Gallegos incorporan las TIC en su práctica 
pedagógica?; ¿Cómo se implementan, de manera situada y contextualizada, las Tecnologías digitales en la enseñanza?;¿Qué factores prevalecen a la hora de optar por el uso de herramientas TIC en el aula?; ¿Qué desafíos y dificultades plantea para la práctica pedagógica los nuevos escenarios de alta disposición tecnológica en las aulas?

\section{1.-Estructura del documento}

El trabajo tiene como horizonte situar las problemáticas que plantean las prácticas pedagógicas con TIC, sobre todo a partir de las iniciativas de inclusión digital en la escuela que proliferaron en los últimos años, en nuestra región. Por ello nos proponemos realizar el siguiente recorrido:

En el apartado siguiente se presentan definiciones y perspectivas marco de orden teórico realizando un desarrollo conceptual sobre las cuestiones vinculadas a la competencia digital, las nuevas alfabetizaciones y en particular los procesos de incorporación de tecnología en la educación formal. Seguidamente se analizan los antecedentes del estado del Arte, a partir de la implementación de los programas 1 a 1 de inclusión digital. Se destacan los informes e investigaciones realizadas en la región, en el país, y en las provincias de la Patagonia Austral, subrayando los principales desafíos que plantean las TIC para la práctica pedagógica y la formación del docente. Luego, se presenta la estrategia metodológica del trabajo, señalando las particularidades teóricas y metodológicas de la investigación. Se detalla la validación y construcción de los instrumentos, tanto de la encuesta como del guión de las entrevistas llevadas a cabo. Finalmente se realiza un análisis de los resultados obtenidos y una construcción comprensiva de los aspectos relevantes de nuestra problemática abordada.

El último apartado recogemos las conclusiones y notas reflexivas del recorrido del trabajo de investigación, dejando planteado algunos horizontes para seguir profundizando la investigación en el campo de los procesos de integración de las TIC en la educación.

\section{2.- Perspectivas y definiciones marco}

Dado el contexto donde predominan los procesos de inclusión digital en las escuelas, nos proponemos focalizar en el marco de las políticas 1 a 1 , las particularidades que asume el trabajo docentes mediado por las tecnologías; Es decir, nos preguntamos sobre cuáles son las prácticas de enseñanza y las representaciones construidas acerca de las políticas de inclusión digital por parte de los profesores de escuelas secundarias de Rio Gallegos

En este apartado, centraremos nuestra atención en poner en evidencia los problemas de índole teórico que fueron necesarios relevar para llevar adelante nuestra investigación.

Consideramos que el campo de problemas que nos ocupa, implica un objeto complejo, con lo cual es necesario un abordaje que dé cuenta de las múltiples dimensiones de análisis que atraviesan al fenómeno. En este horizonte, se considera un entrecruzamiento propio del análisis de las prácticas de enseñanza en ambientes particulares, como lo son los de alta disposición tecnológica (Maggio 2012)

Comenzamos planteando una contextualización del problema y significado de la educación en la sociedad digital para definir y poner en evidencia la tensa relación entre la sociedad digital, las TIC y la Educación. Dicha relación atraviesa la práctica pedagógica y necesita una explicación respecto al papel y rol del docente en este contexto. En este marco de planteos de corte teórico nos urge revisar el concepto de Alfabetización digital, definiendo la evolución de las diferentes alfabetizaciones, marcos y modelos de la competencia digital, llegando a revisar diferentes bibliografías de los programas de integración TIC en Educación. 
En el presente apartado, se presentarán también las diferentes miradas y reflexiones teóricas en relación a las iniciativas de alfabetización digital, enmarcadas en las denominadas políticas educativas de inclusión digital 1 a 1 . En particular, se subrayan los principales aportes teóricos acerca de los planes "una computadora, un alumno" en general y de éstos en tanto políticas públicas en particular. Finalmente, se pone de relieve la importancia de las políticas de alfabetización e inclusión digital en la educación, entendiéndolas no como un todo homogéneo, lineal, sino como una instancia que abre a la complejidad del cambio, transformación de las prácticas pedagógicas en el aula.

En el marco de nuestro trabajo, entendemos que las Tecnologías de la Información y la Comunicación (TIC), se encuentran comprendidas por un universo de múltiples dispositivos: desde computadoras portátiles, celulares, videojuegos, etc., que posibilitan modos y medios de comunicación cada vez mayores y más variados, incorporándose a gran escala en nuestra cotidianeidad y desde luego en ambientes como el educativo. Sostenemos también la perspectiva de que las TIC no deben considerarse como meras herramientas neutras o materiales de enseñanza sin sentido, sino como representaciones sociales que constituyen modalidades de pensamientos prácticos orientados hacia la comunicación, la comprensión y el dominio del entorno social, material e ideal que permiten mediar el cambio.

Esta es la mirada que atraviesa al marco teórico. Para poder acercar anclajes conceptuales que permitan comprender qué y cómo son estas prácticas de enseñanza mediadas por tic; Resulta necesario, asimismo, en el marco referencial de nuestro trabajo focalizarnos en una perspectiva cultural de la sociedad dela información, donde proliferan nuevos territorios digitales que van reflejando los límites y posibilidades de estas tecnologías y se vislumbran nuevas interacciones con los modos de consumir, crear e interactuar en el horizonte de esta sociedad digital, conformando nuevos sentidos y discursos para el campo educativo.

En síntesis, se presentan perspectivas para organizar este marco teórico, donde, más allá de la especificidad de cada una, hay un entrecruzamiento y foco propio de un análisis de los sentido que adquieren las prácticas pedagógicas de los docentes, en particular aquellas que se sitúan en los nuevos procesos de inclusión digital, a partir de las políticas de inmersión de tecnología en las escuelas.

\section{1.- La educación en la sociedad digital}

¿Cuáles son esas prácticas educativas digitales que representan nuevas formas de alfabetización, nuevas experiencias que podrían articularse con diversos contenidos? ¿Cómo pueden reconfigurar el escenario educativo en el horizonte de la sociedad de la información? ¿Por qué implicaría un cambio en las formas de enseñar y aprender?

Estas son tan solo algunas de las preguntas que orientaron la investigación pero que no se pueden entender sin una lectura amplia del contexto y sin un recorrido teórico que nos acerque de manera global a nuestra problemática.

Nuestras sociedades han experimentado en las últimas décadas un profundo proceso de transformación estructural, significado por la importante revolución digital basada en las TIC, que conforma una economía global, así como otros proceso y cambio culturales importantes (Castell 2000). Los cambios que han acontecido a partir de la emergencia del mundo digital, signada por «el nuevo conjunto de herramientas, soportes y canales para el tratamiento y acceso a la información» (González Soto et al., 1996, p. 413), van interpelando tanto las prácticas institucionales como así también la manera de comprender nuestro comportamiento y comunicación con los demás y el mundo (Adell, 2006; Coll \& Monereo, 2008). 
Según Cabero (2008), se trata de una sociedad globalizada, dinámica, conectada, que gira alrededor de las TIC evolucionando a gran velocidad, amenazada por una nueva desigualdad o brechas digitales, que van marcando nuevos horizontes de transformación de los conceptos de espacio y tiempo, por la saturación de la información, y que ha dado lugar a un nuevo tipo de inteligencia, colectiva y ambiental. Como sostiene (Negroponte, 1995), las TIC han desmaterializado, deslocalizado y globalizado la información, pasando de una cultura basada en el átomo a una cultura basada en el bit. En las últimas décadas, diversidad de autores han apuntalado el concepto de «sociedad de la información» para dar cuenta de aquellos procesos que se instalan en la denominada "sociedad postindustrial", que en su conjunto implican profundas transformaciones tanto en los aspectos económicos, como sociales, y culturales dando referencia a una nueva conformación de nuestras comunidades contemporáneas (Adell, 2006; Colas, 2003).

Asimismo, vamos transitando un nuevo cambio de paradigma centrado tanto en el acceso como la producción de información y conocimiento, donde las tecnologías digitales se van incorporando a todos los campos de nuestra esfera social, educativa, económica, transformando nuestra cotidianidad y dando lugar a significativas transformaciones históricas, que se enmarcan en la llamada sociedad de la información y el conocimiento (Castells, 2000). En términos de (Castells, 2004; van Dijk, 2006) asistimos a una nueva transformación a la que algunos autores llaman sociedad red.

Como sostiene Vacas (2010) las tecnologías móviles implican mucho más que la movilidad que brinda el dispositivo del teléfono celular, sino que también abarca un conjunto amplio de dispositivos, cada vez más ligeros y accesibles, y es, sobre todo, un factor disruptivo que ha favorecido la completa desmaterialización digital actual y que introduce nuevos escenarios inéditos. Estos nuevos escenarios, suponen una nueva transformación del contexto espaciotemporal, la necesidad de estar siempre conectados, la inmediatez, la mayor importancia de las relaciones sociales o la creación y compartición de contenidos en red, permitiendo pasar de ser consumers, consumidores pasivos de información, a prosumers (acrónimo formado por las palabras producer y consumer, acuñado inicialmente por la obra de Alvin Toffler, 1980]) de la misma, entre otras características (Feijo, 2010).

En estas coordenadas, planteamos el debate que nos asiste en este trabajo, en relación al entramado que vincula el fenómeno de las TIC y la educación. Estas cuestiones implican pensar nuevas formas de modernización de las instituciones escolares, y en este orden, las tecnologías digitales poseen un enorme potencial para transformar procesos formativos y proporcionar a los estudiantes nuevas oportunidades de aprendizaje. Como sostiene (García et al., 2010), en la época contemporánea los proceso de integración de las TIC en la educación está favoreciendo que el conocimiento se «descentralice», que los profesores como así también las instituciones escolares en donde realizan sus prácticas, vayan perdiendo paulatinamente sus recelos hacia las tecnologías y los entornos de aprendizaje están experimentando una importante transformación. Este nuevo proceso de incorporación de las tecnologías digitales en la organización escolar se subraya al docente como un agente protagonista indispensable en la instancia del diseño formativo. Preparar a los estudiantes para el siglo XXI representa un desafío para los educadores (Hall et al., 2014; Mishra, Koehler \& Henirksen, 2011).

Por su parte Gairín y Muñoz (2008) afirman que estos procesos de cambios, no implican sólo una necesidad sino que supone una nueva realidad que tiende a conformarse en nuestras sociedades signadas por la dinámica de la constante transformación. En tal sentido (Salinas 2004) propone que todo proceso de trasformación supone además el involucramiento de 
varios aspectos, entramados en conjunto, tales como: el profesorado, el alumno, las metodologías y las propias instituciones educativas

Asimismo, en una sociedad cada día más en red, Touriñán (2001) apunta que el papel del profesor resulta fundamental como guía e instrumento para un aprendizaje significativo, centrado en ayudar a construir conocimiento en red, gestionando capacidades, habilidades y conocimientos de sus alumnos, y motivando y aprovechando sus posibilidades de aprendizaje (Colás, 2003).

\section{2.- La competencia digital y las nuevas alfabetizaciones}

Como venimos planteando, la sociedad en los últimos años ha vivido un importante proceso de transformación, motivado en parte por la revolución que ha supuesto la incorporación de las TIC que incluye las diversas dimensiones y actores que interviene en ella. En orden a ello, (Cabero \& Llorente, 2008; Castells, 2004), sostienen que una sociedad globalizada en la que se proponen cambios a gran velocidad, marcada por la transformación espaciotemporal, la saturación de información, y nuevas formas de inteligencia colectiva y en red implica una nueva conformación social que además, plantea nuevos escenarios y nuevos retos, frente a nuevas desigualdades y amenazas como la que supone la denominada "brecha digital".

Ante tales desafíos, diferentes administraciones e instituciones manifiestan la necesidad de replantearse nuevas prioridades educativas para el siglo XXI que proporcione al ciudadano las estrategias necesarias para hacer frente a tales demandas, entre ellas la necesaria adquisición de competencias relacionadas con los medios digitales para participar de manera activa y funcional en la sociedad actual (Ferrari, 2012). En este marco, es importante preguntarse sobre dos categorías que se abren como importantes: la alfabetización y la competencia digital.

La nueva sociedad de la información y comunicación, pone de manifiesto la necesidad de una ciudadanía capaz de acceder, evaluar de manera crítica, organizar, interpretar la información y comunicarse a través de múltiples formatos digitales, en constante transformación (Somerville, Lampert, Dabbour, Harlan \& Schader, 2007). La enorme proliferación de las TIC ha provocado que, cada día de forma más evidente, los individuos tengan que enfrentarse a situaciones que requieren la utilización de nuevas habilidades técnicas, cognitivas y sociales. Habilidades que han dado lugar a la comúnmente denominada «alfabetización digital» (Eshet-Alkalai, 2012; Gilster, 1997; Lankshear \& Knobel, 2008).

En relación a la alfabetización o competencia digital, Area, (2011, p. 5) plantean que «hace varias décadas se consideraba una persona alfabeta y culta a aquella que sabía leer un periódico, un libro, o una revista y comentar lo que allí estaba escrito. Hoy en día, además de todo esto, debemos ser capaces de manejarnos con cualquier dispositivo, y navegar o consultar la información desde cualquier ordenador, tableta digital, o teléfono móvill”.

Desde un sentido amplio, la cuestión de la alfabetización está íntimamente relacionada con la lectura, la escritura, el habla, la adquisición del lenguaje y en general, con las tecnologías que, de manera cambiante afectan al texto (Buschman, 2010). Alfabetizar, según García Carrasco (2009), es transmitir ese «poder de traducción» que los seres humanos adquieren al hablar, ampliando su vocabulario y adquiriendo la habilidad de interpretar los signos gráficos que representan palabras y oraciones con sentido. Es la habilidad de dotar a los individuos de la capacidad de expresar, comunicar, conocer y compartir, a través del lenguaje, su propia experiencia, la de los demás y la del mundo que le rodea, y en este sentido, es un concepto dinámico, y que varía en función del contexto cultural y tecnológico específico de cada 
período histórico (Area et al., 2012). Un concepto que, según este autor, ha estado muy vinculado desde un inicio a la invención de la imprenta y de un sistema que giraba alrededor del libro y que produjo una serie de efectos económicos, sociales y también educativos que han estado vigentes hasta el presente siglo XXI.

Con la llegada del siglo XX y de los diferentes avances tecnológicos como la radio, la fotografía, el cine o la televisión aparecieron nuevas formas de representación de la información ligadas al lenguaje audiovisual. Como señalan Lankshear y Knobel (2008), a mediados de siglo XX la alfabetización pasó a centrarse en la interpretación y la expresión crítica de las diferentes manifestaciones audiovisuales y artísticas. Tras esta revolución audiovisual, a partir de los años 70 comenzó una revolución digital con la aparición y expansión de las computadoras, y el posterior inicio de Internet.

En los años 70 la alfabetización pasó a centrarse especialmente en el acceso y el manejo de esta tecnología. Por ello, la denominada alfabetización tecnológica, informática o computacional abarca los conocimientos y las destrezas necesarias para entender y utilizar las computadoras y las aplicaciones informáticas de manera productiva y eficaz, tanto para finalidades personales como laborales (Ferrari, 2012; Nawaz \& Kundi, 2010).

Años más tarde, en la década de los 80 y 90, fruto de los avances tecnológicos en campos como la biblioteconomía y la documentación, y de la posterior influencia de la red, el foco de atención se situó en la alfabetización informacional. En estos años, se fueron estableciendo una serie de normas y estándares, y se definió esta alfabetización como «la capacidad de acceder, evaluar y utilizar información de una variedad de fuentes» (Doyle, 1994, p.1). Durante esos años, diferentes instituciones la ALA, entre otras, desarrollaron de forma exhaustiva la alfabetización informacional, estableciendo una serie de normas y estándares, y definiéndola como «la capacidad de acceder, evaluar y utilizar información de una variedad de fuentes» (Carbó, 1997).

Según la ALA (2006), una persona alfabetizada en información es capaz de:

- determinar el alcance de la información necesaria;

- acceder a la información requerida de manera eficaz y eficiente;

- evaluar la información y sus fuentes de forma crítica;

- incorporar la información seleccionada a su conocimiento;

- usar la información de manera efectiva para lograr un propósito determinado; y

- entender los aspectos económicos, legales y sociales que rodean al uso de la información ética y legalmente.

En los últimos veinte años, asociaciones como la mencionada anteriormente han seguido trabajando en esta alfabetización y han realizado un importante esfuerzo por reformularla y adaptarla a los nuevos tiempos, alejándola de los enfoques más tradicionales vinculados únicamente a la alfabetización impresa y bibliotecaria (Buschman, 2010).

Además de la alfabetización tecnológica y de la informacional, en estos años han aparecido en la literatura científica y de divulgación distintas alfabetizaciones relacionadas con los medios digitales, una de ellas es la alfabetización media o mediática. Rubin (1998) define la alfabetización media como el proceso de acceso, análisis crítico y creación de mensajes a través de herramientas multimedia, y cuyo objetivo es promover la autonomía mediante el desarrollo del análisis, el razonamiento y la comunicación. Para estos autores, la alfabetización va más allá que el mero hecho de la comprensión. No se trata solo de leer los medios digitales y multimedia sino de tomar conciencia de por qué esos mensajes están ahí, los códigos que se utilizan, comprender las fuentes y las tecnologías, la interpretación y el impacto de los mensajes (Rubin, 1998). 
La National Association for Media Literacy Education (NAMLE) (AMLA, 2007) afirma que es la alfabetización es una actitud reflexiva y crítica sobre los mensajes que recibimos y creamos, y propone una ampliación del concepto de alfabetización incluyendo todas las formas multimedia. Muy vinculadas o integradas en esta han quedado alfabetizaciones más clásicas como la visual, entendida como la capacidad de «leer», interpretar y comprender la información presentada a través de imágenes pictóricas o gráficas, y convertir la información de todo tipo en imágenes, gráficos o formas que ayudan a comunicar la información; o la alfabetización comunicativa, como aquella capacidad de comunicar de manera efectiva como individuos y trabajar de manera colaborativa en grupos utilizando distintas herramientas (Covello, 2010).

Siguiendo estos razonamientos, la alfabetización y la competencia digital se convierten en problemas que deben ser abordados de manera rigurosa. Uno de los primeros autores en abordar el concepto de la alfabetización digital fue Gilster (1997), quien la definió en términos muy ligados a la educación y al papel revolucionario que ha supuesto internet, e identificando al estudiante que está alfabetizado digitalmente como aquel que posee un conjunto de habilidades relacionadas con el acceso, la evaluación y la gestión de la información, de carácter multimedia y a través de la red, aplicándolas a su proceso formal de aprendizaje (Meyers, Erickson \& Small, 2013). A partir de la definición de Gilster (1997), Bawden (2008) presenta una seria de habilidades y actitudes que conforman la alfabetización digital:

- construir el conocimiento a través de diferentes fuentes y discriminando su veracidad;

- buscar y analizar de manera crítica la información, revisando su validez e integridad;

- leer y entender material dinámico y no secuencial;

- tomar conciencia del valor de las herramientas tradicionales junto con los actuales medios de comunicación;

- conocer la importancia de las redes de personas para la colaboración y ayuda mutua;

- utilizar sistemas de filtrado y gestión de la información; y

- publicar y comunicar información habitualmente y de manera fácil.

Según Martin (2005) la alfabetización digital es la conciencia, la actitud y la capacidad de los individuos para utilizar adecuadamente las herramientas y utilidades para identificar, acceder, gestionar, integrar, evaluar, analizar y sintetizar los recursos digitales, construir nuevos conocimientos, crear expresiones de los medios y comunicarse.

Según Ferrari, Punie y Redecker (2012), existen dos principales aproximaciones al concepto de alfabetización o competencia digital. El primer enfoque entiende la competencia digital como la convergencia de múltiples alfabetizaciones, por lo que desde esta perspectiva se entiende la competencia digital como la suma de la alfabetización tecnológica o informática, la alfabetización informacional, la alfabetización audiovisual o mediática, y la alfabetización comunicativa (Larraz, 2012). Desde la otra aproximación, la competencia digital se entiende como una nueva alfabetización. A pesar de que todas las alfabetizaciones pueden llegar a converger en la digital, la suma de todas no equivale a lo que podríamos denominar competencia digital sino que va más allá e implica nuevos componentes y una mayor complejidad (Ferrari et al., 2012). 
Desde otro ángulo, se observan también dos aproximaciones al concepto de alfabetización digital, una de tipo más instrumental y objetivista, y otro más de tipo sustantivo y constructivista (Nawaz \& Kundi, 2010), como a continuación describimos.

Desde el primer enfoque se entiende la alfabetización como el conjunto de habilidades y destrezas en relación a las TIC, necesarias para moverse en la sociedad del siglo XXI. Desde esta óptica, según los autores, se considera a la tecnología como una herramienta neutra, sin ningún valor inherente y su impacto radica en cómo se utiliza, por lo que el grado de adquisición de esta resulta fácil de evaluar y medir a través de pruebas e instrumentos objetivos. Según Claro et al. (2012), se trata de un enfoque muy ligado a las habilidades o competencias clave para el siglo XXI, tales como la resolución de problemas, el pensamiento crítico y creativo, o la autogestión, especialmente en entornos digitales y con contenidos digitales.

Desde un enfoque más crítico, algunos autores plantean que la alfabetización digital no puede limitarse a una visión utilitarista y reduccionista de determinadas habilidades digitales que un grupo de personas no alfabetizadas debe adquirir, sino que va ligado a una visión más amplia y crítica de la sociedad, que abarca desde la economía a la política (Buschman, 2010), y por tanto implica movilizar de manera crítica una serie de habilidades, conocimientos y actitudes en contextos regidos por reglas y normas convenidas socialmente (Kahn \& Kellner, 2005).

\section{3.- Las tic en la escuela}

La investigación se enmarca en un escenario educativo particular, que se encuentra en constante expansión y desarrollo en materia de integración de tecnologías en las aulas a gran escala. Esto se debe principalmente a programas como los que impulsaron el modelo $1 \mathrm{a} 1 \mathrm{y}$ que se implementaron recientemente en la región, para los distintos niveles del sistema educativo formal.

La disponibilidad de TIC en las escuelas es un eje clave para las agendas públicas, ya que incrementa las condiciones de infraestructura física que dan posibilidades para el desarrollo de diversas prácticas de enseñanza; según Sunkel (2011) esto se relaciona con el concepto de densidad informática, es decir, la tasa de estudiantes por computadora, un factor que condiciona el uso que estudiantes y profesores pueden hacer de las TIC .

Entonces, en un escenario más amplio, los sistemas y objetos tecnológicos que atraviesan la cotidianeidad llevan a un constante replanteo sobre qué es la sociedad, la educación, la producción y la vida.

En este contexto el rol social de la escuela se torna imprescindible, ya que su función principal es la de acercar conocimientos y experiencias, contextos y motivaciones sociales para aprender, que no se experimentan en otros espacios (Sunkel, 2011).

Por lo que en relación a los desafíos de la sociedad actual, la escuela se presenta como la institución central para desarrollar una comprensión crítica de la cultura mediática en la que se encuentran inmersos los sujetos (Buckingham, 2008).

Esto implica brindar las herramientas necesarias para garantizar una participación activa en la sociedad en general, que les permita a los estudiantes interpretar, entender y evaluar conocimientos, así como también reflexionar y explorar las posibilidades para crearlos y compartirlos.

Dado el importante proceso de transformación, motivado en parte por la revolución que ha supuesto la sociedad de la información y la comunicación, con sus diversas dimensiones y aspectos que intervienen en ella, en el presente apartado, se presentarán las diferentes 
miradas y reflexiones teóricas en relación a las iniciativas de alfabetización digital, enmarcadas en las denominadas políticas educativas de inclusión digital 1 a 1.

En particular, se subrayan los principales aportes teóricos acerca de los planes "una computadora, un alumno" en general y de éstos en tanto políticas públicas en particular. Específicamente, se intenta dar cuenta de los diversos de los trabajos que recuperan a estos planes como objeto de estudio y su diversidad de ejes temáticos. Finalmente, se pone de relieve la importancia de las políticas de alfabetización e inclusión digital en la educación, entendiéndolas no como un todo homogéneo, lineal, sino como una instancia que abre a la complejidad del cambio, la transformación socio-educativa.

En la actualidad, podemos identificar multiplicidad de estudios e investigaciones que han proliferado en nuestra región y que se han propuesto focalizar en la vinculación de las TIC y la Educación. En dichas investigaciones se presentan varios núcleos o ejes problemáticos que pueden focalizarse en: estudios sobre las representaciones de los actores educativos, Estudios sobre evaluación de implementación de los planes o programas 1 a 1; Estudios centrados en la dimensión pedagógica-didáctica; Estudios focalizados en la educación formal en su conjunto, entendiendo los planes 1:1 como una pieza más del engranaje de las prácticas y Estudios sobre la vinculación de los planes 1 a 1 y la institución educativa (Dughera 2016)

Los estudios sobre las representación de actores educativos, reúne aquellos trabajos que se dedican a describir y analizar las representaciones que portan los principales destinatarios de las políticas de inclusión 1 a 1: los docentes y los alumnos (Celaya Ramírez et al., 2010; Zidán, 2010; Rivoir, 2010; Winocour Iparraguirre, 2013; Pittaluga y Rivoir, 2012); a partir de estos se analizan la relación existente (o no) entre tales representaciones y los usos de las mismas (Cabello y Levis, 2007; Sancho et al., 2011; Dussel y Quevedo; 2010; Tedesco; 2000; Zidán, 2010; Claro, 2010).

Asimismo en el conjunto de estos rasgos estudiados, encontramos también aquella bibliografía que refiere a otros actores educativos, tales como : los equipos de conducción y supervisores, o las familias de los alumnos, entre otros.

Con respecto a las representaciones de los docentes, podríamos poner de relieve que la mayoría de la bibliografía identifica tres grandes posicionamientos acerca de las TIC y su integración en las practicas escolares:

los indiferentes,

los que han comenzado a acercarse a este tipo de tecnologías y

los innovadores (Apple y Ferraro, 201; Trucco y Espejo, 2013).

Al respecto Zidán $(2010 ; 2011)$, analiza que dicho posicionamiento y representación respecto a las computadoras portátiles en la escuela y en particular en las aulas no debe trasladarse, ni debe ser entendido como una cuestión de desconocimiento o falta de uso personal por parte de los docentes o alumnos. En cierto sentido, poseer una representación positiva de los planes de integración de tecnología en la escuela, como asi también, tener un uso intensivo o cotidiano de las netbooks que se entregan en los programas 1 a 1 (Programa Conectar Igualdad, plan CEIBAL, etc...), no implica necesariamente una transformación en las practicas pedagógicas, ni un cambio en las concepciones y supuestos teórico metodológicos de la enseñanza (Dussel, 2011; Dughera, 2014).

Las investigaciones que refieren a los usos que realizan los docentes, subrayan entre varios aspectos, la utilización en el desarrollo de sus planificaciones y la preparación de clases en la instancia pedagógica, comúnmente con la utilización de software tales como: procesador de 
textos, hojas de cálculo, programas para presentaciones y navegadores de Internet NolascoVázquez, P. y Ojeda-Ramírez, M. (2016)

Por otra parte, tal como nos advierte Dussel $(2011,2012)$ con frecuencia muchas de las actividades propuestas por los docentes no implica necesariamente desafíos, ni aprendizajes nuevos por parte de los aprendices. En cierto sentido, las propuestas llevadas a cabo en la escuela, muchas veces desalientes los usos innovadores de las TIC o se reducen a extrapolaciones de prácticas tradicionales al formato digital. En tal línea, se va conformando un primer uso de las TIC, más bien sumido en una especie de "mito de complementariedad (Tilve, Gewerc y Álvarez, 2009) donde la aplicación de las TIC, brinda cierta satisfacción y no implicaría un cambio profundo, pero a la vez, esto podría implicar que los textos escolares continúan regulando los procesos de desarrollo curricular en la escuela.

Los estudios, presentan el debate, indicando que en más de una oportunidad es posible advertir que las actividades propuestas se podrían haber llevado a cabo con o sin la netbook. En este sentido el impacto de la incorporación de las tecnologías digitales a las prácticas de enseñanza se proyecta en pequeñas innovaciones educativas ad hoc a la metodología habitual del profesor (Dughera 2016).

Asimismo, estas prácticas de enseñanza se basan en modelos didácticos tradicionales, en los que el empleo de dichas tecnologías, así como principalmente el papel a desempeñar por aquel que aprende no juegan un papel determinante para ampliar o mejorar la calidad de lo aprendido, sino que constituye un recurso más añadido. Se observa que los usos propuestos se adaptan, en mayor o menor grado, al modelo pedagógico habitualmente desarrollado por cada profesor, dependiendo de la formación y concepción del docente hacia la enseñanza y el aprendizaje y no como un recurso catalizador de la innovación pedagógica (Area Moreira, 2010). Este proceso de implantación y cambio tecnológico en las escuelas se parece más a una modernización conservadora que a una transformación real de las prácticas educativas (Sancho y Correa, 2010).

En otro aspecto, los trabajos o estudios focalizados sobre los alumnos se orientan hacia los usos escolares y extraescolares que dichos actores realizan de este tipo de tecnologías digitales. Desde este enfoque, los estudios de investigación se focalizan en determinar el grado de impacto, analizando en qué medida el disponer de computadoras favorece cierta predisposición a los proceso de aprendizaje por parte del alumnado. En este sentido , aun no existiría evidencia consistente que permita afirmar que el uso de las TIC implique una mejora en el rendimiento escolar o una mayor aprendizaje por parte de los alumnos (Tondeur, van Braak y Valcke, 2007; Finquelievich y Feldman, 2013; Duflo, E., Linden, L., 2007;; P. Ibarraran, S. Cueto, A. Santiago y E. Severin, 2010)

Por otra parte, como señala Dughera (2016), existirá también bibliografía especializada donde se señala que la distribución de las netbooks no conlleva a una mayor permanencia en el sistema educativo, contrariamente a los supuestos contenidos en la mayoría de los programas de inclusión 1 a 1 que se implementaron en los últimos años en nuestra región latinoamericana. En cierto sentido, no se indica por tanto, que la disponibilidad e inmersión de las TIC en la escuela, no aliente a este tipo de prácticas, sino simplemente que, hasta el momento, no tiene el nivel de incidencia planeado. Asimismo, se encuentran también los estudios destinados a caracterizar, y describir las representaciones o miradas que portan al respeto los equipos de conducción, o referentes TIC institucionales (Celaya Ramírez et al., 2010; Vega García y Merchán Jaramillo, 2011). Con frecuencia este tipo de investigaciones se focalizan en las representaciones de los directivos, buscando identificar el rol significativo de 
éstos en los proceso de integración de las TIC tanto en las prácticas escolares como en las aulas.

En el conjunto de la bibliografía relevada, encontramos los estudios que propiamente se enmarcan en las investigaciones de carácter evaluativo sobre la implementación de planes o programas 1 a 1. Estos trabajos se dedican a describir y analizar este tipo de incorporación de tecnologías como política pública. La mayoría de estos estudios plantean a dichas políticas en términos intersectoriales y enfatizan el lugar destacado de los Estados en este tipo de implementaciones. La perspectiva de trabajo, pone de relieve los aspectos relacionados a los procesos y fases de implementación de los programas "una computadora por alumno".

Es decir, buscan dan cuenta de los procesos que se desarrollan a partir del "cómo", "cuando", "porque" llevar adelante este tipo de incorporaciones para que alcancen los objetivos propuestos, tales como: la inclusión social y digital, la calidad educativa y la formación para el trabajo (Valiente González, 2011, Area 2012, Sunkel, Trucco y Espejo, 2013; Sunkel y Trucco, 2012; Dussel, 2014; Vachieri, 2013).

Este tipo de trabajo, realiza aportes que refieren a la construcción de dimensiones de análisis, constructos y variables, tales como: los insumos necesarios en cada una de las etapas de ejecución de los planes, las etapas de ejecución, el tipo de financiamiento, las unidades responsables de la implementación, la comunicación y coordinación entre actores de diferentes dependencias estatales y las principales fortalezas y debilidades de éstas (OREALC/UNESCO Santiago, 2011; Sunkel, 2006; Severín, 2010; Severín y Capota, 2010) Otro aporte importante en los estudios relevados, son los trabajos que focalizan su indagación en la dimensión pedagógico didáctica; estos trabajos se dedican a describir y analizar los modos pedagógicos didácticos de incorporación de las TIC, en a partir del modelo 1 a 1 en la escuela. Dentro de éste se hallan, en mayor medida, trabajos que concentran la mirada en el tipo de configuración pedagógica dentro del espacio áulico, y las tramas que se construyen a partir de los campos de conocimiento o disciplinas del currriculum (Maggio 2012). En ellos las preguntas giran en torno a dos grandes inquietudes:

a.- cómo aprenden los alumnos destinatarios de este tipo de planes y, en algunos casos, si dicha incorporación mejora los aprendizajes y consecuentemente el rendimiento de los estudiantes (S. Papert, 1993, Negroponte, 1995, Fullan y otros, 2013;)

b.- cómo enseñan los docentes por medio de este tipo de tecnologías, si se experimentan transformaciones en las prácticas de enseñanza y en qué disciplinas estas ocurren; así como en qué instancias del momento pedagógico se suscitan. Por ejemplo, si se utilizan como disparadores de un tema (inicio de la clase), para realizar simulaciones o explicaciones (intermezzo) y/o si se incorporan al finalizar una temática o para evaluarla (cierre de la clase) (Maggio 2012)

Asimismo, dentro de esta perspectiva, los resultados sobre las posibles mejoras o el impacto de las TIC en los proceso de aprendizaje de los alumnos, resulta aún controversial. Es decir, dentro de este aspecto, existen miradas dicotómicas o posicionamientos a veces, antagónicos donde por un lado, se ubican los autores que consideran que la integración de las TIC generan mejores aprendizajes, y por otro lado se encuentran posicionamientos donde se señalan que dichas mejoras e impactos están lejos aún de producirse en la escuela (Area 2012).

Una mención particular, merecen los estudios e investigaciones centrados en las prácticas de enseñanza, donde el foco de análisis se orienta a observar, precisar y analizar la densidad y configuración que adquieren dichas prácticas mediadas por TIC.

En este tipo de trabajos, encontramos investigaciones proclives a señalar las caracterizaciones de los usos y con qué frecuencia los docentes, realizan propuestas de enseñanza-aprendizaje a 
partir de los nuevos escenarios digitales. Asimismo, se busca identificar qué tipo de usos en las prácticas de enseñzan se desarrollan y por qué se sucedería determinado tipo de uso, en relación a situaciones de enseñanza. Los trabajos que se dedican a describir las prácticas y señalan en primer lugar que falta una descripción detallada y una mayor dedicación a este tipo de investigaciones en el marco de los programas de "una computadora, un alumno" (Dunleavy, 2007). Otro aspecto destacado, consiste en observar que las transformaciones identificadas son con frecuencia secundarias o laterales en relación a las prácticas habituales de los docentes. Es decir, en general, no hay una práctica significativa a partir de la inmersión de las TIC en las aulas. De tal modo, se señala que en más de una oportunidad las netbooks se incorporan a sus planificaciones y clases sin variaciones en la concepción acerca del rol docente y en las actividades propuestas en las aulas (Cabello, R. 2011).

Pero, no obstante, existen también trabajos que han resaltado algunas transformaciones y disrupciones en la enseñanza con TIC; estos estudios señalan aspectos tales como:

a) centrar el aprendizaje en el alumno (Salinas 2004)

b) modificar el rol docente al interior de las clases (Hill \& Reeves, 2004; Russell et al., 2004),

c) mayor cantidad de horas de preparación de los contenidos a utilizar durante el desarrollo de las clases (Tounder 2005; Kerr et al., 2003), entre otros.

Al mismo tiempo, se advierte la importancia y la centralidad que tiene el disponer de Internet al momento de realizar las actividades de enseñanza con TIC (Dunleavy, 2007; Dughera, 2013).

En esta línea, se pondría de relieve el lugar destacado de las actividades on line y de aquellas que se realizan en plataformas o entornos digitales de aprendizaje. Un lugar relevante merecen también, los aportes a partir de la noción de PLE - EPL Entorno Personal de Aprendizaje (EPL) - Personal Learning Environment (PLE) (Castaneda y Adell 2011)

En otro orden, dentro de la perspectiva de los estudios sobre da dimensión didácticopedagógico, se encuentran trabajos que identifican una diversidad de obstáculos respecto al uso y apropiación de este tipo de tecnologías por parte de los docentes en las practicas escolares (Hill et al., 2002). Por ejemplo, se señalan las dificultades en relación a la inadecuación en la duración de la batería, las deficiencias en el software, o la problemática frente a la pérdida de datos, las deficiencias en la infraestructura de conectividad a Internet entre otras (Kerr et al., 2003; Hill \& Reeves, 2004).

Muchas investigaciones, permiten analizar y distinguir las continuidades y rupturas o transformaciones en el aula partir de los las nuevos modos de construcción del conocimientos en las sociedad digital. No obstante, es posible señalar que los aportes de estas investigaciones poco toman en cuenta la relación entre la dinámica de los procesos de institucionales de integración de las TIC en el aula y la dimensión pedagógico didáctica en general. En esta línea, sin embargo, resulta relevante la bibliografía encontrada que analiza la articulación entre la implementación del modelo 1 a 1 a partir de los programas de políticas TIC "una computadora, un alumno" y la organización escolar de la institución educativa en su conjunto (Lugo y Kelly, 2011; 2012; Dussel, 2014; Vega García y Merchán Jaramillo, 2011; Dughera, 2014).

En esta articulación de las TIC y la organización escolar, se hallan trabajos que sistematizan los diferentes factores que en términos organizacionales que favorecen y/o potencian la integración de tecnología y la apropiación de la misma por parte de los actores institucionales. En particular, las preguntas que orientan estos trabajos generalmente indagan acerca de la organización del tiempo y el espacio de trabajo escolar (Cabello 2011), así como los diseños 
curriculares y su vinculación respecto de las tecnologías digitales en los diferentes niveles y modalidades del sistema educativo entre otros (Lugo y Kelly, 2012).

Cabe mencionar que los procesos de innovación pedagógica, que en cierto modo, exceden por mucho únicamente a la inclusión de tecnologías digitales en las escuelas, supone superar obstáculos y dificultades, que con frecuencia implica:

a) falta de tiempo en los horarios de los actores educativos para la investigación y experimentación con las TIC;

b) insuficiente capacitación pedagógica de los docentes;

c) prevalencia del modelo tradicional de enseñanza sobre las innovaciones;

d) insuficiente apoyo de los equipos de conducción;

e) escasez de recursos educativos digitales (Dussel, 2011; Dughera, 2013).

Estos aportes, nos advierten acerca de la necesidad e implicancia de una reestructuración organizativa e integral de los centros educativos.

A modo de cierre, en este apartado hemos referido a los principales aportes teóricos e investigaciones en el campo de los programas "una computadora, un alumno" en general y de éstos, en tanto políticas educativas TIC en particular. Específicamente, se intenta dar cuenta de los múltiples aspectos que intervienen en los trabajos que recuperan a dichos programas 1 a 1 como objeto de estudio y sus implicancias en la diversidad de ejes abordados.

Finalmente, se pone de relieve la importancia de los procesos de alfabetización e integración digital en la educación, entendiéndolas no como un todo homogéneo lineal, sino como una instancia que abre a las complejidades del cambio, la transformación educativa.

\section{4.- De la sala de informática al modelo 1 a 1}

En el presente apartado, se pretende realizar una síntesis y análisis de las diferentes dispositivos y configuraciones con los cuales se ha llevado a cabo la incorporación de las TIC en el sistema de educación formal. Varios autores confluyen en señalar que estas modalidades estuvieron representadas por configuraciones tales como: el aula de laboratorio de informática, el aula con computadoras de escritorio, el dispositivo de aula móvil (gabinetes móviles) y el denominado modelo 1 a 1 .

Estas diferentes maneras de enfocar la integración de tecnología en la institución escolar permiten rastrear ciertas configuraciones, que a modo de sedimentaciones de la práctica pedagógica mediada por tecnología, permiten comprenden un proceso, complejo caracterizado por ciertos contextos, negociaciones e intereses de los diversos actores, que forman parte de la política educativa TIC.

Podemos señalar que las primeras iniciativas que impulsaron la incorporación de tecnologías digitales en la organización escolar giraron fundamentalmente en el espacio denominado comúnmente: laboratorio de informática o computación. Este tipo de configuración de experiencia pedagógica con computadoras tuvo fuerte presencia en nuestra región principalmente en la década de los noventa. La creación de la sala de computación en el colegio, suponía la incorporación de la función del profesor entendido en la materia, el cual se encargaba de enseñar a los alumnos los contenidos estipulados por el currículum o en su defecto, aquellos que consideraban pertinentes para la enseñanza del alumno (Dussel y Quevedo, 2010)

A principios de la década de los '90, las salas de informática no disponían de conexión a Internet. 
La inversión necesaria para instalar el laboratorio de computación, implicaba en cierta medida la adaptación de un aula o en el mejor de los casos la creación de un espacio destinado a tal fin, con los correspondientes mobiliarios distribuidos eventualmente según las disposiciones que permitía un rearmado de la instalación eléctrica de la institución escolar. Las salas de informática contaban, comúnmente con la máquina de escritorio e impresora (y en algunos casos estas estaban conectadas por una red interna). Como principales preocupación en el discurso de la política pública, a través de la voz de los funcionarios, giraba en torno la preocupación por la cantidad de alumnos por máquina (Kelly, 2012; Dussel y Quevedo, 2010); Dichos discursos se inscriben en un horizonte de época, marcada por la definición y delimitación de las denominadas brechas digitales entre países y al interior de estos.

Dichas preocupaciones y debates se asociaron a cierta primacía por medición de cantidades de equipamiento disponibles, para establecer las mediciones y análisis de las brechas digitales.

Asimismo múltiples programas de política educativa focalizan el interés en la inmersión del equipamiento en los centros escolares, como, por ejemplo, PROMSE, en Argentina, o Proinfo, en Brasil (Dughera 2016)

Como sostiene Galarza (2006) existía una notable ausencia respecto a los contenidos oficiales del currículum a enseñar en computación. De igual modo, las cuestiones sobre las aplicaciones y el software a utilizar para el funcionamiento de los máquinas de informática no tuvieron una definición clara y en diversas ocasiones muchas decisiones fueron quedado librados a los profesores encargados del laboratorio de informática, a las tendencias del mercado o eventualmente también a diversas modas respecto programas enseñar, tales como LOGO, que tuvo su significativa incidencia en los años 80’ (Buckingham, 2008).

Acorde con (Dughera 2014), es posible señalar que la utilización del software operativos de las computadoras como así también los programas específicos que portaban las pc, no formaba parte de los debates y discusiones de las políticas destinadas a la incorporación de tecnología en la escuela. Al respecto algunos autores señalan que recién entrados en la última década, a partir de los programas y políticas 1 a 1 será posible advertir, cómo esta problemática estará vinculada a las decisiones y debates e intereses entorno al diseño de los planes y programas una computadora por alumno en la región.

En este sentido, fundamentalmente la creación de contenidos y programas no emanaba de las dependencias del estado, sino que estaban supeditados a las elecciones de los encargados de la materia

Tal como menciona Buckingham (2008), se instruía, tanto a docentes como alumnos, en torno a un currículum vinculado en muchas ocasiones a programas específicos de edición de textos, planillas de cálculo o presentación digitales, girando básicamente en la enseñanza del software de Microsoft Office.

Como modalidad y configuración pedagógica, la etapa de los 90’caracterizada por las salas de laboratorio de informática, poseían una concepción "técnico operativa" de las tecnologías digitales -específicamente de las computadoras-. Es decir, la enseñanza y aprendizaje se restringen a la dimensión técnica y operatoria de los medios informáticos, fuertemente impregnada por la tradicional perspectiva que que entiende que la escuela debe enseñar a usar la computadora (Levis, 2007).

En síntesis, podemos señalar que en esta configuración del diseño de las políticas de integración de tecnología basadas en las salas de laboratorios de informática subrayan el énfasis más bien en la puesta a punto de los equipamientos e instalaciones de las aulas y en la cantidad de computadoras disponible por alumno, quedando en un lugar relegado los aspectos que refieren a los contenidos de los programas, el software operativo de las 
máquinas y el tipo de desarrollo curricular del campo a enseñar. Este enfoque de la integración tecnologica fue objeto de, no pocas críticas, basadas fundamentalmente en el hecho de que solamente permite un uso ocasional de las tecnologías digitales, con la consecuente pérdida de tiempo en traslados y despersonalización de los equipos (Kelly, 2012; Dussel y Quevedo, 2010). De igual modo, parecería que no logra integrarse al cotidiano de las áreas disciplinares restantes, quedando asi reducida al uso de docentes innovadores. Asimismo, desde esta perspectiva, se subrayan las dificultades operativas y organizativas de las escuelas, que desalientan el uso sistemático de éstas (Area 2012; Perazza et al., 2010).

A partir de estas revisiones y miradas críticas, sumadas a una diversidad de elementos, que paulatinamente se van suscitando (tales como el fuerte baja en los precios de los equipos tecnológicos, el desarrollo y crecimiento del denominado software libre, entre otros, se empieza a reformular nuevas estrategias para los procesos de integración digital en el escenario de las instituciones escolares

Como señala Dughera (2016) a partir del nuevo siglo, empiezan a identificarse diversas modalidades y configuración a para los procesos de integración digital, tales como:

-- la inclusión de computadora de escritorio en las aulas.

-- la inclusión de set de computadoras móviles para el trabajo en el aula

-- los programas y planes denominados una computadora por alumno (modelo 1 a 1 )

En relación a la incorporación de la computadora de escritorio con posibilidad de acceso a internet en las aulas, es decir, la modalidad de tecnología con conectividad, supone que dichos equipo ingresan a "los salones de clase, a fin de que los dispositivos digitales estén al alcance de alumnos y docentes como recurso didáctico para todas las actividades" (Kelly, 2012: 211). Asimismo, esta configuración de integración de tecnología en la escuela, supone cierto acondicionamiento para que exista la disponibilidad de conexión a la web, y la ubicación de la computadora para el acceso a los distintos actores, habitualmente supuso que se las ubicara en las aulas o bibliotecas y/o direcciones del establecimiento.

La cantidad de máquinas de escritorio por escuela no guarda necesariamente relación con la cantidad de alumnos en el establecimiento escolar, sin embargo, esta modalidad permitía el uso de esta tecnología cada vez que el docente lo considera necesario (Kelly 2012).

En cuanto a los contenidos educativo, bajo esta configuración de integración de tecnología, el eje ya no estaría tanto en la cuestión de enseñar programas o contenidos curriculares vinculados a la los software de la ofimática o del mundo de la informática, sino que se intentó transpolar dicho mundo a las diferentes áreas curriculares.

Como subrraya Levis (2008), se comienza operar un cambio en la configuración de integración de las TIC, a partir de esta nueva modalidad respecto a lo que significaba la "sala de computación"; en tal sentido la configuración "técnico operativa" propia de la modalidad desarrollada en la configuración del espacio de la sala de computación, empieza virar hacia un enfoque más de carácter instrumental donde propugna la utilización de las TIC (en particular computadoras y redes) como recursos didácticos, como herramientas destinadas a complementar y facilitar las prácticas de enseñanza y el aprendizaje de las disciplinas.

Estos nuevos enfoques suponen que la incorporación de las tecnologías debe estar al "servicio" del resto de las áreas curriculares, como una herramienta más. En tal sentido, se advierte cierta transformación en las representaciones que predominaban en este tipo de incorporaciones. De tal modo, mientras en el laboratorio de informática el énfasis se volcaba en "enseñar sobre tecnología" (los contenidos estaban basados en la enseñanza de programas específicos de diseños de texto, hojas de cálculos etc...), a partir de estas nuevas configuración o modalidades, la propuesta consistirá en enseñar con tecnología, con nuevas 
herramientas que facilitan o potenciarán en el mejor de los casos la enseñanza y el aprendizaje. En cierto sentido, este nuevo enfoque implica y conlleva ciertas (des)articulaciones, ciertas revisiones en lo que respecta al rol y el saber técnico por parte del docente, como así también de la presencia y rol del profesor de computación en el espacio del aula, por ejemplo.

Los procesos de incorporación de tecnología e internet en la escuela y sus transformaciones en los modos y enfoques de entender los contenidos a enseñar en las escuelas, permite identificar los distintos componentes que entran en juego a la hora de plantear iniciativas por parte de las administraciones educativas.

En cierto sentido, las cuestiones ligadas a las adaptaciones de infraestructura y la inversión en el hardware de las máquinas aparece como relieve, mientras que la cuestión de los programas y software educativo aún no resulta un problemática en cuestión por parte de la incipiente política de integración de TIC en esta época.

Como señala (Kelly 2012) por lo general queda así en "manos" de los docentes tutores y por transición de las empresas privadas las definiciones sobre los programas y contenidos a enseñar.

En la mayoría de la región de América Latina y el Caribe, una iniciativa importante que empieza a gestarse en esta época es la creación de los denominado "portales educativos" (Jara y Toledo, 2009)

Estos constituyen básicamente repositorios de recursos y servicios digitales orientados a los diferentes actores del sistema escolar: padres, estudiantes, directivos y, especialmente, profesores de aula.

En particular, los portales ofrecen recursos para el aprendizaje y orientaciones metodológicas que pueden ser utilizadas por los docentes para enriquecer las experiencias educativas de sus estudiantes. (...) "Los portales organizan sus contenidos de acuerdo a las categorías del currículum local de las comunidades educativas que atienden y les ofrecen sistemas de búsqueda y navegación. Asimismo, los portales cumplen un rol de garantes de la pertinencia curricular y de la calidad de los contenidos que ofrecen, aliviando a los profesores del trabajo de navegar y evaluar contenidos en el infinito mar de Internet. (Jara y Toledo, 2009: 30 y 31). Finalmente, en nuestra región de América Latina y el Caribe, como así también en gran parte del resto del, mundo, comienza adquirir importancia una nueva configuración de integración de tecnologías en la escuela a partir de la modalidad de las "aulas móviles" y la modalidad "una computadora por alumno".

Cabe mencionar que el modelo 1 a 1 , fue una iniciativa que se implementa en la década de los 90 fundamentalmente en Estados Unidos y Australia. En particular fue en el estado de Maine, E.E.U.U., el primero en llevar adelante una experiencia de ésta índole. Si bien consistieron en computadoras de escritorio y al momento de comenzar no disponían de conexión a Internet, será a posterior con su correspondiente creación y expansión que se agregue conectividad (Warschauer, 2010).

Asimismo entrado el nuevo milenio los estados comienzan a optar por estas iniciativas de integración de tecnología, tanto por el modelo 1 a 1 , como por la configuración de aulas móviles, representando hoy en día las principales opciones que buscan dar respuesta a la integración de TIC en la educación formal. 


\section{Las Aulas móviles}

Esta configuración de integración de TIC consiste en la en la puesta a disposición de un gabinete móvil o racks que contienen por lo general unas 30 computadoras portátiles, que se trasladaban según las necesidades por las diferentes o espacios de la institución (Kelly, 2012). Los dispositivos utilizados en la mayoría de estas iniciativas corresponden las computadoras tipo classmate de la empresa Intel y la infraestructura que acompaña estos programas de integración de TIC, supone la instalación de internet y el tendido de una red escolar o piso tecnológico (que por lo general es garantizado por la Administración central Ministerio de Educación o por iniciativas como las cooperadoras de los colegios, asociaciones de padre etc) En las Aulas Móviles -a diferencia del Laboratorio de Informática y de las Computadoras de Escritorio en las Aulas- la convivencia de actores públicos y privados comienza a ser más evidente, en relación a qué tipo de inversión realizar, qué tipos de programas o software deben contener las computadoras etc...

Es decir, en lo que se refiere a el escritorio digital, los software educativos y contenidos específicos para los niveles educativos, se advierte un tratamiento diferente y una preocupación más notable que en los casos anteriores.

Específicamente en lo que refiere a sistema operativo de las computadoras comienza advertirse como una discusión o problema a resolver por tarde la política pública destinada a la inclusión digital

De este modo, es posible observar tanto la presencia de actores proclives al software privativo como al software libre. Es posible hallar defensores del software privativo, como Windows, y del software libre o de código abierto Debían (Dughera, 2013).

Asimismo en cuanto a las aplicaciones y programas educativos, es posible identificar un crecimiento significativo de este tipo de producciones por parte de empresas privadas. Es decir, se observa cierto incremento en la producción de los recursos digitales y en la inclusión de éstos en el hardware. Los actores que realizan dicha producción son actores tanto privados como estatales (Dughera, 2013).

La integración tecnológica a partir del dispositivo de gabinete móvil con computadoras portátiles para usar en el aula, comienza implementarse fundamentalmente a mediados de la primer década del milenio.

\section{Modelo 1 a 1}

Por último, se ubican los planes "una computadora, un alumno" (como el Plan ceibal en Uruguay o el Programa Conectar Igualdad en Argentina). Esta modalidad se comenzó a implementar en la década del ochenta en Estados Unidos (Warschauer, 2010). Es el estado de Maine, E.E.U.U., el primero en llevar adelante una experiencia de esta índole. Este primer plan "una computadora, un alumno" consistió a nivel del hardware en computadoras de escritorio, sin conexión a Internet, será a posteriori que se agregue conectividad (Warschauer, 2010).

La denominación "una computadora, un alumno" es utilizada para dar cuenta de la cantidad de artefactos por niño. Típicamente se refiere a que cada niño/adolescente disponga y acceda a una computadora. Cabe insistir en que no todas las experiencias bajo esta modalidad supusieron la incorporación adicional de conexión a Internet, aunque actualmente, en la mayoría de las experiencias 1 a 1, se ha dispuesto conectividad. En América Latina, y en la 
mayoría de los países en desarrollo, algunos factores han sido particularmente significativos en la configuración de esta modalidad.

Fundamentalmente a partir del año 2005, junto al posicionamiento y apoyo brindado por organismos internacionales se expandió en la región el denominado Programa One Laptop Per Child (OLPC por sus siglas en inglés, que en español significa una computadora portátil por niño), impulsado por el Instituto de Tecnología de Massachusetts (MIT).

Este programa fue presentado por primera vez en el Foro Mundial de Davos en 2005 por Nicholas Negroponte, director del Laboratorio de Medios del MIT (Area Moreira, 2010:52)

Los organismos internacionales tales como el Banco Interamericano de Desarrollo como así también el Banco Mundial manifestaron un fuerte apoyo para la concreción e incorporación de de tecnologia en la escuela. En esta misma línea los organismos tales como UNESCO, a través de la formulación de las denominadas Metas 2021 para educación, específicamente en la segunda meta se realiza una mención clara a "la necesidad de ofrecer un currículo que integre el computador en el proceso de enseñanza y aprendizaje". Así mismo, la Organización de Estados Iberoamericanos para la Educación, la Ciencia y la Cultura - OEI sostiene en sus metas educativas 2010 la siguiente formulación:

"Actualmente, la inclusión social se vincula, cada vez más, con el acceso al conocimiento, por la participación en redes y por el uso de TIC (Hopenhayn, 2002). El sistema de educación formal es la clave para difundir ese acceso, dado que permite masificar la conectividad y uso de redes electrónicas".

Estas iniciativas se fueron consolidando principalmente por el significativo abaratamiento tanto del hardware como del software y la construcción de este tipo de temáticas se van conformando como problemas sociales necesarios de ser resueltos por parte de las políticas públicas en su dinámica de legitimación y penetración por parte del Estado (Oszlak y O'Donnell, 1999).

La trayectoria tecnológica de inmersión de tecnología de manera masiva a través de los programas 1 a 1 que se inicia en Uruguay a principios de 2007 con el Programa de Conectividad Educativa de Informática Básica para el Aprendizaje en Línea (CEIBAL) ha sido implementada por la mayoría de los países de la región.

Tanto la modalidad Aula móvil y los planes "una computadora, un alumno" se comenzaron a implementar en América Latina y el Caribe aproximadamente al mismo tiempo, desde comienzos del nuevo milenio. Ambas modalidades buscan soluciones para la la problemática de los procesos de integración digital en la escuela, bajo la impronta de lo que se denomina las políticas de inclusión digital.

Asimismo, encontramos diferentes debates y discusiones, respecto a las diferentes perspectivas desarrolladas a través del concepto de inclusión digital (Warschauer, 2010) que no estaría dentro del alcance del presente trabajo.

De igual modo, nivel discursivo, los programas 1 a 1 y las aulas móviles tienen varios aspectos en común, tales como, la importancia del acceso a Internet en el aula, la preocupación por mejorar las ratios entre cantidad de computadoras portátiles y alumnos, y la mejora en la incorporación de softwares educativos y contenidos escolares para trabajar en la enseñanza y el aprendizaje.

No obstante las principales diferencias de estas configuraciones digitales, radica en la disponibilidad que supone la entrega y apropiación del equipo por parte de los actores implicados en ambos programas. 
En el caso de las aulas móviles la computadora está limitada espacio temporalmente al aula y a momentos determinados; mientras que en el programa de una computadora por alumno, el educando dispone de ésta tanto al interior de la institución educativa, como por fuera de ella.

Si bien la disponibilidad de la notebook no se traduce necesariamente en un uso más intensivo o significativo de la tecnología en tiempos constantes y espacios extraescolares, a diferencia de la aulas móviles, la tenencia del dispositivo supone una apropiación diferente a solamente disponerlo en tiempos acotados para trabajos específicos en el aula, dado que la entrega de la computadora en el programa 1 a 1, implica la apropiación para sí de las reglas de uso del objeto tecnológico que le ha sido entregado (Morales, 2007). .

Asimismo, más allá de las diferencias y similitudes de estas configuraciones de integración de tecnología, es importante poner de relieve que en los últimos años han coercitivo ambas modalidades. Dicha coexistencia, entre otros factores, permite pensar que aún hoy la respuesta acerca del cómo introducir las tecnologías digitales en los sistemas educativos formales está lejos de haberse resuelto de manera cabal.

\section{3.- Metodología}

Dado la conformación compleja del campo de investigación que nos ocupa, nuestro proyecto se inscribe en la perspectiva del horizonte cualitativo. El encuadre metodológico de la investigación cualitativa se sustenta en un proceso reflexivo, y su propósito principal consiste en comprender la realidad, sus significaciones e intenciones humanas para descubrir lo nuevo, generando, ampliando, cambiando o superando teorías con fundamento empírico, y con el desarrollo de explicaciones causales.

\section{1.- La propuesta metodológica}

La perspectiva teórico-metodológica, resulta como corolario de la pertinencia que implica el abordaje multidimensional de nuestro problema de investigación.

Dado que este trabajo constituye una investigación educativa, las metodologías que se seleccionaron pretenden estudiar de manera significativa hechos referentes a la vida laboral de los docentes en escuelas secundarias: su trabajo de enseñanza, sus historias de formación, sus opiniones y representaciones acerca de las políticas actuales de inclusión digital, sus problemas, limitaciones, logros y posibilidades en relación a la utilización de las herramientas, recursos y estrategias que proveen las tecnologías digitales.

El objetivo general que nos planteamos en esta investigación buscó analizar las tendencias de los docentes de nivel medio en la Patagonia Austral, en cuanto al uso e integración de las TIC en la práctica pedagógica, identificando las posibilidades reales de uso, los obstáculos percibidos que genera la implementación y uso de tecnología en la clase.

Asimismo como objetivos específicos buscamos: Determinar el conocimiento y uso de las TIC en las prácticas pedagógicas de los docentes de nivel secundario; Reconocer las variables que promueven una inclusión genuina de las TIC en escenarios de alta disposición tecnológica en las aulas; Establecer las estrategias que están implementando en propuestas pedagógico didácticas en clase y conocer los posibles problemas asociados a la práctica pedagógica mediada por TIC; Identificar el grado de apropiación de las TIC por parte de los docentes y su relación con el logro de objetivos planteados en sus prácticas pedagógicas áulicas. 
El proyecto de investigación es siempre un plan de trabajo flexible, que orienta los procesos de construcción sistemática de conocimientos en relación a los problemas que se intenta estudiar. Por ello no existe "un diseño" a priori, sino muchos posibles. En este orden como sostiene Sampieri y otros (2000), el proyecto de investigación se propone diferentes alcances, y en tal sentido, sin perder nuestro horizonte comprensivista (cualitativo) en la investigación, diseñamos una primera fase inicial donde exploramos con la construcción descriptiva de dimensiones y variables una primera caracterización de los docentes de nuestra localidad, a partir de la instrumentación de una encuesta que más adelante detallaremos. No obstante, el diseño de la investigación es de carácter cualitativo y se optó por la estrategias de entrevistas en profundidad donde se seleccionaron 11 docentes como método de estudio de casos, pues los casos priorizan la particularización, preservando "las realidades múltiples, las visiones diferentes e incluso contradictorias de lo que sucede". (R. Stake, 2005).

En este sentido, para propender al logro de estos objetivos, se emplearon distintas estrategias buscando una complementación en el análisis del trabajo de campo; en orden a ello se desarrolló un Cuestionario a docentes del secundario (fase descriptiva exploratoria) denominado EDUTICRG; se realizó análisis documental referido a la normativa vigente del programa de inclusión digital en santa cruz y se diseñó un guión para realizar entrevistas en profundidad a docentes que están actualmente impartiendo clases en la localidad.

Las entrevistas nos permitieron indagar de manera holística e integrada las diferentes experiencias profesionales, configuraciones y formas de trabajo docente de los sujetos entrevistados en las distintas instituciones, lo cual posibilitó también analizar prácticas educativas favorecedoras de una visión enriquecida acerca de la enseñanza mediada por tecnologías, sin dejar de lado la complejidad que estas prácticas suponen, ni intentar proponer categorías con sentido aplicativo que las empobrezcan.

En esta estrategia, con forme a nuestro objetivo del trabajo, se buscó comprender las particularidades de las condiciones en los cuales tienen lugar las prácticas de los profesores, entendiendo estos territorios, como espacios dinámicos en los que participan múltiples actores, se reconstruyen tramas diversas que hacen a la propia vida escolar en la localidad.

Algunas de las preguntas que orientaron la investigación, y que luego fue adquiriendo mayor especificidad cuando se abordó el trabajo empírico, fueron las siguientes:

¿De qué modo las prácticas y las representaciones de los docentes logran vincular sus expectativas, sus conflictos o tensiones de orden educativo?; ¿Cómo se incorporan, de manera situada y contextualizada, las Tecnologías digitales en las practicas pedagogicas?; ¿La formación docente, resulta apropiada para generar prácticas docentes mediadas por tecnologías que promuevan procesos de apropiación y comprensión?; ¿Qué efectos tienen las políticas de inclusión digital en las prácticas y las representaciones de los docentes de las escuelas medias de la localidad?

En este sentido se buscó incorporar de modo sustancial la "voz" de los actores participantes, y se indagó acerca de sus concepciones, ideas, creencias, opiniones, actitudes, reflexiones y experiencias, a partir de su propia expresión.

Asimismo, siguiendo autores como (Casetti y Di Chio, 1999; Sautu, 2003), se tomaron en cuenta que los diferentes diseños de una investigación pueden evaluarse como válidos según dos criterios: 
- el externo, que determina su capacidad para brindar significación a través de ejemplos estadísticamente representativos y/o datos extensibles y generalizables;

- el interno, que determina la coherencia entre el enfoque de la investigación, los modelos explicativos y la organización de los datos; es decir, su consistencia en relación con la estructura construida y con el enlace causal de sus observaciones.

En este sentido en las primeras fases de análisis se hizo imperante contar con el juicio de expertos para su validación. Se detalla seguidamente en relación a la etapa exploratoria, la construcción del instrumento de encuesta para nuestro estudio.

\section{2.- Diseño del instrumento: EDUTICRG}

En base a la bibliografía relevada, se optó para esta parte exploratoria descriptiva de la investigación, por el diseño de una herramienta de cuestionario, que nos permita obtener datos sobre los usos tecno pedagógicos de los docentes, como así también su percepción y valoración de su formación y competencia digital.

En la siguiente tabla, presentamos un ficha síntesis del diseño del instrumento que denominaremos EDUTICRG.

\section{Diseño del Instrumento: "EDUTICRG"}

\begin{tabular}{|l|l|}
\hline $\begin{array}{l}\text { Sector de aplicación del } \\
\text { estudio }\end{array}$ & $\begin{array}{l}\text { Centros de Educación Secundaria de la Localidad de Rio } \\
\text { gallegos, Provincia de Santa Cruz. }\end{array}$ \\
\hline Personal encuestado & $\begin{array}{l}\text { Profesores que imparten clases en centros educativos secundarios } \\
\text { Modelo } 1 \text { a } 1\end{array}$ \\
\hline $\begin{array}{l}\text { Población / Muestra (para } \\
\text { aplicación pre-test) }\end{array}$ & $\begin{array}{l}\text { Profesores que imparten clases en las 15 escuelas secundarias de } \\
\text { RG -- pre-test impartido en un total de 35 profesores }\end{array}$ \\
\hline Instrumento & Cuestionario EDUTICRG \\
\hline $\begin{array}{l}\text { Método de recogida de datos } \\
\text { del cuestionario }\end{array}$ & Encuesta online (ver anexo) \\
\hline $\begin{array}{l}\text { Período de recogida de la } \\
\text { información }\end{array}$ & Mes de mayo-junio 2015 \\
\hline
\end{tabular}

El diseño del cuestionario implica formar un conjunto de cuestiones y aspectos que conforman el universo de supuestos, e ideas sobre el horizonte del problema a investigar.

El proceso seguido en la construcción del cuestionario ha sido basado fundamentalmente en:

- La revisión de la literatura que sobre el tema hemos realizado. 
- La revisión de documentos e informes referidos a la los estudios evaluativos e investigaciones sobre la integración de TIC en la escuela y sobre los programas 1 a 1 en particular.

Partiendo de estas premisas, podemos decir que el proceso siguiendo en su confección se ha seguido los siguientes pasos:

En primer lugar, revisión de la literatura y de los cuestionarios diseñados en otros estudios relacionados con el uso de las TIC en el campo educativo, con el fin de aproximarnos a la realidad objeto de estudio, formular nuestros objetivos a conseguir, y fundamentar la información y variables que incidían en nuestro tema a estudiar.

Una vez realizado este paso, se procedió a la elaboración de la primera versión del cuestionario, confeccionando un conjunto limitado de preguntas e items que respondieron al universo de variables y dimensiones sobre el horizonte de toda la información que queríamos obtener, acorde a los objetivos específicos planteado por nuestra investigación

Para la formulación y disposición de las preguntas, seguimos una serie de recomendaciones realizadas por los autores Rodríguez y otros (1996) tales como:

1) la orden de dificultad, ir siempre de lo más simple a lo más complejo.

2) formular preguntas concretas, evitando la ambigüedad que después comportara errores de interpretación por parte del encuestado.

3) formular preguntas fáciles de entender, con un lenguaje sencillo y claro, y un vocabulario adecuado al público al que iba destinado.

4) procurar hacer diferentes tipos de preguntas.

La búsqueda bibliográfica para la delimitación de los constructos y dimensiones del instrumento se desarrolló a través de las bases de datos: TDX, TESEO, Scopus, Google Scholar, a través de internet mediantes los descriptores: "TIC" Integración de TIC Enseñanza con TIC, en el idioma Español e Inglés (mediante los descriptores "ICT" Integration ITC) «modelo 1 a 1 », «computación ubicua en las escuelas» o «inmersión tecnológica» (o «1:1 model», «ubiquitous computing»o $\mathrm{o}$ «technology immersion») ${ }^{1}$

Se consultaron documentos en idioma portugués, con especial atención a la región de Iberoamérica. En Argentina como en el ámbito latinoamericano e internacional la bibliografía encontrada sobre TIC aplicadas en el nivel secundario fue considerable y se encontraron multitud de artículos tesinas y proyectos que aunque no estaban dirigidos específicamente a la realidad local nos ayudaron a construir una aproximación e impacto de las TIC en el ámbito educativo.

La REVISIÓN BIBLIOGRÁFICA de las INVESTIGACIONES RELEVADAS fue organizada en tablas según regiones y países. Asimismo se conformó, un análisis sobre un conjunto de 27 estudios sobre integración de TIC en la Educación en general; como así también un análisis de 19 estudios referidos al impacto de las TIC en el marco del modelo 1

\footnotetext{
${ }^{1}$ Los ámbitos de la búsqueda fueron, comenzando con el ámbito internacional, luego regional, y se realizó una búsqueda más en detalle, en la región latinoamericana del cono sur - argentina, chile, Uruguay, Perú, Paraguay.
} 
a 1. Asimismo, con el propósito de fundamentar un conjunto de dimensiones, variables e indicadores para nuestra investigación, realizamos un análisis comparativo entre diversos estudios descriptivos e investigaciones relevadas sobre integración de TIC en educación, identificando diversas recurrencias a la hora de identificar variables y dimensiones que conforman el impacto de las TIC en los procesos pedagógicos de enseñanza aprendizaje

Finalmente a modo de síntesis, se decidió dividir el cuestionario en un apartado para los datos personales y profesionales y cuatro grandes apartados de acuerdo a las principales variables intervinientes en este tema, es decir:

\begin{tabular}{|l|}
\hline A. DATOS PERSONALES Y PROFESIONALES \\
\hline B. APROPIACIÓN DE LAS TIC \\
\hline C. CAPACITACIÓN Y HABILIDADES TIC \\
\hline D. ACTITUD Y VALORACIÓN DE LAS TIC \\
\hline E. USO PEDAGÓGICO DE LAS TIC \\
\hline
\end{tabular}

A partir de aquí se elaboraron las preguntas de cada apartado, para luego ordenarlas de la manera más adecuada. Así la primera versión del cuestionario (ver anexo) quedó constituida por 5 dimensiones y 32 preguntas. Una vez constituida esta primera versión del instrumento, se procedió a realizar un proceso de validación por expertos, a través del Panel Internacional de Investigación en Tecnología Educativa (PI2TE) en http://gte2.uib.es/panel. La elaboración del cuestionario se llevó a cabo a partir de la información encontrada sobre el tema de estudio y la consulta dialogada con expertos de acreditada experiencia en el ámbito de las TIC ${ }^{2}$.

Partiendo de las 5 áreas o dimensiones de contenido señalada y con el objeto de concretar los diferentes temas que iban a desarrollar las cuestiones de la encuesta se procedió a identificar las diferentes variables a tratar dentro de cada una de las áreas de contenido identificado.

Así las 32 preguntas del cuestionario se elaboraron partiendo de 21 variables o temas que fueron identificados dentro de las 5 áreas de contenido referidas.

\footnotetext{
${ }^{2}$ El Panel Internacional está conformada por un Comité de por varios expertos en el campo de la tecnología educativa nombrados por la junta directiva (de EDUTEC España), de modo tal, que se puedan garantizar la validez del procedimiento de selección y asimismo acreditación adecuada de la participación de dicho panel por parte de los expertos. Esta comunidad de especialistas, permiten llevar a cabo el trabajo técnico que brindan garantía a los procedimientos metodológicos de validación por expertos.

parte de los expertos
} 


\begin{tabular}{|c|c|c|}
\hline DIMENSIONES & INDICADORES & PREGUNTAS \\
\hline $\begin{array}{l}\text { A. DATOS PERSONALES Y } \\
\text { PROFESIONALES }\end{array}$ & Datos de identificación y profesionales & $1,2,3,4,5,6$ \\
\hline \multirow[t]{3}{*}{ B. APROPIACIÓN DE LAS TIC } & $\begin{array}{l}\text { Valoración sobre la inclusión de las TIC en la } \\
\text { escuela }\end{array}$ & 7 \\
\hline & $\begin{array}{l}\text { Aporte que supone la introducción de las TIC en } \\
\text { el centro educativo }\end{array}$ & 8 \\
\hline & $\begin{array}{l}\text { Grado de satisfacción dela inclusión de las TIC en } \\
\text { el aula }\end{array}$ & 9 \\
\hline \multirow{4}{*}{$\begin{array}{l}\text { C. CAPACITACIÓN Y } \\
\text { HABILIDADES TIC }\end{array}$} & Capacitación recibida en TIC & 10,11 \\
\hline & Modalidad de capacitación & 12,13 \\
\hline & Valoración de la formación en TIC & 14 \\
\hline & Autopercepción de la competencia TIC & 15,16 \\
\hline \multirow{2}{*}{$\begin{array}{l}\text { D. ACTITUD Y VALORACIÓN } \\
\text { DEL USO LAS TIC }\end{array}$} & Valoración de la inclusión de las TIC & 17 \\
\hline & Valoración del impacto en la práctica & 18 \\
\hline \multirow{6}{*}{$\begin{array}{l}\text { E. USO PEDAGÓGICO DE LAS } \\
\text { TIC }\end{array}$} & Las TIC en la planificación & 19,20 \\
\hline & Tipos de recurso TIC para el aula & 21,22 \\
\hline & Acompañamiento para la integración de las tic & 23 \\
\hline & Uso de las TIC para la comunicación & 24,25 \\
\hline & Uso de las TIC para la búsqueda de información & $26,27,28,29,30$ \\
\hline & Uso de las redes sociales & 31,32 \\
\hline
\end{tabular}

\section{3.- Dimensiones, Indicadores y número de preguntas del cuestionario}

Con esta conformación, el instrumento fue presentado y revisado primero informalmente por especialistas en el tema alguno de ellos realizaron correcciones de estilo sugirieron incorporaciones otros aspectos a cambiar algunos términos con el fin de que las preguntas fueran más clara y específicas.

Luego fue sometido a un proceso de validación por el Panel Internacional de Investigación en Tecnología Educativa (PI2TE) que detallaremos más adelante.

Las preguntas del cuestionario se han conformado teniendo en cuenta dos criterios en su formulación: a) por un lado la forma en la que están formuladas dichas preguntas; y b ) según el contenido de la información.

Según su contenido diferenciamos preguntas:

- Explicativas o de identificación $(1,2,3,4,5,6,7,8$, y 9) formuladas con la pretensión de recoger información para identificar a las personas encuestadas, estas preguntas se convertirán en variables estructurales (variables sociodemográficas), 
- Preguntas de información, de conocimientos y de actitud $(10,11,12,13,14,18,19$, $21,22,23$, y 24) que nos permiten comprobar el conocimiento y actitud del profesorado encuestado respecto a diversos aspectos del tema objeto de estudio,

- Y preguntas de opinión $(15,16,17$, y 20$)$ a través de las cuales hemos captado las valoraciones del profesorado en relación a determinados aspectos.

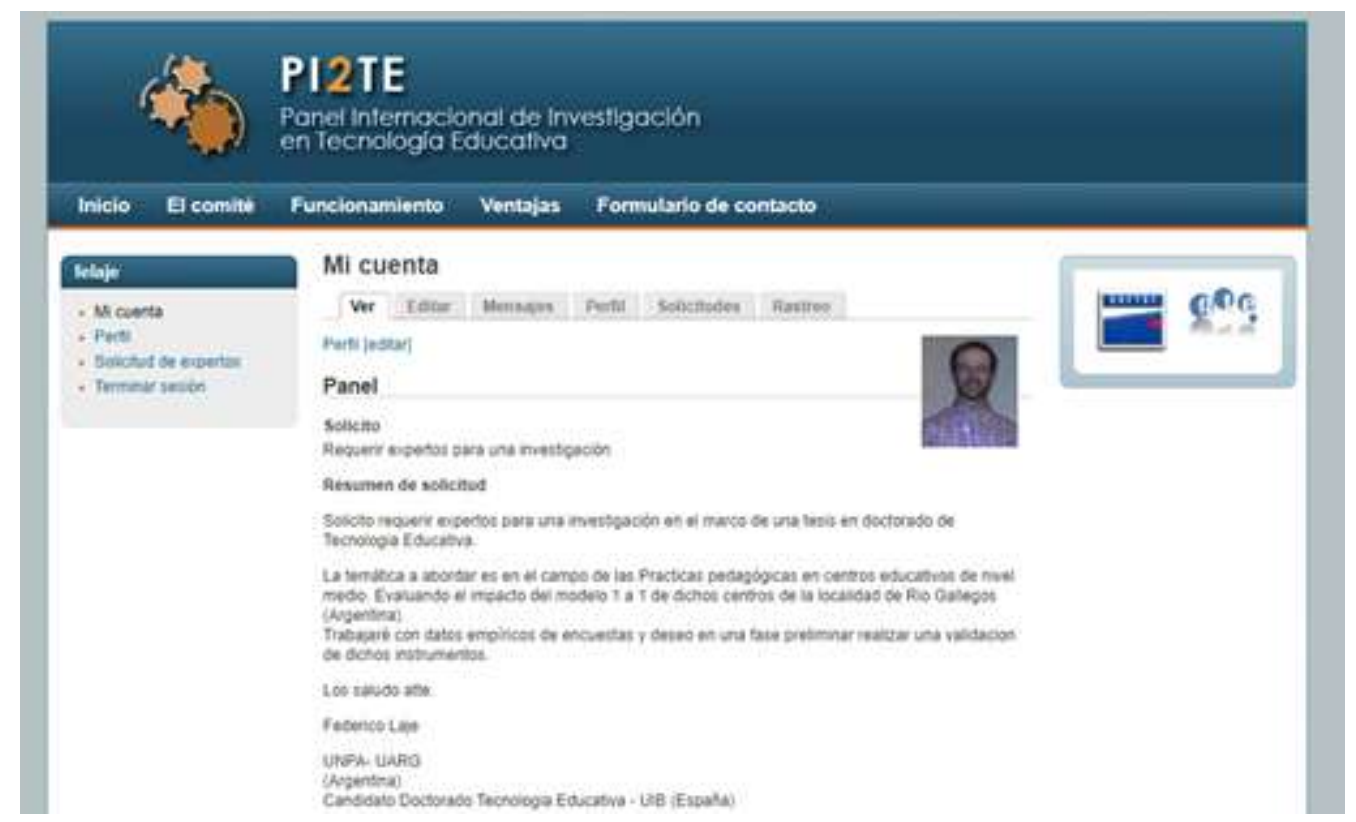

Para facilitar el proceso, se confección un documento, orientativo con el propósito luego de realizar un análisis de los distintos señalamientos, recomendaciones y sugerencias a tener en cuenta por parte de los experto. Con este propósito, se diseñó la siguiente grilla identificando algunos criterios para el análisis, para cada una de las variables y dimensiones que conforma el instrumento de encuesta.

\begin{tabular}{|c|c|c|}
\hline Aspecto validar & Criterio & Escala \\
\hline \multirow{3}{*}{$\begin{array}{l}\text { Los indicadores de cada resultado de } \\
\text { aprendizaje }\end{array}$} & Comprensión & \multirow{3}{*}{ Escala del 1 al 4} \\
\hline & Pertinencia & \\
\hline & Importancia & \\
\hline
\end{tabular}

4.- Criterios y Escala para la valoración del instrumento

Comprensión: ¿Se entiende el ítem? ¿Está bien expresado y/o redactado y no conlleva ambigüedad?

Pertinencia: ¿Se adecua el ítem a los objetivos de la investigación? ¿Es pertinente?

Importancia: Valore entre 1 y 4 el grado de importancia que a su parecer tiene el ítem respecto a los objetivos de la investigación.

Comentarios: Indique libremente los comentarios adicionales que considere oportuno sobre el ítem en cuestión. 
Con el cuestionario EDUTIC RG v2, se realizó una muestra piloto de 35 profesores de educación secundaria, para poder establecer la Fiabilidad y Funcionamiento del cuestionario, así también como detectar posibles problemas en su administración.

Dichos docentes fueron contactados de manera voluntaria a través del correo electrónico obtenido por las bases de datos del programa "aula modelo" de la provincia de Santa Cruz, en nuestra localidad y se los invitó a rellenar el cuestionario, retroalimentándonos con sus comentario las posibles observaciones u obstáculos a la hora de su cumplimiento

Este pilotaje también sirvió para valorar el tiempo medio necesario para cumplimentar el cuestionario y poder incluir las instrucciones de cumplimiento que se elaborarán cuando se administre de manera online al conjunto de los docentes de nuestra localidad.

\section{4.- Resultados}

La investigación se realizó en un campo particular: el de las prácticas pedagógicas mediadas por tecnológica en escuelas secundarias de Rio Gallegos. En este apartado presentamos algunas reflexiones obtenidas a través del instrumento de encuesta llevadas a cabo durante el año 2014 y 2015 los cuales nos han posibilitado generar aportes para profundizar luego en un análisis de carácter cualitativo e interpretativo donde se trabajó en la reflexión de la observación directa y el análisis narrativo de entrevistas a profesores de secundaria desarrolladas durante el año 2016 y 2017. A partir de los relatos de los docentes entrevistados sumados a los demás aspectos observados, presentamos la construcción de los sentidos y resultados acorde a los objetivos que nos planteamos en este trabajo de investigación.

\section{1.- Análisis de las encuestas -EDUTIC RG}

Para facilitar el tratamiento y análisis de la información recogida, se conformaron gráficos con representación de frecuencias relativas, focalizando en las cuestiones descriptivas sobre las distintas particularidades vinculadas a las condiciones para su trabajo docente en relación a las TIC, sus actitudes y valoraciones vinculadas su práctica mediada por la tecnología y sus capacidades y habilidades referidas al uso de la tecnología

Como se mencionó con anterioridad, en el proceso de construcción de encuesta EDUTIC RG se contó con la validación de expertos y se realizaron prácticas para ajustar el instrumento en pruebas $_{\text {piloto }}^{3}$ respecto algunos ítems significativos propuestos ${ }^{4}$.

Actitud y valoraciones sobre el uso de las TIC en el ámbito escolar.

Respecto a la dimensiones que busca indagar sobre las prácticas con TIC la opinión de los profesores respecto a la inclusión de las TIC en la escuela, tuvo una valoración positiva señalando como algo bastante beneficioso para los proceso de enseñanza aprendizaje, como así también en referencia a que las TIC supone una modernización de las practicas escolares,

\footnotetext{
${ }^{3}$ Para la implementación de la encuesta y para el análisis de las pruebas, se contó con la colaboración de los alumnos de 3er año de la Materia: Teoría y Metodología de la Investigación en Ciencias Sociales (con módulo de estadística) de la cual soy profesor Adjunto Ordinario, responsable de la asignatura en la carrera de Licenciatura de Psicopedagogia, en unidad académica de Rio Gallegos UNPA

${ }^{4}$ También se realizaron presentaciones sobre el diseño y construcción del instrumento en jornada de Tesistas de EVEA año 2014; SIITE UIB año 2015
} 
y que mayormente facilita su tarea y labor. No obstante, podemos advertir que la opinión se muestra contradictoria observándose una frecuencia relativa del $35 \%$ de docentes que se manifiesta propensos a considerar aspectos referidos a que las TIC alientan el facilismo de los estudiantes.

Asimismo, respecto las preguntas orientadas a identificar las actitudes sobre el uso pedagógico de las TIC, los docentes han señalado:

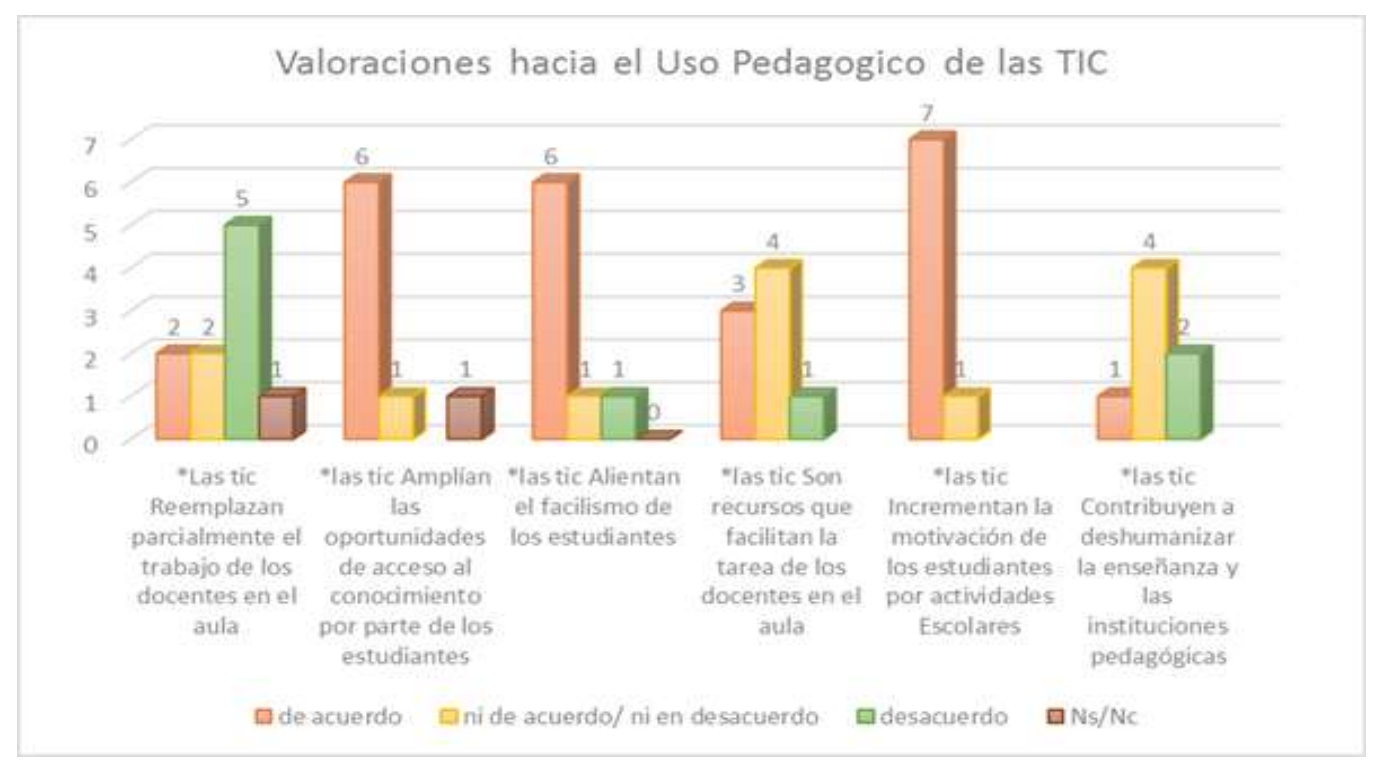

Tabla 1 Valoraciones hacia el uso Pedagógico de las TIC

Como principales obstáculos o dificultades para que las netbook puedan incorporarse efectivamente en las actividades de enseñanza, los docentes manifiesta: "no sé cómo usarla; los estudiantes no saben usar las netbook; no siempre está disponible el gabinete con las notebook para usarlas en clase; genera distracción en los estudiantes; no se me ocurren ideas significativas para integrar este recurso al aprendizaje de las temáticas del curriculum".

Apropiación, y uso pedagógico - didácticos de las tic

Un $64 \%$ de docente manifiesta que en su diseño de planificación anual, ha contemplado el uso de la TIC, en su materia.

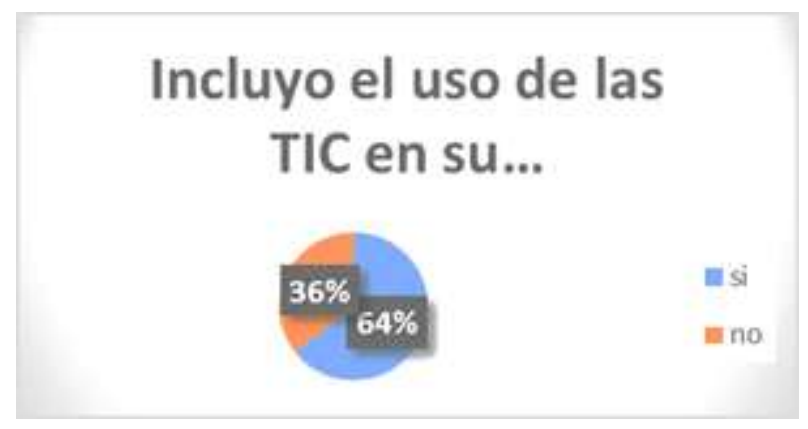

Tabla 2 Inclusión de proyecto con TIC 
Asimismo se corresponde el mismo porcentaje de docentes que manifiesta que durante al último año realizaron alguna actividad o proyecto específico con alumnos, donde si incluyeron las TIC.

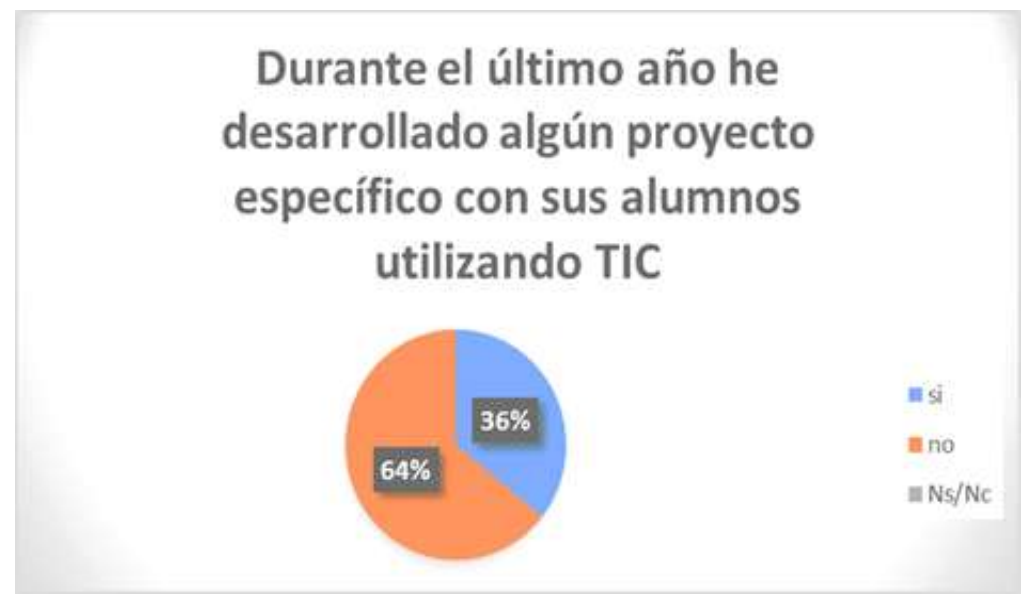

Tabla 3 Desarrollo de proyecto con TIC con alumnos en el último año

Respecto a la pregunta sobre los tipos de usos, en relación a la comunicación a través de medios digitales, podemos señalar (se les preguntaba en relación al año en curso) que: hay un $43 \%$ de docentes que se comunica entre colegas a través de internet, un $29 \%$ se ha comunicado con la dirección del colegio; siendo menor el porcentaje de docentes que utiliza el medio digital para comunicarse con los alumnos del curso.

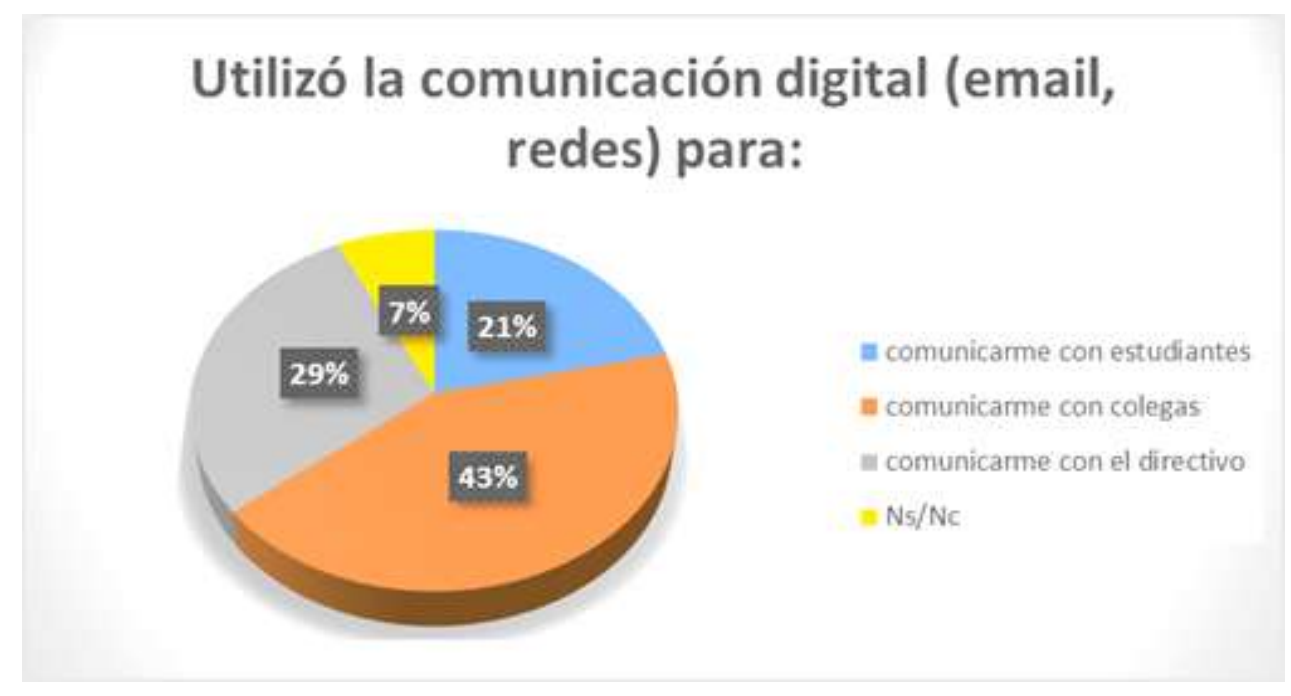

Tabla 4 Utilización de comunicación digital

Respecto a la pregunta sobre si en la escuela existe alguna persona que lo acompañe en relación a la integración de las TIC para su práctica, solo la mitad de los docentes manifiesta que ha recibido algún tipo de apoyo (ya sea de colegas o del referente informático del colegio).

Asimismo, frente a la pregunta sobre que le resulto más útil en el proceso de incorporación de las TIC en la enseñanza, los docentes manifestaron: 


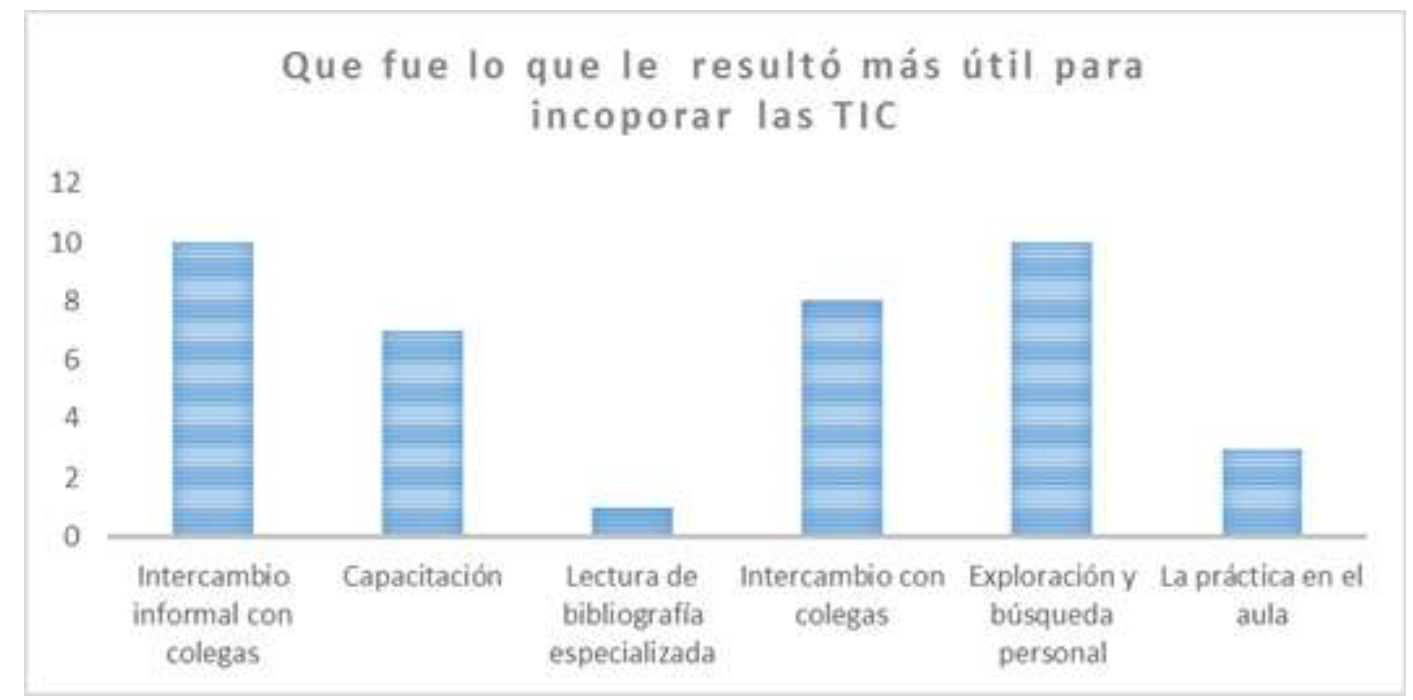

Tabla 5 Aspectos útiles para incorporar las TIC

Conjuntamente frente a la pregunta sobre los recursos digitales usados con mayor frecuencia, se señalan:

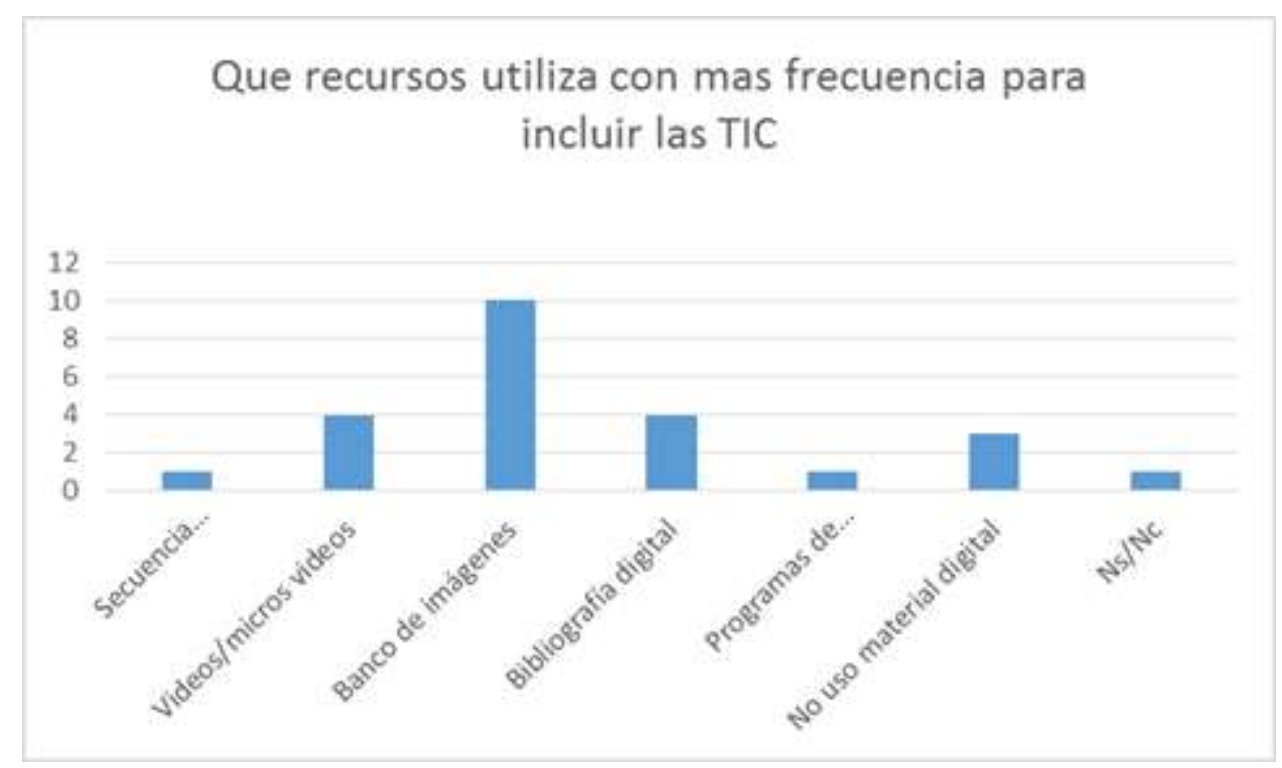

Tabla 6 - recursos TIC utilizados con mayor frecuencia

Del mismo modo, se le preguntó a los docentes sobre la preparación de algún material digital para su inclusión en el aula. En este sentido, existe un 73\% de los profesores que manifestó no haber elaborado recursos TIC personales para sus prácticas de enseñanza con los alumnos.

Capacitación y habilidades TIC de los docentes

Más de la mitad de los docentes encuestas manifiesta haber tendió alguna capacitación referida a TIC en los últimos años. 


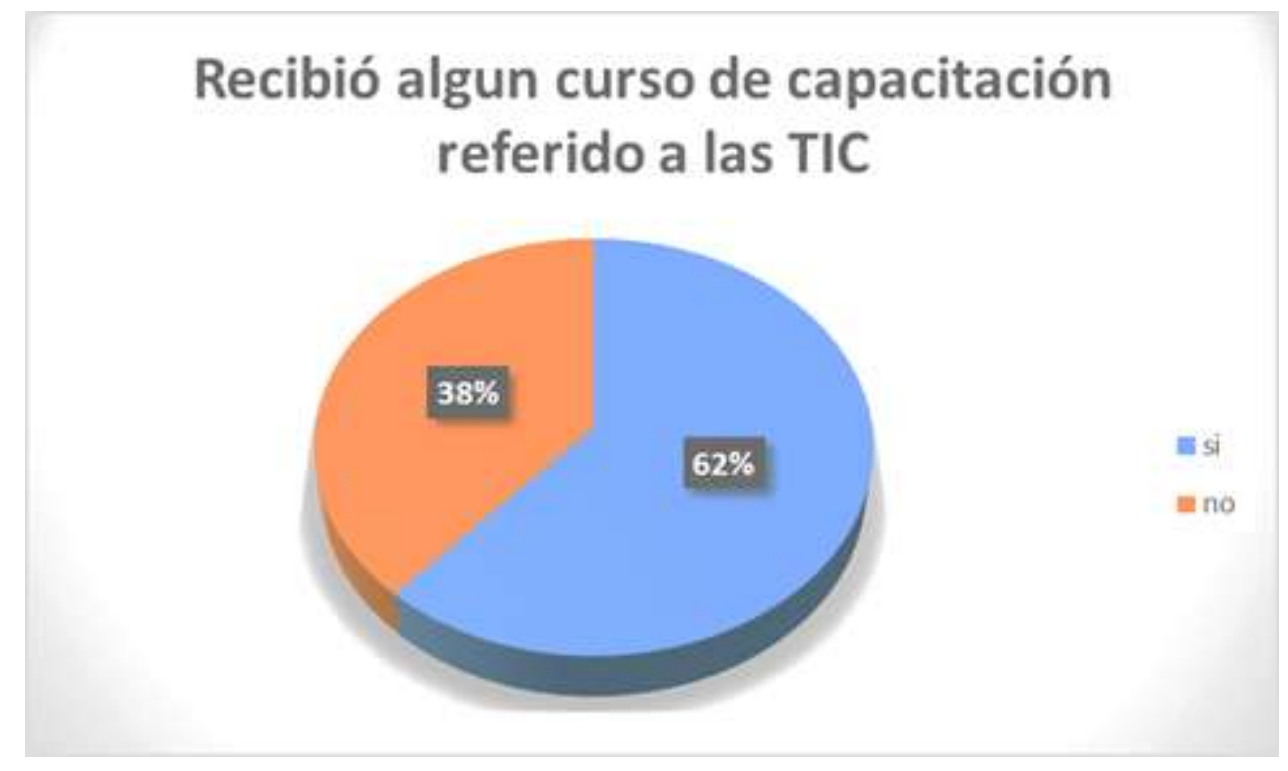

Tabla 7 cursos de capacitación TIC recibidos

Sobre la modalidad de las ofertas de capacitación las mismas han sido tanto en la modalidad virtual, como presencial y mixta.

De igual modo, sobre la indagación en las habilidades TIC que posee los profesores, se advierte los siguientes aspectos:

\section{Habilidades TIC}

Instalar y desinstalar soit ware educativos en la netbook Usar TIC para monitorear el progreso de alumnos y.. Preparar clases que involucran el uso de las TIC Encontrar recursos pedagógicos útiles en internet Comprar por internet Seleccionar sitios web/grupos de interés educado para. Crear yeditar videos Producir presentaciones con animaciones simples (power. Compartir experiencias con otros en un foro de internet Usar hoja de calculo para mantener una lista de alumnos Archivar documentos electrónicos en carpetas $y$. Tomar fotosy mostrarlas en las netbook Enviar un archivo a un colega por correo electrónico
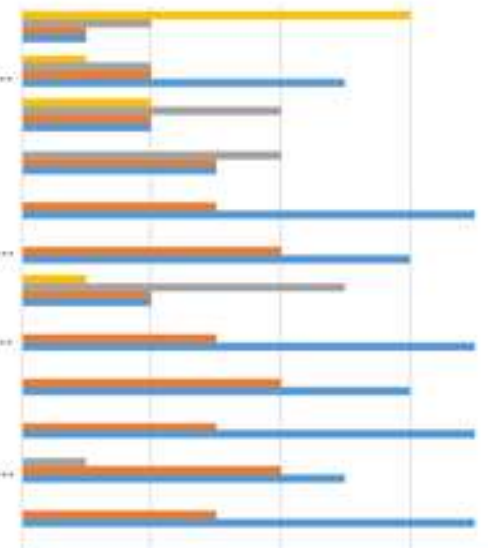

$$
\begin{aligned}
& 0 \\
& \text { = No se usarlo }=\text { Bastante dificultad } \\
& \begin{array}{llllll}
0 & 2 & 4 & 6 & 8 & 10
\end{array} \\
& \text { Algo de dificultad } \mathbf{m} \text { Sin dificultad }
\end{aligned}
$$




\section{2.- Análisis de las prácticas pedagógicas con TIC}

A partir de los relatos de los docentes entrevistados sumados a algunos aspectos observados en la experiencia del campo, podemos construir algunos sentidos y resultados acorde a los objetivos que nos planteamos en este trabajo de investigación.

En este apartado presentamos algunas reflexiones que surgen del análisis del material recogido y de las lecturas y debates teóricos sobre las políticas, realidades y contextos de la enseñanza. En este sentido puntualizamos los replanteos sobre el rol docente a partir de las TIC, como así también los sentidos surgidos a partir de cierta recuperación de propuestas didácticas de enseñanza mediadas por las tecnologías. Rescatamos también las potencialidades de los recursos tecnológicos observados y los desafíos que implican la apreciación crítica de las TIC y sus perspectivas epistemológicas de prácticas.

Son varios los comentarios de los docentes entrevistados que dan cuenta acerca de discontinuidades, contradicciones y las dificultades en general respecto a las políticas relativas a la incorporación de tecnologías educativas en el sistema educativo. En este sentido, se manifiesta cierto descontento respecto a las expectativas sobre las acciones desarrolladas, tanto por el gobierno central de la educación a través del programa nacional de Conectar Igualdad, como así también los proyectos o iniciativas realizadas por la jurisdicción.

En este orden, resulta un aspecto relevante el rol poco claro que parecerían tener los equipos técnicos y de gestión jurisdiccionales responsables de la implementación de los proyectos o programas de inclusión digital para que prevalezca cierta continuidad de sentido en las escuelas, de modo tal de conseguir la puesta en práctica de procesos de innovación genuina, vinculados a las tecnologías digitales en la educación. En este sentido, el factor indispensable del apoyo, sostenimiento y continuidad en las etapas que requería la implementación del programa, adoleció de consistencia, según relatan algunas las voces de los docentes. Además, en las escuelas secundarias de la localidad, los cambios y poca continuidad de los responsables jurisdiccionales contribuían a la dificultad para hacerle frente a las demandas y necesidades heterogenias que plantea la población escolar, inmersa en procesos de transformación y reforma de la educación secundaria obligatoria.

Sin embargo, más allá de estas problemáticas planteadas y de los obstáculos reales respecto a cuestiones de deficiencias específicas, como los edificios escolares o las cuestiones de la gestión técnica educativa jurisdiccional, se destaca que la entrega de las computadoras del programa conectar igualdad a todos los alumnos de las escuela públicas secundaria contribuyo a la representación de un hecho significativo y de relevancia simbólica en materia de política educativa de inclusión para los docentes en la localidad. El hecho de que los jóvenes pudieran disponer de sus netbooks, llevándoselas a sus domicilios para luego ser sus propietarios una vez finalizada la escuela, ha sido un hecho inédito y valioso que dio cuenta de políticas educativas tendientes a propiciar la inclusión digital. Así lo manifiestan por ejemplo alguno de los docentes del nivel medio entrevistados, señalando en su testimonio que las máquinas no habían llegado para los alumnos ingresantes, a primer año. También se encontraba el problema de los alumnos que estaban cursando el tercer año de las escuela secundarias, y les tocó comenzar en la nueva estructura de ESO (educación Secundaria Obligatoria). Estos problemas de falta de continuidad e incoherencia respecto a ciertas decisiones políticas centrales para la mejora del sistema educativo han existido en varias ocasiones. Otro ejemplo de ello han sido los cambios curriculares profundos en el sistema educativo -como la estructuración de los ciclos de la Enseñanza General Básica y el Polimodal en la década del 
noventa, y luego la reforma de la educación básica en educación primaria y educación secundaria, a partir del año 2013 en la provincia de Santa Cruz-.

Por otra parte, en las escuelas secundarias donde trabajan los docente entrevistados, existía cierta heterogeneidad respecto a los tiempos y al desarrollo de la implementación y concreción del programa uno a uno. Este desfasaje respecto a los problemas recurrentes en la entrega y disponibilidad de los equipos en las aulas, marcaron un escenario particular respecto a lo que se pretendía, en relación a la institución educativa y los procesos de cambio e innovación en las prácticas pedagógicas mediadas por la tecnología. En orden a ello, la posibilidad de planificar acciones pedagógicas o proyectos curriculares conjuntos, se vieron dificultados por las posibilidades concretas materiales de llevarlas a cabo. Ejemplos de estas cuestiones son los planteos que realizan docentes en las entrevistas donde señalaban que las maquinas que entregaron en el programa dado que llegaron muy tarde al colegio, muy tarde con respecto al momento en que se desestructura la EGB , entonces se entregan las "netbook" a octavo y noveno año un año antes que se lleve a cabo la Reforma de la Ley de Educación acá; otros profesores expresaban la dificultad que suponía la entrega de la computadoras, "sin ninguna capacitación para su implementación..."; otros testimonios señalaban que Los chicos recibían las computadoras, los maestros y profesores recibían también las maquinas, pero sin embargo no se contaba con los saberes y competencias necearías para utilizarlas en propuestas pedagógicas: "no sabíamos cómo utilizarla, qué programas tenia dentro de la maquina... cómo vincular esa tecnología en nuestra tarea..."

Otro aspecto recogido en los testimonios, se vincula a las situación de rotura de las computadoras entregadas a los estudiantes, y la imposibilidad de contar con un servicio técnico que fuera eficiente para la reparación en el propio contexto de la provincia, lo cual marca como característica la falta de una planificación y previsión estratégica situada del programa 1 a 1 . En tal orden, las netbooks que se averiaban o el sistema operativo no podía ser instalado, o no se podían desbloquear, ocurría que el equipo debía enviarse a la Ciudad de Buenos Aires. Luego, habitualmente sucedía que no eran devueltas a los alumnos en tiempo y forma. Es decir, la nueva entrega se demoraba demasiado, lo cual originaba dificultades en el trabajo de los docentes para lograr dar continuidad a las tareas programadas para todo el grupo de alumnos, y una gran desilusión en los jóvenes que se quedaban sin la computadora.

En algunos casos puntuales, se señala que los alumnos no volvieron a recibir la netbook correspondiente durante todo el ciclo lectivo. Este tipo de circunstancias remite a la problemática de que no se previó la importancia de una gestión más de orden descentralizado y operativo de los aspectos técnicos y del arreglo de los desperfectos en las computadoras de los alumnos. Así lo testimonian los docentes: "el tema es que las computadoras se iban rompiendo, o quedaban inutilizadas y eso significaba que debían mandarlas al servicio técnico que queda en Buenos Aires... por lo cual los chicos andaban con un período muy largo sin las máquinas..."

Otra situación recurrente señalado en las entrevistas, da cuenta de cierta la falta de coherencia entre los discursos de la política TIC y las decisiones concretas vinculadas al programas de inclusión digital en el sistema educativo, o en particular a la realidad de las escuelas secundarias de Rio Gallegos. En tal aspecto se menciona la inexistencia de acceso a la conectividad en muchas de las escuelas de la localidad, lo cual genera indefectiblemente dificultades para planificar la enseñanza a partir de propuestas didácticas que requieran la conexión a Internet. En tal sentido se menciona: "las computadoras en los colegios nunca se conectaron a Internet"; asimismo "la única forma que tenemos de trabajar con las compradores es pasando archivos de maquina en maquina a través de memoria portátil o 
"pendrive" a los alumnos"; "otra alternativa es proponerles actividad que los chicos puedan trabajarlo de otra manera, porque de internet nunca había"

Las dificultades expresadas nos ponen de manifiesto que, para que estas propuestas prosperen, es necesario que exista una organización institucional adecuada para su desarrollo. Los directivos y responsables de la gestión en general deben tener una visión consolidada acerca de su importancia, generando un ambiente propicio y dinámico para integrar las tecnologías. En tal circunstancia un rol clave en los procesos de incorporación de las TIC, está dado por el acompañamiento situado, continuo y real logrado por los supervisores, directores o la comunidad educativa en general. Este aspecto resulta indispensable cuando lo que se pretende es lograr instancias innovadoras genuinas en la escuela, cuyo carácter no sea un "como si" meramente cosmético, sino cambios cuyo alcance y sentido se debatan en forma democrática en la escuela, logrando consenso para trabajar en pos de transformaciones profundas.

En relación al contexto de la cultura digital y del amplio acceso a los medios tecnológicos, son los jóvenes quienes cuentan con unas mayores oportunidades para el uso de las TIC, tanto fuera como dentro de la escuela. Esto fue dando curso a un nuevo tipo de vínculo entre docentes y alumnos, a partir de otras formas de comunicación. Los roles tradicionales basados en el vínculo asimétrico docente alumno, van siendo interpelados en este contextos y generando nuevas representaciones de la tarea pedagógica para muchos profesores.

Lo profesores reconocen que las nuevas generaciones cuentan con prácticas habituales y saberes relacionados con el mundo de la tecnológica y en este aspecto, cuando la actitud del docente es de apertura y respeto hacia las nuevas formas de la cultura digital, se generan instancias de reflexión y resignficación acerca de su rol como docente, del lugar que tiene las nuevas formas de construcción del conocimiento, y de la posibilidad que brinda hoy una inteligencia distribuida en la escuela, en donde se pueden compartir saberes y competencias. Algunos testimonios narrados en la entrevistas narraban: "resulta que los alumnos van trabajando con tal material que sería para presentar en el acto del 25 de mayo, pero finalmente ellos me devuelven toda una producción traducida en un soporte de video, mezclando audio, con entrevistas etc.. (...) es decir, que la tecnología está muy presente” ; en cierto sentido “... a veces nosotros profesores orientamos en la selección de contenidos, a veces ellos son como expertos que nos enseñan a usar los programas de edición o de compaginación etc...."

Las prácticas de enseñanza mediada por tecnologías en las escuelas secundarias suele llevar implícito cuestionamientos respecto las formas y modelos pedagógicos. Este tipo de propuestas deben analizarse desde cierta perspectiva de "flexibilidad", pues las estrategias didácticas que incorporan recursos TIC descartan la canonización pedagógica que apela a una educación repetitiva, academicista o tradicional. Los docentes entrevistados, se manifiestan inmersos en una realidad educativa distinta, a la que caracterizó su propia biografía escolar, y se subraya cierta tensión entre los modos de enseñar y aprender propios de una escuela que funcionó de una manera bastante similar durante los siglos diecinueve y veinte, y las nuevas formas que se instalan en este siglo a partir de la irrupción de una cultura tecnológica digital.

En el marco de las reflexiones y experiencias que destacan los docentes, surgen valoraciones respeto al potencial que implican los dispositivos, entornos y recursos tecnológicos de los que actualmente pueden disponer para poder abordar, propuestas pedagógicas enriquecidas, poderosas (Maggio 2012). De igual modo, se expresan algunos desafíos respecto a la complejidad que suponen los procesos de enseñanza y aprendizaje en la era actual. En este 
sentido, una situación recurrente manifestada por los docentes, refiere a la práctica habitual de toma de apuntes y seguimiento de la clase escolar, a través de la toma manual escrita en el cuaderno o carpeta de apunte, la cual empieza ser percibirse por parte de los alumnos como una práctica poco importante, es decir, como una posibilidad de abandonar dicha rutina predecible en esta etapa educativa.

Es decir, en ocasiones frecuentes empieza notarse cómo los estudiantes prefieren la captura fotográfica con la cámara que posee el teléfono de los contenidos que son plasmados en el pizarrón, o por ejemplo, grabar una audio de la exposición dialogada del docente, o también recurrir de manera sistemática a la información que puede obtenerse en la web a partir de la mayor conectividad que brinda la conectividad de datos de internet $4 \mathrm{G}$ de los teléfonos etc. Una lectura crítica de esta experiencia, por parte de los profesores es que, de alguna manera el contenido educativo implica siempre una intencionalidad y una selección que se hizo conformando prioridades de un diseño de propuesta pedagógica; es decir, existen unos criterios didácticos o epistemológicos que devienen de tal configuración de propuesta pedagógica, la cual no siempre son plasmados, captados o reflejados de manera consistente por parte del alumno. Esto contrasta e interpela a los docentes respecto a estas formas digitales de tomar registro de la actividad de la clase. Por otra parte, las posibilidades de recuperar de manera comprensiva los ejes temáticos trabajados, los esquemas, ejemplos, analogías u orientaciones conceptuales sobre las nociones vertidas en la clase para lograr una mejor apropiación y profundización del aprendizaje se van dispersando o postergando en la tarea presencial de la clase, dado que se abandona la práctica concentrada de toma de apuntes escrito. Esto puede verse reflejado en el testimonio de docentes que manifiestan:

“... notamos que cada vez sacan más fotos al pizarrón o están con el celular grabando la clase porque piensan que supuestamente más adelante en su casa van a pasar el apunte escrito..."

Por otra parte las nuevas maneras de comunicación que proliferan entre los jóvenes tales como las redes sociales van confluyendo en una alternativa cada vez más válida para que los docentes puedan canalizar allí su tarea de orientación y apoyo pedagógico a los alumnos. Situaciones tales como la orientación y las consignas de tareas escolares a través de entornos como Edmodo o la red social de Facebook o directamente la mensajería por grupo de WhatsApp donde se brinda una estructura reticular que permite interacciones, intercambios, compartir recursos información, en el momento preciso qué se necesita hacerlo y llegando de modo directo a los estudiantes. Pero ocurre en ocasiones que la tarea con los alumnos tiende a relativizar la situación del encuadre de la clase propiamente dicha, desplazándose la realización de las tareas fuera de la escuela, sumando la posibilidad detener el canal de comunicación de las redes para evacuar las dudas, las inquietudes acordando las particularidades a través de mensajes directos. De este modo surgen comentarios en las entrevistas docentes que señalan que fijan un horario en donde le indican a los alumnos que se encontrarán conectados en el Facebook: ... yo le digo a mis alumnos que en tal horario voy a estar online... y bueno los alumnos se conectan y me dicen: vamos a preguntarle Tal cosa... o te escriben profe Cuál era el apunte que hay que estudiar.... A qué se refiere esta idea.... me está pasando ahora hace poco con la utilización de grupos de WhatsApp con envíos de audios o de la tarea en Word. a veces son los fines de semana no hay horario restringido $\mathrm{Y}$ esto es tremendo. Es decir el encuadre de la clase y las explicaciones del profesor en el aula tienden a sub valorarse, y se pierde cierta tensión a las consignas de las tareas lo cual supone la necesidad de reforzar una y otra vez en los entornos virtuales y especialmente en las redes sociales, por fuera del horario escolar según documental los testimonios de las entrevistas. 
El reconocimiento del potencial que conlleva el diseño de propuestas y dispositivos pedagógicos válidos para la enseñanza y el aprendizaje es un rasgo característico de la narrativa que refieren los profesores entrevistados. La conformación de que las tecnologías promueven el desarrollo de un pensamiento complejo -a partir de soluciones creativas a los problemas planteados- como también la generación de hipótesis diversas, que permiten reflexionar recursivamente. En ciertas áreas o espacios curriculares, ocurren notables cambios a la hora de encarar propuestas de actividades, tal como ocurre con la asignatura de matemática, donde los docentes refieren a que los alumnos trabajan con herramientas dónde sacan un mejor provecho al explorar de manera conjunta con programas como el Geogebra, entre otros. Asimismo refieren a que ya no se tiene la exigencia de estar graficando funciones en el pizarrón, y por lo tanto se dispone de un mayor tiempo para priorizar la profundización teórica y comprensiva de las temáticas, validar operaciones, visualizar conjeturas, etc..

Las tecnologías digitales vienen acompañadas de representaciones prometedoras respecto a las posibilidades didácticas que ofrecen los nuevos entornos para potenciar los procesos de enseñanza y aprendizaje en las escuelas. La orientación de los aprendizajes en tiempos reales y la organización de experiencias en las que se pueden compartir diferentes tipos de saberes entre alumnos y docentes, por ejemplo, propicia la generación de procesos genuinos de comprensión del conocimiento. La comunicación entre expertos y novatos a través de redes sociales; las estrategias de simulación que permiten aprender desde situaciones que recuperan problemas de la vida real, son algunas de las propuestas valiosas que ofrecen estas tecnologías. En su mayoría, los profesores de las escuelas medias valoran estos recursos, pues a partir de los mismos se instaura una mayor apertura a contenidos y estrategias: “...hablamos de la "netbook", hablamos del celular, pero también hay otra herramienta, un cañón por ejemplo. Yo ahora me compré un proyector chiquito y entonces también me sirve y a veces recurro al proyector para presentar o para abrir una clase, o ver un documental, entonces es una herramienta válida para trabajar con los alumnos, y aparte es como que uno también les está mostrando alternativas de trabajo en clase, entonces también es válido ese tipo de herramientas. Ni hablar lo que dijo la profe del canal "Encuentro", donde también hay disponible documentales muy interesantes para trabajarlos, entonces uno trata de aprovecharlos".

En estos nuevos escenarios de enseñanza y aprendizaje se modifican las formas de acceder a la información para construir conocimientos. Las tecnologías digitales desde la red internet ayudan a configurar ambientes de aprendizaje y entornos particulares para la interacción y comunicación educativa. Por tal motivo, los docentes destacan las actividades planificadas a partir del diseño de aulas virtuales en plataformas tecnológicas, por ejemplo, permitiendo que los estudiantes controlen las coordenadas témporo-espaciales, replanteando sus marcos de referencia con respecto a su interacción con los docentes desde instancias sincrónicas o asincrónicas. Así lo testimonian voces mencionadas en la entrevistas referidas a que: "ahora tenemos posibilidad de contar con aulas virtuales que ayudan mucho para la interacción fluida con el aula, la selección de materiales digitales o la planificación de agendas de trabajo". De esta manera, las TIC no son concebidas como recursos meramente "motivadores", utilizadas sólo para lograr despertar y mantener el interés de los jóvenes alumnos a partir de modos diferentes de presentación de los contenidos, sino que su incorporación sustancial posibilita diseñar actividades, generar mayores niveles de seguimiento, comprensión del aprendizaje logrados y mantener una interacción permanente con los estudiantes,. 


\section{5.- Conclusiones}

La investigación en el campo particular de las prácticas pedagógicas, supone un conjunto de desafíos que atravesaron el recorrido de este proyecto de investigación. A lo largo del trabajo pudimos relevar que existe una preocupación por lograr aportes y contribuir al desarrollo de estudios vinculados a dimensionar los procesos de incorporación de las TIC en las prácticas pedagógicas escolares. Sin embargo cabe señalar que siempre existen los problemas vinculados a la generabilidad y replicabilidad de las conclusiones o resultados a los que podemos arribar en la investigación educativa de estas características, dado la especificidad de las unidades de análisis que investigamos donde el ámbito de las escuelas concretas, los profesores, las aulas, etc, son siempre realidades situadas, contextualizadas y difícilmente sustituibles.

Teniendo en cuenta este horizonte, en el estudio, se trató de abarcar, el desafío de investigar las particularidades que asume el trabajo pedagógico de los docentes de escuelas secundarias de Rio Gallegos, donde buscamos incorporar las voces de educadores y el contacto directo en entrevistas en profundidad con los profesores, complementando los aportes en línea con el diseño de una encuestas validada para docentes de las escuelas locales.

A modo de conclusión y discusiones finales podemos advertir que las acciones y esfuerzos desarrollados, en el marco de programas e iniciativas de inclusión digital no son procesos lineales sino que conforman escenarios complejos atravesados por tensiones e interpelaciones sobre los sentidos pedagógicos de la práctica educativa actual. Son varios los aportes vinculados a la necesidad que da cuenta acerca de ciertas discontinuidades o contradicciones que ponen de relieve que estamos ante un fenómeno multidimensional donde no hay una linealidad respecto procesos y prácticas pedagógicas mediadas por las tecnologías que se configuran en los centros educativos destinatarios de dichas políticas

En este sentido, los procesos de incorporación de las TIC en la educación implican cambios en las instituciones, hacia nuevas formas de organización del trabajo pedagógico del docente. Pero para que éstas adquieran sentido hay que reflexionar acerca de algunas cuestiones básicas, como por ejemplo:

¿Por qué cambiar? ¿Para qué? ¿Hacia dónde se dirige el cambio pretendido?

¿Por qué hay que pensar en integrar las transformaciones de la cultura digital en la vida escolar?

En varias de las escuelas secundarias donde trabajan los docentes que indagamos, los aspectos operativos vinculados a la incorporación de tecnologías digitales en las aulas suelen adolecer aun de un encuadre estratégico claro que posibilite su concreción y desarrollo con continuidad. Cuando se pretenden procesos de cambios significativos respecto a formas de enseñanza mediadas por tecnologías, se requiere de un conjunto de acciones que contemplen y prevean las condiciones de posibilidad tanto en las dimensiones institucionales, como así también políticas, económicas, sociales y pedagógicas.

El apoyo de los distintos roles, tales como supervisores, directores y la comunidad educativa en general resultan condiciones indispensables para lograr instancias innovadoras en las practicas pedagógicas cuyo carácter no sea un "como si" sólo cosmético, sino que impliquen innovaciones cuyo alcance y sentido se debatan en forma democrática en la escuela, logrando 
consenso para trabajar en pos de transformaciones profundas. Por estos andariveles, las posibilidades didácticas que ofrecen las tecnologías digitales para potenciar los procesos de enseñanza y aprendizaje en las escuelas, son realmente prometedoras. Aunque no deja de ser un desafío la cuestión de cómo orientar los aprendizajes en tiempos reales y la organizar experiencias de diferentes tipos de saberes entre alumnos y docentes.

Entre las discusiones que deja planteado el trabajo de esta investigación, podemos mencionar, la importancia de un nuevo rol docente y de la necesaria profundizaciones en las habilidades que requiere la práctica pedagógica en el escenario de la alfabetización en la cultura digital. Esta nuevas competencias digital, nos sitúan ante el desafío de reflexionar e interpelar nuestra práctica, que como nos plantea Dussel (2011) requiere también de aprender junto con los estudiantes de manera proactiva, en contextos donde los alumnos también están aportando sus propias ideas, experiencias y conocimientos al proceso de aprendizaje (Dussel, I., 2011, p. 13)

Para los docentes, la escuela se transforma así en una institución donde todos pueden aprender de todos. La cultura digital de la cual formamos parte como ciudadanos de esta época posibilita que el conocimiento, en todas sus dimensiones y configuraciones, se distribuya masivamente, se comparta y se re-elabore. En esta nueva escuela se minimizan las jerarquías, porque se valora la conformación de redes para que el aprendizaje pueda ser un proyecto de construcción colaborativa por parte de la comunidad educativa.

A la luz de los recorridos planteados en el trabajo, creemos necesario mencionar, la recuperación de propuestas didácticas que la enseñanza mediada por las TIC nos impulsa. En este sentido, la implementación de una enseñanza mediada por tecnologías en las escuelas secundarias suele implicar un cierto cuestionamiento respecto a las formas y modelos pedagógicos. Este tipo de propuestas deben analizarse fundamentalmente desde perspectivas comprensivistas, abierta a la "flexibilidad", pues las estrategias didácticas que incorporan recursos tecnológicos basados en las TIC descartan las formas canónicas pedagógicas y nos invitan a interpelar la práctica rescatando nuevos sentidos de la trama cultural actual.

La cultura de los docentes y las competencias profesionales para su práctica debe ser constitutiva de los cambios que se generan en el sistema educativo, por lo cual es fundamental que la cultura de las reformas e iniciativas de las políticas de inclusión de las TIC, forme parte consustancial de la conciencia de los docentes. De otro modo, se corre el riesgo de generar propuestas tecnocráticas alejadas de los verdaderos intereses y problemas del profesorado. La necesidad de contar con una nueva conciencia pedagógica por parte de los docentes a partir de las TIC, nos abre nuevos interrogantes para seguir profundizado en futuras investigación en el campo de la integración de tecnología en el sistema educativo.

\section{6.- Bibliografía}

ADELL, J. (2006). Tendencias en educación en la sociedad de las tecnologías de la información. Edutec. Revista Electrónica de Tecnología Educativa (7). https://doi.org/10.21556/edutec.1997.7.570

ADELL, J., \& Castañeda, L. (2011). Los entornos personales de aprendizaje (PLEs): Una nueva manera de entender el aprendizaje. In R. Roig Vila \& M. Fiorucci (Eds.), Claves para la investigación en innovación y calidad educativas. Alcoy: Marfil - Roma TRE Universita degli studi. https://doi.org/10.21071/edmetic.v3i2.2892 
AMLA. (2007). Core principles of media literacy education in the united states. Alliance for a Media Literate America (AMLA). In.

AREA MOREIRA, M. (2010). El proceso de Integracion y uso de las TIC en los centros educativos. Un estudio de caso. Revista de Educacion, N 352 Mayo-Agosto 2010, 7797. https://doi.org/10.5944/educxx1.17907

AREA M, M. (2012). Los efectos del modelo 1:1 en el cambio educativo en las escuelas. Evidencias y desafíos para las políticas iberoamericanas1 Revista Iberoamericana De Educación. N. ${ }^{\circ} 56$ (2011), pp. 49-74 (ISSN: 1022-6508). https://doi.org/10.22201/iisue.20072872e.2011.4.36

BANERJEE, A., \& Duflo, E. E., S. Cole, y L. Linden,(2007). Remedying Education: Evidence from Two Randomized Experiments in India, forthcoming. Quarterly Journal of Economics. https://doi.org/10.3386/w11904

BARBERÀ, E, Mauri T. y Onrubia J. (coord.) (2008) Cómo valorar la calidad de la enseñanza basada en las TIC, Graó, Barcelona

BAWDEN, D. (2008). Origins and concepts of digital literacy. Digital literacies: Concepts, policies and practices, 30, 17-32.

BUCKINGHAM D. (2008), Más allá de la tecnología. Aprendizaje infantil en la era de la cultura digital, Manantial, Buenos Aires.

BURBULES N. y Callister T. (2001) Educación: Riesgos y promesas de las nuevas tecnologías de la información, Granica, Barcelona.

BUSCHMAN, J. (2010). Alfabetización informacional, «nuevas» alfabetizaciones y alfabetización. Boletín de la Asociación Andaluza de Bibliotecarios, 98-99, 155-183.

CABERO ALMENARA, J., \& Llorente Cejudo, M. d. C. (2008). La alfabetización digital de los alumnos. Competencias digitales para el siglo XXI. Revista Portuguesa de Pedagogia, 42 (2), 7-28. https://doi.org/10.14195/1647-8614_42-2_1

CABELLO R y otros (2013) Migraciones digitales. Comunicación, educación y tecnologías digitales interactivas. Universidad Nacional General Sarmiento. E-Book

CAMILLONI, A., \& Cols, E. (2010). La problemática de la investigación didáctica (pp. 127143). WAINERMAN, C. y DI VIRGINIA, M.(Comps.) El quehacer de la investigación en educación. Buenos Aires: Manantial. https://doi.org/10.1016/j.riem.2017.01.120

CASTELLS, M. (2004). The network society A cross-cultural perspective: Edward Elgar.

CELAYA RAMÍREZ, R., Lozano Martínez, F., \& Ramírez Montoya, M. S. (2010). Apropiación tecnológica en profesores que incorporan recursos educativos abiertos en educación media superior. Revista mexicana de investigación educativa, 15. https://doi.org/10.21556/edutec.2015.53.282

ClARO, M., Preiss, D. D., San MartíN, E., Jara, I., Hinostroza, J. E., Valenzuela, S., . . . Nussbaum, M. (2012). Assessment of 21st century ICT skills in Chile: Test design and results from high school level students. Computers \& Education, 59(3), 1042-1053. https://doi.org/10.1016/j.compedu.2012.04.004

COICAUD S. (2012) La construcción de una Didáctica Tecnológica. Enseñar y aprender con materiales de estudio en propuestas extendidas y mediadas por tecnologías, publicado por Editorial Académica Española, Madrid, ISBN 978-3-659-03518-0

COLÁS BRAVO, P. (2003). Internet y aprendizaje en la sociedad del conocimiento.

COVELLO, S., \& Lei, J. (2010). A review of Digital Literacy Assessment Instruments. IDE712 Front-End Analysis Research. Analysis for Human Performance Technology Decisions. Syracuse University, School of Education. In.

CUBAN, L. (2001). Oversold and Underused: Reforming Schools Through Technology, 1980-2000. Cambridge MA: Harvard University Press.

DE PABLOS PONS, J., Colás Bravo, P., \& González Ramírez, T. (2010). Factores facilitadores de la innovación con TIC en los centros escolares. Un análisis 
comparativo entre diferentes políticas educativas autonómicas. Revista de Educación, 352, 23-51. https://doi.org/10.11144/javeriana.uh83.pelv

DOYLE, D. (2010). Immersed in learning: Supporting creative practice in virtual worlds. Learning, Media and Technology, 35(2), 99-110. https://doi.org/10.1080/17439884.2010.494418

DUGHERA, L. (2016). De Internet, computadoras portátiles, softwares y contenidos: un análisis comparativo de planes" una computadora, un alumno" en tres provincias de la Argentina.

DUEÑAS, S. N., y Rivas, F. G. P. (2005). Una iniciativa de modernización educativa: el proyecto Ponte dos Brozos. Novática: Revista de la Asociación de Técnicos de Informática, 177, 61-67.

DUSSEL, I. (2011). Aprender y enseñar en la cultura digital. Documento Básico del VII Foro.

ESHET, Y. (2012). Thinking in the digital era: A revised model for digital literacy. Issues in Informing Science and Information Technology, 9(2), 267-276. https://doi.org/10.28945/1621

ESTEVE, F. \& Gisbert, M. (2011). El nuevo paradigma de aprendizaje y las nuevas tecnologías. REDU: Revista de Docencia Universitaria, 9(3), 55-73. https://doi.org/10.4995/redu.2011.6149

FEIJOO GONZALEZ, C. A. (2010). Una Vía de Doble Sentido: Comunicaciones Móviles y Sociedad. Telos: Cuadernos de comunicación e innovación(84), 18-29.

FERRARI, A. (2012). Digital competence in practice: An analysis of frameworks. Sevilla: JRC IPTS.(DOI: 10.2791/82116).

FRASER, J., Atkins, L., \& Richard, H. (2013). DigiLit leicester. Supporting teachers, promoting digital literacy, transforming learning. Leicester City Council.

GAIRÍN SALLÁN, J., \& Muñoz Moreno, J. L. (2008). El agente de cambio en el desarrollo de las organizaciones.

GARCIA, I., Peña-López, P., Johnson, L., Smith, R., Levine, A., \& Haywood, K. (2010). Informe Horizon: Edición iberoamericana 2010. Austin, Texas: The New Media Consortiu

GARCÍA CARRASCO, J. (2009). Las formas de la alfabetización cultural en la sociedad de la información. Teoría de la Educación. Educación y Cultura en la Sociedad de la Información, 10(1). https://doi.org/10.4272/84-9745-045-0.ch11

GIL, J. M. S., \& Gorospe, J. M. C. (2010). Cambio y continuidad en sistemas educativos en transformación Change continuity in changing education systems. CONSEJO DE DIRECCIÓN/MANAGING BOARD, 352, 17-21.

GILSTER, P., \& Glister, P. (1997). Digital literacy: Wiley Computer Pub. New York.

GONZÁlEZ, I. G., Peña-López, I., Johnson, L., Smith, R., Levine, A., \& Haywood, K. (2010). Informe Horizon: Edición Iberoamericana 2010.

GUBA, E. G., \& Lincoln, Y. S. (1994). Competing paradigms in qualitative research. Handbook of qualitative research, 2(163-194), 105.

HALL, R., Atkins, L., \& Fraser, J. (2014). Defining a self-evaluation digital literacy framework for secondary educators: the DigiLit Leicester project. Research in Learning Technology, 22(1), 21440. https://doi.org/10.3402/rlt.v22.21440

HILL, J., y Reeves, T. (2004). Change takes time: The promise of ubiquitous computing in schools. A report of a four year evaluation of the laptop initiative at Athens Academy. Atlanta, GA: Department of Instructional Technology, University of Georgia.

HOPENHAYN, M. (2002). El reto de las identidades y la multiculturalidad. Pensar Iberoamérica: Revista de cultura, 1. 
INAN, F. A., \& Lowther, D. L. (2010). Factors affecting technology integration in K-12 classrooms: a path model. Educational Technology Research and Development, 58(2), 137-154. https://doi.org/10.1007/s11423-009-9132-y

JARA, I. (2008). Las Políticas de Tecnología para Escuelas en América Latina y el Mundo: Visiones y Lecciones. Santiago: CEPAL-Naciones Unidas.

JENKINS, H. (2006). Convergence culture: Where old and new media collide: NYU press.

KAHN, R., \& Kellner, D. (2005). Reconstructing technoliteracy: A multiple literacies approach. E-Learning and Digital Media, 2(3), 238-251. https://doi.org/10.2304/elea.2005.2.3.4

KATIĆ, E. K. (2008). Preservice teachers' conceptions about computers: An ongoing search for transformative appropriations of modern technologies. Teachers and Teaching: theory and practice, 14(2), 157-179. https://doi.org/10.1080/13540600801983344

LANKSHEAR, C. J., \& Knobel, M. (2008). Introduction: Digital literacies: Concepts, policies and practices. In: Peter Lang Publishing.

LIPSMAN, M. (2005) Los misterios de la evaluación en la era de Internet en Tecnologías educativas en tiempos de Internet coord. por Edith Litwin, Buenos Aires, Amorrourtu. https://doi.org/10.5294/pacla.2014.17.3.7

LITWIN E. -comp- (2005) Tecnologías educativas en tiempos de Internet, Amorrortu, Buenos Aires

LUGO, Ma Teresa, Kelly, Valeria B. A. A., \& Sebastian Schurmanz, B. A. A. (2012). Políticas TIC en educación en América Latina: más allá del modelo 1:1. Campus Virtuales, Vol 1, 31-42.

MAGGIO, M. (2012). Entre la inclusión digital y la recreación de la enseñanza: el modelo 1 a 1 en Argentina Campus Virtuales, Vol 1, 51-65.

MAGGIO, M., Lion, C., Masnatta, M., Penacca, L., Perosi,M.V., Pinto, L., Latorre, M., Sarlé, P., (2012) Creaciones, experiencias y horizontes inspiradores. La trama de Conectar Igualdad (TIC para la inclusión), ISBN: 978-987-1433-89-6. Educ.ar S.E.; Buenos Aires, Ministerio de Educación de la Nación. https://doi.org/10.25145/c.educomp.2018.16.018

MORALES, S. (2007). Brecha digital y educación en la sociedad global de la información. En Cabello, R. y Levis, D. (eds) Medios informáticos en la educación. Perspectivas en América Latina y Europa. Buenos Aires: Prometeo. https://doi.org/10.25145/c.educomp.2018.16.018

NAWAZ, A., \& Kundi, G. M. (2010De). Digital literacy: An analysis of the contemporary paradigms. International Journal of Science and Technology Education Research, 1(2), 19-29.

NEGROPONTE, N. (1995). Being Digital. New York, Alfred A. Kopf. In: Inc.

NOLASCO-VÁZQUEZ, P. y Ojeda-Ramírez, M. (2016). La evaluación de la integración de las TIC en la educación superior: fundamento para una metodología. RED. Revista de Educación a Distancia. 48(9). Consultado el (dd/mm/aaaa) en http://www.um.es/ead/red/48/nolasco.pdf. https://doi.org/10.6018/red/47/3

OREALC/UNESCO Santiago (2011). Educación de calidad en la era digital. Una oportunidad de cooperación para UNESCO en América Latina y el Caribe”. Chile: UNESCO, Oficina de Santiago. https://doi.org/10.15220/978-92-9189-198-6-sp

OSZLAK, O., \& O'donnell, G. (1995). Estado y políticas estatales en América Latina: hacia una estrategia de investigación. Redes, 2(4).

PALAMIDESSI, M. I., Galarza, D., Landau, M., y Schneider, D. (2006). La escuela en la sociedad de redes: Una introducción a las tecnologías de la informática y la comunicación en la educación. Buenos Aires: Fondo de Cultura Económica. https://doi.org/10.4272/84-9745-045-0.ch11 
PAPERT, S. (1993). The children's machine: Rethinking school in the age of the computer. New York: BasicBooks.

PITTALUGA, L., y Rivoir, A. (2012). Proyectos 1 a 1 y Reducción de la Brecha Digital: El Caso del Plan CEIBAL en Uruguay (Español). Information Technologies \& International Development, (8) 4, 161.

REMONDINO, G. (2012). Blog y redes sociales: un análisis de las tecnologías de la sociedad y el género. Athenea Digital. Revista de pensamiento e investigación social. https://doi.org/10.5565/rev/athenea.15

RESINO, D. A. (2013). Valverde Berrocoso, J.(Coord.)(2011). Docentes ecompetentesbuenas prácticas educativas con TIC. Barcelona: Octaedro. Educación XXI: Revista de la Facultad de Educación, 16(2), 373-374.

RIVOIR, A., \& Lamschtein, S. (2014). Brecha digital e inclusión social, contribuciones y dilemas de las políticas 1 a 1 . El caso de Ceibal en Uruguay. RAZÓN Y PALABRA Primera Revista Electrónica en Iberoamérica Especializada en Comunicación.

RUBIN, A. M. (1998). Media literacy. Journal of Communication, 48(1), 3-4. https://doi:10.1111/j.1460-2466.1998.tb02732.x

SALINAS, J. (2004). Innovación docente y uso de las TIC en la enseñanza universitaria. RUSC. Universities and Knowledge Society Journal, 1(1).

SALINAS, J. (2012). La investigación ante los desafíos de los escenarios de aprendizaje futuros. RED. Revista de Educación a Distancia(32), 1-23. https://doi.org/10.6018/red/50/13

SAMAJA, J. (1999). Epistemología y metodología: elementos para una teoría de la investigación científica (No. 165/168). https://doi.org/10.18294/pm.2007.517

SÁNCHEZ, M. R. F., Berrocoso, J. V., \& Domínguez, F. I. R. (2012). Una revisión sobre la perspectiva social del e-learning: TIC, inclusión digital y cambio social. RedEs(1), 4863.

SANCHO, J. M., y Correa, J. M. (2010). Cambio y continuidad en sistemas educativos en transformación (PDF 2.1 MB). Revista de Educación, 352, 17-21.

SEGURA, J. A., \& Quintero, L. C. (2010). Los Entornos Personales de Aprendizaje (PLEs): una nueva manera de entender el aprendizaje. Roig Vila \& Fiorucci M.

SEVERIN, E. (2010). Tecnologías de la Información y la Comunicación (TICs) en Educación: Marco conceptual e indicadores.

SEVERÍN, E., y Capota, C. (2011). La computación uno a uno: nuevas perspectivas. Revista Iberoamericana de educación, 56, 31-48.

SOMERVILLE, M. M., Lampert, L. D., Dabbour, K. S., Harlan, S., \& Schader, B. (2007). Toward large scale assessment of information and communication technology literacy: Implementation considerations for the ETS ICT literacy instrument. Reference Services Review, 35(1), 8-20. https://doi.org/10.1108/00907320710729337

SUNKEL, G. (2006). Las tecnologías de la información y la comunicación (TIC) en la educación en América Latina. Una exploración de indicadores. Santiago de Chile: Publicación de las Naciones Unidas. https://doi.org/10.18356/6d70f0e2-es

SUNKEL, G, Trucco, D. y Esejo, A. (2013) La integración de las tecnologías digitales en las escuelas de América Latina y el Caribe, Una mirada multidimensional. Santiago de Chile: Cepal- Naciones Unidas. https://doi.org/10.18356/40600545-es

TEDESCO, J. C. (2000). Educar en la sociedad del conocimiento (pp. 87-113). Buenos Aires: Fondo de cultura económica.

TEDESCO, J. C. (2013). Tecnologías de la Información y desigualdad educativa en América Latina. 
TILVE, M.D.; Gewerc, A. y Álvarez, Q. (2009). Proyectos de innovación curricular mediados por TIC: Un estudio de caso. Revista Latinoamericana de Tecnología Educativa - RELATEC, (8) 1, 65-81.

TOURIÑÁN LÓPEZ, J. M. (2001). Tecnología digital y sistema educativo: el reto de la globalización. Revista de Educación. Madrid(úmero extraordinario), 217-230.

VACAS, F. (2010). El poder de la movilidad: de medios de masas a medios personales.

VALIENTE GONZÁLEZ, O. (2011). Los modelos 1: 1 en Educación. Prácticas internacionales, evidencia comparada e implicaciones políticas. Revista Iberoamericana de educación, 56, 113-134.

VALVERDE B, J. E. (2012). Políticas educativas en tecnología educativa: el papel de la investigación y la autonomía del centro en la toma de decisiones Campus Virtuales, Vol 1, 43-55. https://doi.org/10.25009/cpue.v0i9.76

VAN DIJCK, J. (2009). Users like you? Theorizing agency in user-generated content. Media, culture \& society, 31(1), 41-58. https://doi.org/10.1177/0163443708098245

VANDERLINDE, R., Dexter, S., \& van Braak, J. (2012). School-based ICT policy plans in primary education: Elements, typologies and underlying processes. British Journal of Educational Technology, 43(3), 505-519. https://doi.org/10.1111/j.1467$\underline{\text { 8535.2011.01191.X }}$

VEGA GARCÍA P. B. y Merchán Jaramillo A. M. (2011). La revolución educativa del modulo 1 a 1: condiciones de posibilidad. Revista Iberoamericana de Educación, 56, 95-111.

WARSCHAUER, M., y Ames, M. (2010). Can One Laptop per Child save the world's poor?. Journal of International Affairs, (64) 1, 33.

YNOUB , R (2007) El proyecto y la Metodologia de Investigacion Cengage Learning Buenos Aires 1ed

ZIDÁN, E. R. (2010). El Plan Ceibal en la educación pública uruguaya: estudio de la relación entre tecnología, equidad social y cambio educativo desde la perspectiva de los educadores en. Actualidades investigativas en educación, 10(2), 1-25. https://doi.org/10.15517/aie.v10i2.10115 


\section{ANEXO \\ DOCUMENTO GENERAL PARA LA VALIDACIÓN DEL INSTRUMENTO}

El presente documento adjuntado, posee la siguiente estructura:

I.) Contextualización del Instrumento de Investigación; II.) Los criterios de validación; III.) Grilla - Plantilla de validación para llenar por el profesor experto; IV) Datos del profesor experto

\section{I.)Contextualización del Instrumento de Investigación}

Descripción

El presente trabajo se enmarca en la línea de estudio que intenta abordar la incidencia, los efectos y avances de los programas de inclusión digital en establecimientos educativos. Dichas investigaciones se instalan en la necesidad de conocer como las comunidades educativas van incorporado y apropiándose de las nuevas configuraciones pedagógicas que supone el trabajo con las TIC.

Como propósito general, nuestro proyecto tiene como horizonte identificar los rasgos característicos que adquieren los procesos de inclusión de TIC en las practicas escolares en la localidad de Rio Gallegos, en la Patagonia Austral Argentina; Como primeros interrogantes, para indagar nuestro campo de estudio, nos planteamos algunas cuestiones tales como: ¿en qué media y cuál es el alcance de la integración de las TIC en las escuelas secundaria de la provincia de Santa Cruz?; ¿Cómo se utilizan las TIC en las aulas de secundario?; ¿Qué procesos se dinamizan en la escuela a partir de la inclusión de TIC en el aula?; ¿Qué expectativas se generan en los diferentes actores y agentes educativos?; ¿Qué condiciones son necesarias adoptar para lograr una buena integración de las TIC en la enseñanza?; ¿Qué percepciones tiene los docentes de secundaria respecto a su formación y el dominio que poseen de las TIC para la enseñanza?; ¿Qué actitudes favorecen la inclusión de TIC en la escuela?; ¿En qué medida se encuentran preparados los docentes y directivos para incluir las TIC?.

\section{II.)Los criterios de Validación}

Para facilitar el proceso de validación por expertos, se diseño la siguiente grilla identificando algunos criterios para el análisis, para cada una de las variables y dimensiones que conforma el instrumento de encuesta.

\begin{tabular}{|c|l|l|}
\hline Aspecto validar & Criterio & \multirow{2}{*}{ Escalera } \\
\hline \multirow{2}{*}{$\begin{array}{c}\text { Los indicadores de cada } \\
\text { resultado de aprendizaje }\end{array}$} & Comprensión & \multirow{2}{*}{ Escala del 1 al 4 } \\
\cline { 2 - 2 } & Pertinencia & \\
\cline { 2 - 2 } & Importancia & \\
\hline
\end{tabular}

Comprensión: ¿Se entiende el ítem? ¿Está bien expresado y/o redactado y no conlleva ambigüedad?

Pertinencia: ¿Se adecua el ítem a los objetivos de la investigación? ¿Es pertinente?

Importancia: Valore entre 1 y 4 el grado de importancia que a su parecer tiene el ítem respecto a los objetivos de la investigación. 
Comentarios: Indique libremente los comentarios adicionales que considere oportuno sobre el ítem en cuestión.

\section{III.) GRILLA PLANILLA DE VALIDACION}

\begin{tabular}{|c|c|c|c|c|}
\hline & Variable & Tipo & pregunta & Ítem del cuestionario \\
\hline 1 & Sexo & Dicotómica & Cerrada & Varón mujer \\
\hline 2 & $\begin{array}{l}\text { Años de } \\
\text { experiencia } \\
\text { docente }\end{array}$ & Cuantitativa & Cerrada & Cantidad de años de experiencia \\
\hline 3 & Edad & Cuantitativa & Cerrada & 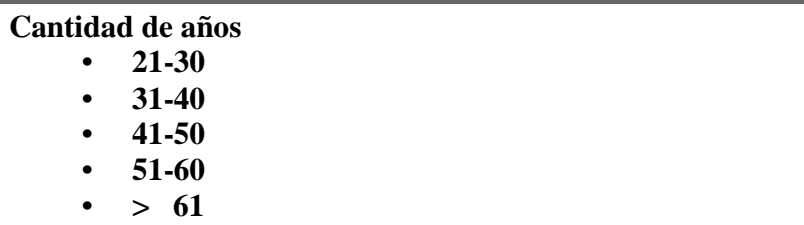 \\
\hline 4 & $\begin{array}{c}\text { Formación / } \\
\text { titulo }\end{array}$ & Politómica & Cerrada & $\begin{array}{l}\text { - Título de Profesor de enseñanza media } \\
\text { - Título de Profesor de materias especiales } \\
\text { - Titulo docente universitario } \\
\text { - Título profesional universitario (no docente) Otro } \\
\text { título no docente }\end{array}$ \\
\hline 5 & $\begin{array}{l}\text { Cantidad de } \\
\text { horas que } \\
\text { trabaja como } \\
\text { profesor }\end{array}$ & Politómica & Cerrada & 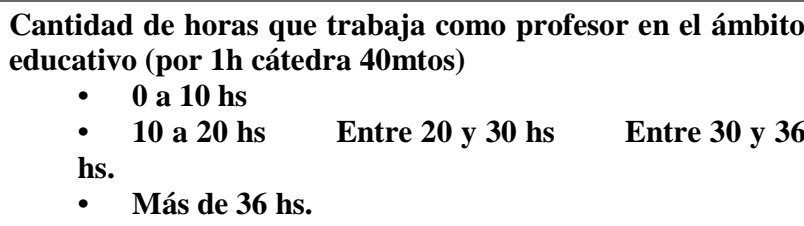 \\
\hline 6 & $\begin{array}{l}\text { Materias que } \\
\text { imparte }\end{array}$ & Cualitativa & $\begin{array}{l}\text { Texto para } \\
\text { completar }\end{array}$ & \\
\hline
\end{tabular}

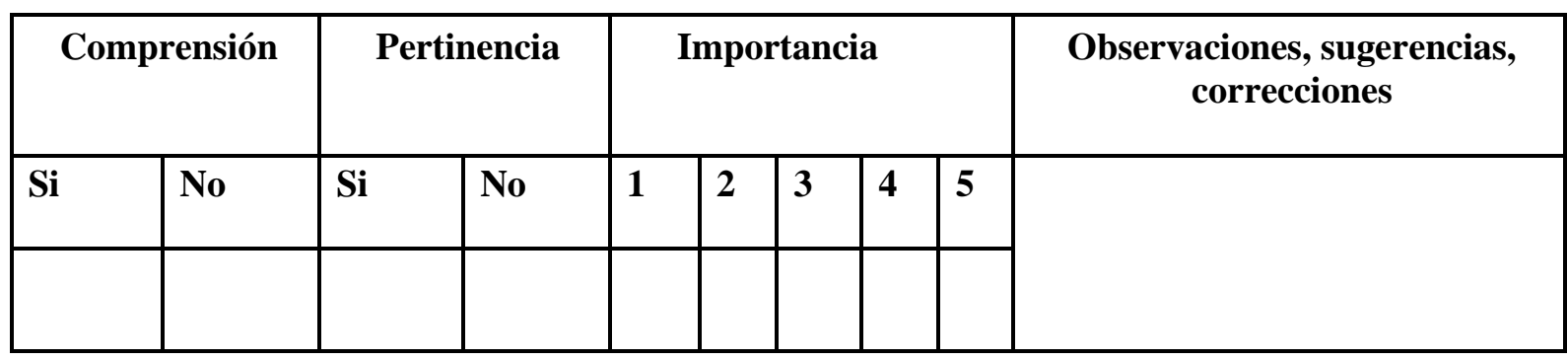




\begin{tabular}{|c|c|c|c|c|}
\hline & Variable & Tipo & pregunta & Ítem del cuestionario \\
\hline 1 & $\begin{array}{l}\text { Valoración sobre la } \\
\text { inclusión de las TIC en } \\
\text { la escuela }\end{array}$ & Politómica & Escala Likert & $\begin{array}{l}\text { Pregunta sobre cuán beneficioso cree que es la } \\
\text { inclusión de las TIC en la escuela } \\
\text { (mucho, bastante, ligeramente, } \\
\text { poco) }\end{array}$ \\
\hline 2 & $\begin{array}{l}\text { Aporte que supone la } \\
\text { introducción de las TIC } \\
\text { en el centro educativo }\end{array}$ & Politómica & $\begin{array}{lr}\text { Escala } & \text { Likert } \\
\text { con } & \text { varios } \\
\text { ítems } & \text { a } \\
\text { valorar. } & \end{array}$ & $\begin{array}{l}\text { Se le pregunta sobre su valoración (de } 0 \text { a } 5 \text { ) } \\
\text { respecto a las siguientes afirmación: } \\
\text { - Las TIC modernizan la escuela } \\
\text { - Las TIC mejoran el proceso de } \\
\text { enseñanza aprendizaje Las TIC facilitan } \\
\text { la tarea institucional }\end{array}$ \\
\hline 3 & $\begin{array}{l}\text { Grado de satisfacción } \\
\text { dela inclusión de las } \\
\text { TIC en el aula }\end{array}$ & Politómica & Escala Likert & $\begin{array}{l}\text { Indique el grado de satisfacción que cree usted } \\
\text { que poseen los alumnos respecto a las TIC }\end{array}$ \\
\hline
\end{tabular}

Total 3 items:

1. Valoración sobre la inclusión de las TIC en la escuela

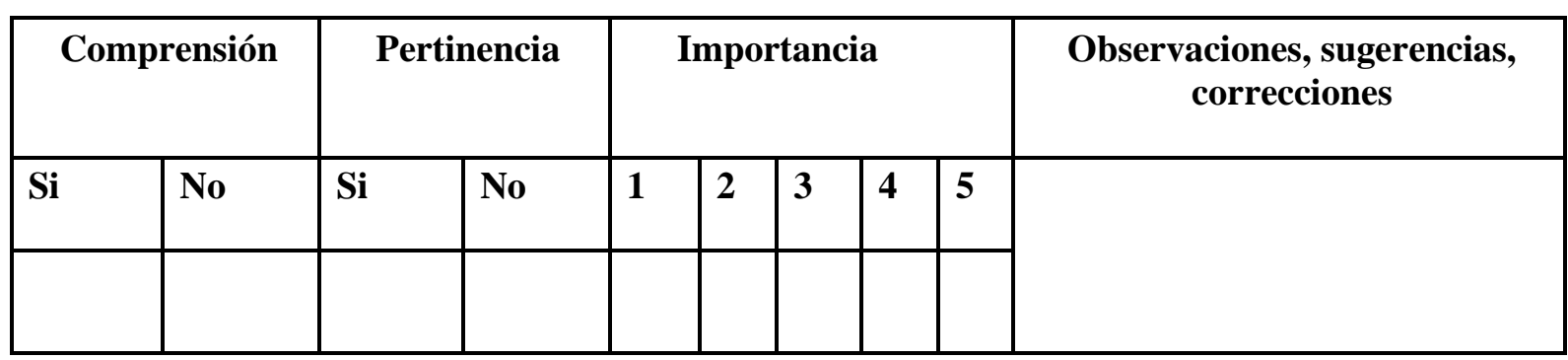

2. Aporte que supone la introducción de las TIC en el centro educativo

\begin{tabular}{|l|l|l|l|l|l|l|l|l|l|l|}
\hline \multicolumn{2}{|c|}{ Comprensión } & \multicolumn{3}{|c|}{ Pertinencia } & \multicolumn{3}{c|}{ Importancia } & \multicolumn{2}{c|}{$\begin{array}{c}\text { Observaciones, sugerencias, } \\
\text { correcciones }\end{array}$} \\
\cline { 1 - 3 } & No & Si & No & 1 & 2 & 3 & 4 & 5 & \\
& & & & & & & & & \\
\end{tabular}

3. Grado de satisfacción dela inclusión de las TIC en el aula

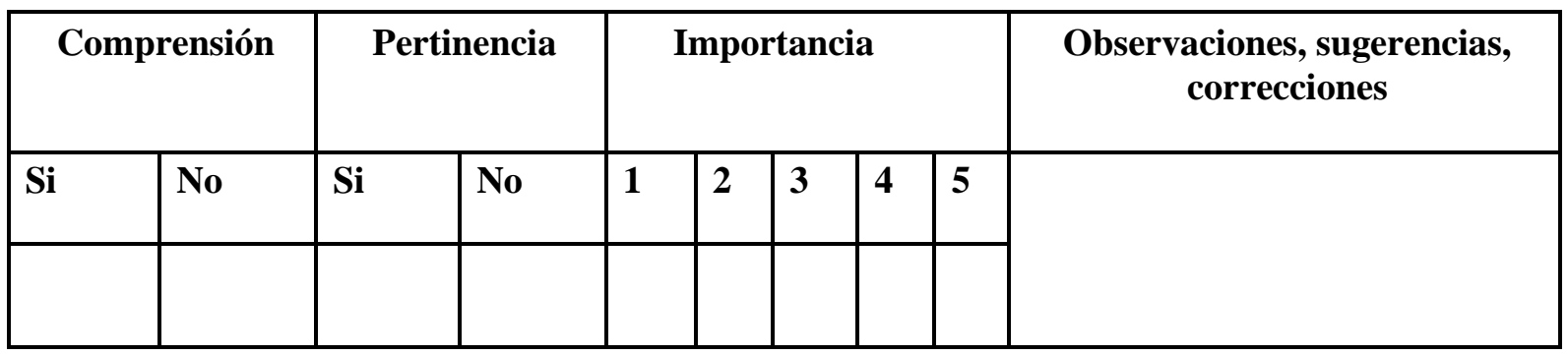




\begin{tabular}{|c|c|c|c|c|}
\hline & Variable & tipo & pregunta & Observable - items del cuestionario \\
\hline 1 & $\begin{array}{l}\text { Curso } \\
\text { recibidos de } \\
\text { capacitación } \\
\text { en TIC }\end{array}$ & Dicotomica & Cerrada & $\begin{array}{l}\text { Se le pregunta si realizo cursos de capacitacion sobre } \\
\text { TIC } \\
\qquad \text { Si o No }\end{array}$ \\
\hline 2 & $\begin{array}{l}\text { Cantidad de } \\
\text { cursos } \\
\text { recibidos }\end{array}$ & Cuantitativa & Cerrada & $\begin{array}{l}\text { Sobre la cantidad de cursos realizados en los últimos } \\
\text { años }\end{array}$ \\
\hline 3 & $\begin{array}{l}\text { Modalidad de } \\
\text { Capacitación }\end{array}$ & Politomica & Cerrada & $\begin{array}{ll}\text { Sobre la modalidad de la capacitación recibida: } \\
\begin{aligned} & \text { Presencial, } \\
& \text { virtual, } \\
\text { - } & \text { Mixta } \\
\text { - } & \text { Capacitacion situada en el colegio }\end{aligned}\end{array}$ \\
\hline 4 & $\begin{array}{l}\text { Temática de } \\
\text { capacitación }\end{array}$ & Politomica & Cerrada & $\begin{array}{l}\text { Sobre temáticas posibles: } \\
\text { - Ofimática (planilla de cálculo, procesador de textos) } \\
\text { - Alfabetización digital (manejo básico de la } \\
\text { computadora) } \\
\text { - Disciplinar (integración de las TIC en mi especialidad) } \\
\text { - Manejo de recursos multimediales (videos, fotos, } \\
\text { edición) } \\
\text { - Sobre uso de software educativos (simuladores, } \\
\text { estimulación, ciencia, etc.) } \\
\text { - Sobre uso responsables de las TIC/seguridad y TIC } \\
\text { Otros (...) }\end{array}$ \\
\hline 5 & $\begin{array}{l}\text { Valoración de } \\
\text { utilidad de la } \\
\text { capacitación } \\
\text { para la clase }\end{array}$ & Politómica & $\begin{array}{l}\text { Escala } \\
\text { Likert }\end{array}$ & 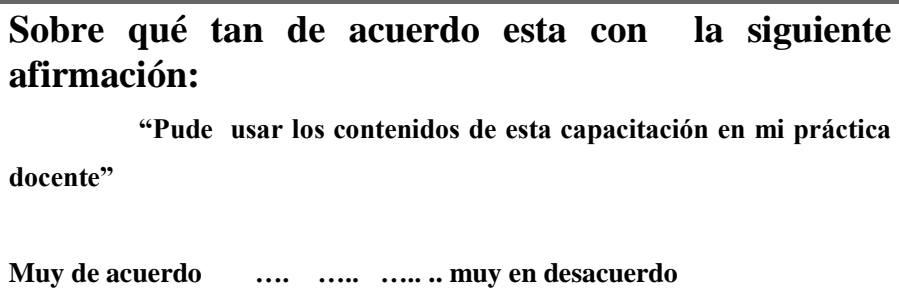 \\
\hline
\end{tabular}




\begin{tabular}{|c|c|c|c|c|}
\hline 6 & \begin{tabular}{l}
\multicolumn{2}{l}{ Habilidades en } \\
TIC del \\
docente
\end{tabular} & Politómica & $\begin{array}{l}\text { Escala } \\
\text { Likert } \\
\text { con } \\
\text { varios } \\
\text { ítems a } \\
\text { valorar. }\end{array}$ & 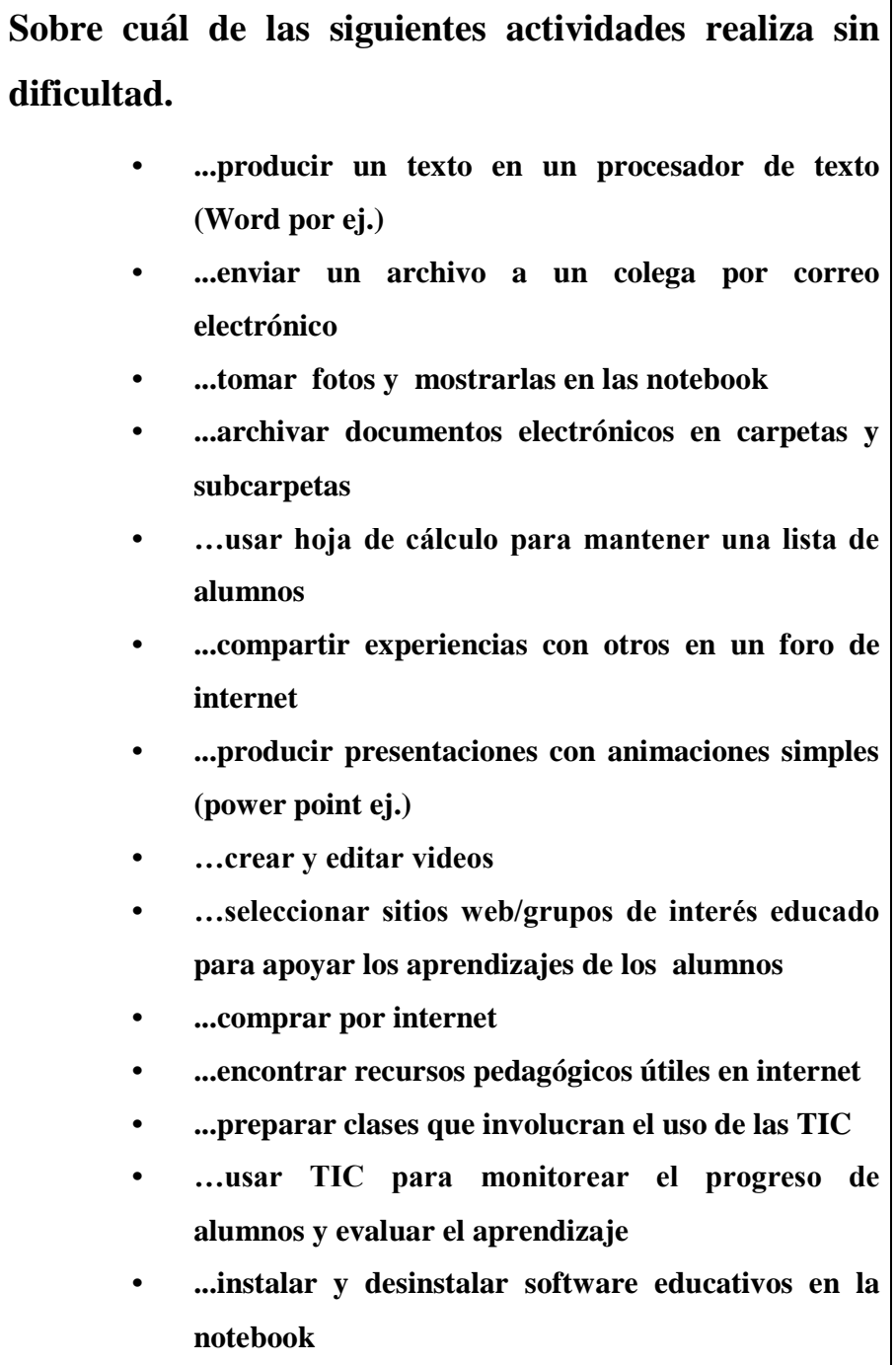 \\
\hline 7 & $\begin{array}{l}\text { Modalidad de } \\
\text { apropiación de } \\
\text { habilidades } \\
\text { TIC }\end{array}$ & Politómica & Cerrada & $\begin{array}{l}\text { Sobre como aprendió a hacer las habilidades TIC que } \\
\text { posee. } \\
\text { • } \quad \text { Explorando solo } \\
\text { - } \quad \text { Gracias a una capacitación......... } \\
\text { - } \quad \text { con la ayuda de un colega ... } \\
\text { - Con el referente TIC de la escuela RTE....... Con la } \\
\text { ayuda de un familiar, }\end{array}$ \\
\hline 8 & $\begin{array}{l}\text { Valoración de } \\
\text { la } \\
\text { Formación en } \\
\text { TIC }\end{array}$ & Politómica & cerrada & 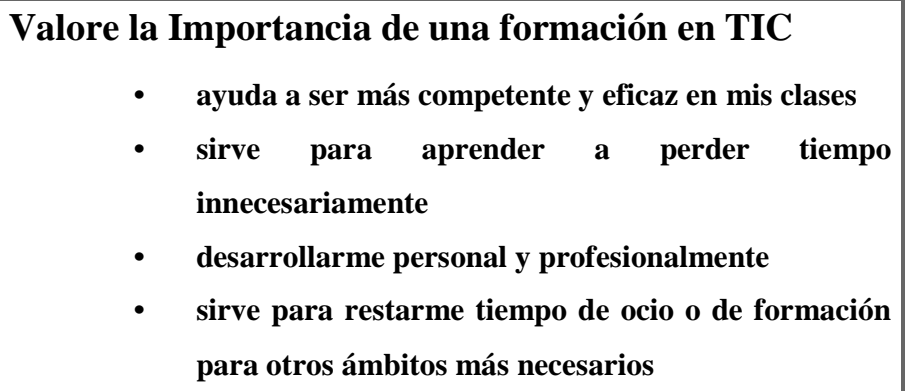 \\
\hline
\end{tabular}


Grilla de Validacion

1. Curso recibidos de capacitación en TIC

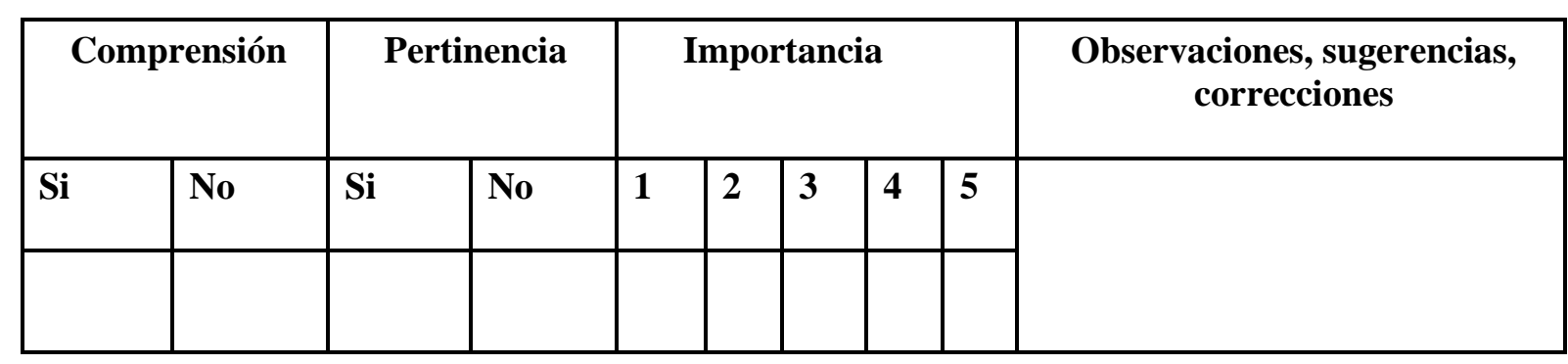

2. Cantidad de cursos recibidos

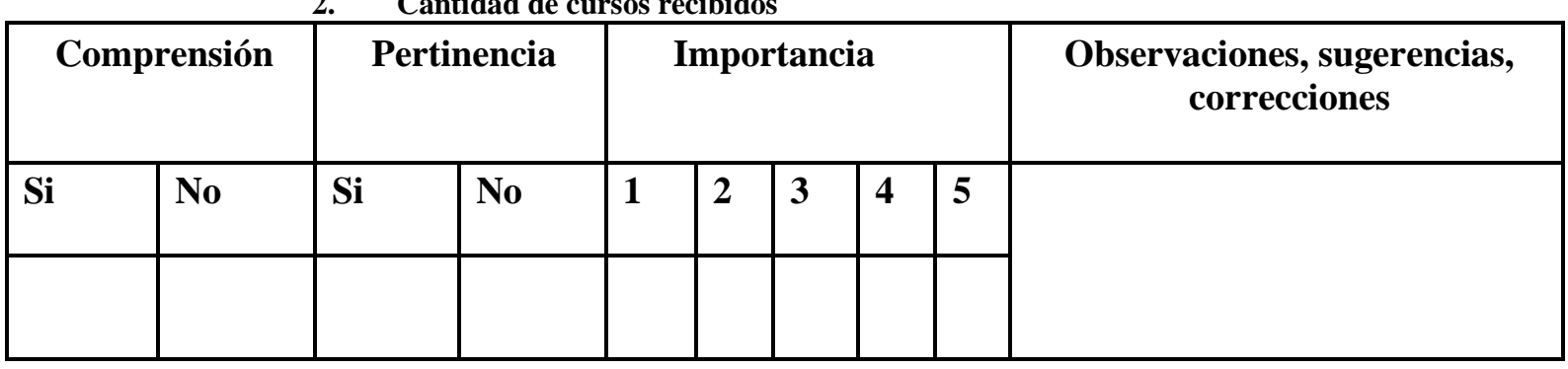

3. Modalidad de Capacitación

\begin{tabular}{|c|c|c|c|c|c|c|c|c|c|}
\hline \multicolumn{2}{|c|}{ Comprensión } & \multicolumn{2}{|c|}{ Pertinencia } & \multicolumn{5}{|c|}{ Importancia } & \multirow{2}{*}{$\begin{array}{c}\text { Observaciones, sugerencias, } \\
\text { correcciones }\end{array}$} \\
\hline $\mathbf{S i}$ & No & $\mathbf{S i}$ & No & 1 & 2 & 3 & 4 & 5 & \\
\hline & & & & & & & & & \\
\hline & & & & & & & & & \\
\hline
\end{tabular}

4. Temática de capacitación

\begin{tabular}{|l|l|l|l|l|l|l|l|l|l|}
\hline \multicolumn{2}{|c|}{ Comprensión } & \multicolumn{3}{|c|}{ Pertinencia } & \multicolumn{3}{c|}{ Importancia } & \multicolumn{3}{c|}{$\begin{array}{c}\text { Observaciones, sugerencias, } \\
\text { correcciones }\end{array}$} \\
\hline Si & No & Si & No & 1 & 2 & 3 & 4 & 5 & \\
& & & & & & & & & \\
\end{tabular}

5. Valoración de utilidad de la capacitación para la clase

\begin{tabular}{|c|c|c|c|c|c|c|c|c|c|}
\hline \multicolumn{2}{|c|}{ Comprensión } & \multicolumn{2}{|c|}{ Pertinencia } & \multicolumn{5}{|c|}{ Importancia } & \multirow{2}{*}{$\begin{array}{c}\text { Observaciones, sugerencias, } \\
\text { correcciones }\end{array}$} \\
\hline $\mathbf{S i}$ & No & $\mathbf{S i}$ & No & 1 & 2 & 3 & 4 & 5 & \\
\hline & & & & & & & & & \\
\hline & & & & & & & & & \\
\hline
\end{tabular}


6. Habilidades en TIC del docente

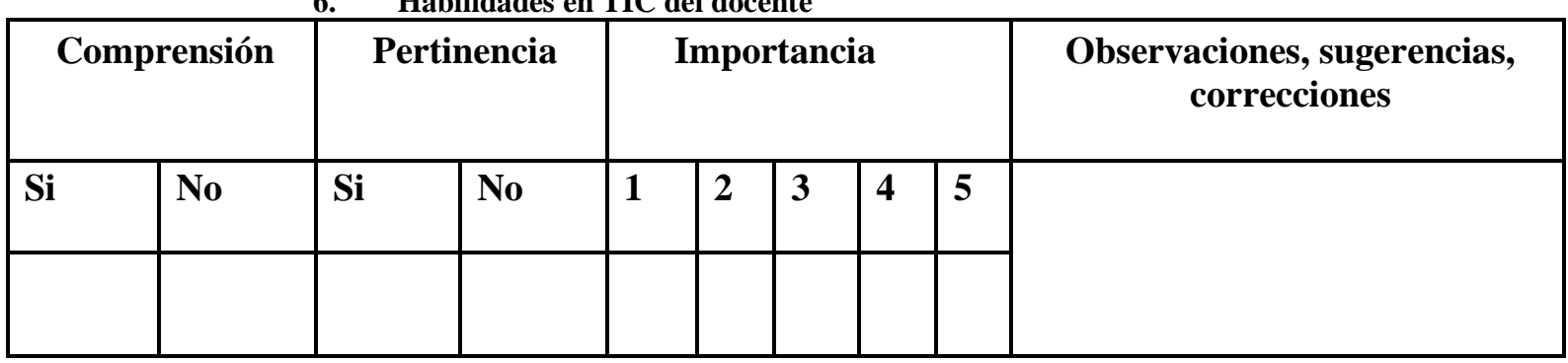

7. Modalidad de apropiación de habilidades TIC

\begin{tabular}{|c|c|c|c|c|c|c|c|c|c|}
\hline \multicolumn{2}{|c|}{ Comprensión } & \multicolumn{2}{|c|}{ Pertinencia } & \multicolumn{5}{|c|}{ Importancia } & \multirow{2}{*}{$\begin{array}{c}\text { Observaciones, sugerencias, } \\
\text { correcciones }\end{array}$} \\
\hline $\mathbf{S i}$ & No & $\mathbf{S i}$ & No & 1 & 2 & 3 & 4 & 5 & \\
\hline & & & & & & & & & \\
\hline & & & & & & & & & \\
\hline
\end{tabular}

8. Valoración de la Formación en TIC

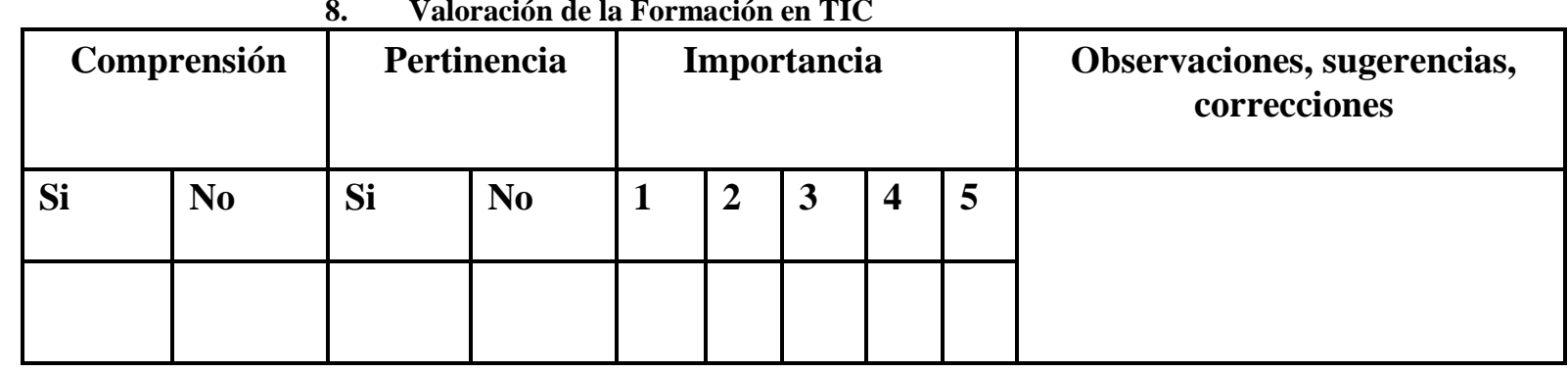

\begin{tabular}{|c|c|c|c|c|}
\hline & Variable & Tipo & pregunta & Ítem del cuestionario \\
\hline 1 & $\begin{array}{l}\text { Valoración } \\
\text { que supone la } \\
\text { inclusión de } \\
\text { las TIC en la } \\
\text { clase }\end{array}$ & Politómica & $\begin{array}{l}\text { Escala } \\
\text { Likert con } \\
\text { varios } \\
\text { ítems a } \\
\text { valorar. }\end{array}$ & $\begin{array}{l}\text { Se le pregunta que valore que tan de acuerdo esta con } \\
\text { las siguientes frases (de } 0 \text { a 5) } \\
\text { - } \quad \text { Las TIC Reemplazan parcialmente el trabajo de los } \\
\text { docentes en el aula } \\
\text { - las TIC Amplían las oportunidades de acceso al } \\
\text { conocimiento por parte de los estudiantes } \\
\text { - las TIC Alientan el facilismo de los estudiantes } \\
\text { las TIC Son recursos que facilitan la tarea de los } \\
\text { docentes en el aula } \\
\text { las TIC Incrementan la motivación de los } \\
\text { estudiantes por actividades Escolares } \\
\text { las TIC Contribuyen a deshumanizar la enseñanza } \\
\text { y las instituciones pedagónicas }\end{array}$ \\
\hline
\end{tabular}




\begin{tabular}{|c|c|c|c|c|}
\hline 2 & $\begin{array}{l}\text { Actitudes y } \\
\text { percepción de } \\
\text { dificultades } \\
\text { para la } \\
\text { inclusión } \\
\text { TIC }\end{array}$ & Politómica & $\begin{array}{l}\text { Escala } \\
\text { Likert con } \\
\text { varios } \\
\text { ítems a } \\
\text { valorar. }\end{array}$ & $\begin{array}{l}\text { Se le pregunta que tan de acuerdo esta con las } \\
\text { siguientes afirmación sobre problemas y obstáculos } \\
\text { - } \quad \text {...no creo que sea fundamental para la enseñanza de } \\
\text { mi materia } \\
\text { - ...no considero que sea apropiado para la } \\
\text { - disciplina/área curricular que enseño } \\
\text { - ...no sé cómo usarla } \\
\text {...los alumnos aprenden igual sin el uso de estas } \\
\text { herramientas } \\
\text {...los directivos de esta escuela no están interesados } \\
\text { en que se utilicen estos recursos } \\
\text {...no se me ocurre una idea para integrar este } \\
\text { recurso al aprendizaje de las temáticas del } \\
\text { curriculum } \\
\text {...no todos los alumnos tienen notebook o hay } \\
\text { muchas que están bloqueadas o rotas } \\
\text {...el servidos/el piso tecnológico/internet no funciona } \\
\text { o no funciona correctamente } \\
\text {....genera distracción en e....................................... }\end{array}$ \\
\hline
\end{tabular}

Grilla de Validación

1. Valoración que supone la inclusión de las TIC en la clase

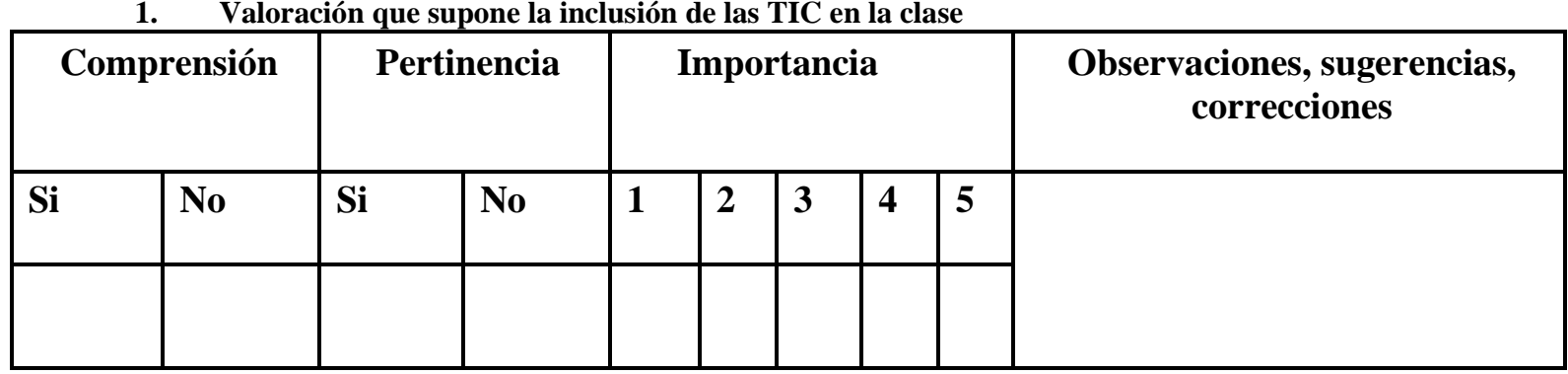

2. Actitudes y percepción de dificultades para la inclusión TIC

\begin{tabular}{|l|l|l|l|l|l|l|l|l|l|}
\hline \multicolumn{2}{|c|}{ Comprensión } & \multicolumn{3}{|c|}{ Pertinencia } & \multicolumn{3}{c|}{ Importancia } & \multicolumn{3}{c|}{$\begin{array}{c}\text { Observaciones, sugerencias, } \\
\text { correcciones }\end{array}$} \\
\cline { 1 - 3 } & No & Si & No & 1 & 2 & 3 & 4 & 5 & \\
& & & & & & & & & \\
\hline
\end{tabular}




\begin{tabular}{|c|c|c|c|c|}
\hline & Variable & Tipo & pregunta & Ítem del cuestionario \\
\hline 1 & $\begin{array}{l}\text { Uso de las TIC en } \\
\text { la planificación }\end{array}$ & Dicotómica & Cerrada & $\begin{array}{l}\text { Se le pregunta si Incluyo el uso de las TIC en su } \\
\text { planificación anual este año } \\
\qquad \text { SI........NO......... }\end{array}$ \\
\hline 2 & $\begin{array}{c}\text { Uso de las TIC en } \\
\text { proyectos } \\
\text { pedagógicos }\end{array}$ & Dicotómica & Cerrada & $\begin{array}{l}\text { Se le pregunta si en el último año ha } \\
\text { desarrollado algún proyecto específico con sus } \\
\text { alumnos para utilizar las TIC. } \\
\text { SI.........NO....... }\end{array}$ \\
\hline 3 & $\begin{array}{c}\text { Usos de recursos } \\
\text { digitales }\end{array}$ & Dicotómica & Cerrada & $\begin{array}{l}\text { Durante el último año ha utilizado la netbook } \\
\text { para preparar materiales y actividades para } \\
\text { usar en clases? } \\
\qquad \text { Si...... No....... }\end{array}$ \\
\hline 4 & $\begin{array}{l}\text { Tipo de recursos } \\
\text { digitales usados }\end{array}$ & Politómica & Cerrada & $\begin{array}{l}\text { Sobre cuáles son los tipos de recursos digital } \\
\text { que se usa con mayor frecuencia) } \\
\text { - Secuencia didáctICas/ recorridos/actividades } \\
\text { - Videos/micros videos } \\
\text { - Banco e imágenes } \\
\text { - Bibliografía digital } \quad \text { Programas de } \\
\text { software } \\
\text { - No uso material digital }\end{array}$ \\
\hline 5 & $\begin{array}{l}\text { Acompañamiento } \\
\text { para el uso de las } \\
\text { TIC }\end{array}$ & Politómica & Cerrada & $\begin{array}{l}\text { Se le pregunta si existe alguien en la escuela } \\
\text { que lo acompañe con la integración de las } \\
\text { TIC (Si.......no.....) En caso afirmativo se } \\
\text { pregunta sobre quien lo acompaña } \\
\text { - Directivo......... } \\
\text { - Jefe de departamento.................... } \\
\text { - } \quad \text { Referente técnico escolar/informático............ } \\
\text { - Colega........ } \\
\text { - Miembro del equipo técnico de Dirección } \\
\text { Provincial... } \\
\text { Otros.................. }\end{array}$ \\
\hline 6 & $\begin{array}{l}\text { Uso de las TIC } \\
\text { para la } \\
\text { comunicación }\end{array}$ & Politómica & Cerrada & 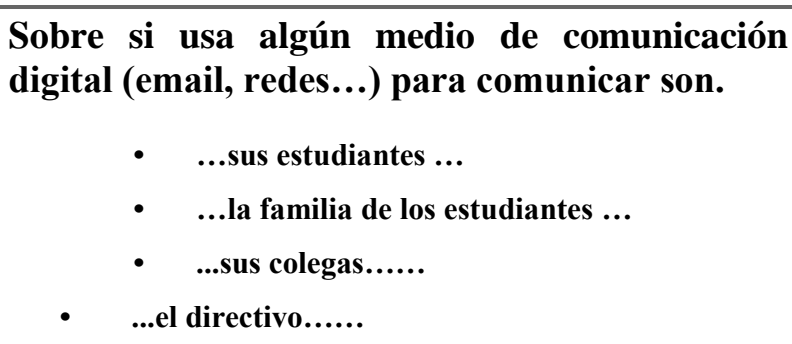 \\
\hline
\end{tabular}




\begin{tabular}{|c|c|c|c|c|}
\hline 7 & $\begin{array}{l}\text { Uso de las ti para } \\
\text { búsqueda de } \\
\text { información }\end{array}$ & Dicotómica & Cerrada & $\begin{array}{l}\text { Realiza busquedas de informacion en internet } \\
\text { para su actividad laboral Si ... no... }\end{array}$ \\
\hline 8 & $\begin{array}{c}\text { Tipos de usos en } \\
\text { relaciona a la } \\
\text { búsqueda de } \\
\text { información en la } \\
\text { red }\end{array}$ & Politómica & Cerrada & $\begin{array}{l}\text { Cual suele ser el proposito de su busqueda de } \\
\text { informacion en internet } \\
\text { - } \quad \text { Resolver una duda o problema } \\
\text { - } \quad \text { Preparar un contnido o recurso } \\
\text { - } \quad \text { Seguir aprendiendo. Actualizarse Otros }\end{array}$ \\
\hline 9 & $\begin{array}{l}\text { Valoración sobre la } \\
\text { búsqueda de } \\
\text { información en la } \\
\quad \text { red }\end{array}$ & Dicotómica & Cerrada & $\begin{array}{l}\text { Considera necesario buscar informacion en } \\
\text { internet acera de las materias y contenidos que } \\
\text { imparte como docente } \\
\text { Si ... no... }\end{array}$ \\
\hline 10 & $\begin{array}{l}\text { Frecuencia de uso de } \\
\text { las TIC en la } \\
\text { relaciona la } \\
\text { búsqueda de } \\
\text { información en la } \\
\text { red }\end{array}$ & Dicotómica & Cerrada & $\begin{array}{l}\text { Sigue en forma frecuente la lectura de } \\
\text { contenidos en diferetnes protales, sitios web, } \\
\text { blogs etc... realcionadas con la materia que } \\
\text { imparte o sobre educacion? } \\
\text { Si ... no... }\end{array}$ \\
\hline 11 & $\begin{array}{l}\text { Frecuencia de uso } \\
\text { de las TIC en la } \\
\text { relaciona la } \\
\text { búsqueda de } \\
\text { información en la } \\
\text { red }\end{array}$ & Politómica & Cerrada & $\begin{array}{l}\text { Aproximadamente cuantos protales, sitios web, } \\
\text { blogs etc... } \\
\begin{aligned} \text { - } & \text { sigue semananlemente } \\
\text { - } & \text { Menos de } 5 \\
\text { - } & \text { Entre } 5 \text { y } 10 \\
\text { - } & \text { Más de } 10\end{aligned}\end{array}$ \\
\hline 12 & $\begin{array}{l}\text { Uso de gestores } \\
\text { de información } \\
\text { en la red }\end{array}$ & Dicotómica & Cerrada & $\begin{array}{l}\text { Usa algún lector marcador o sindicador de } \\
\text { contenidos rss (tipo google realder u otros) } \\
\text { para gestionar los contido que le interesan en } \\
\text { internet } \\
\qquad \text { Si... o no... }\end{array}$ \\
\hline 13 & Uso de redes sociales & Dicotómica & Cerrada & $\begin{array}{l}\text { Es usuario de alguna cuenta de red social } \\
\text { (twitter - facebook, otros) } \\
\text { Si... o no... }\end{array}$ \\
\hline
\end{tabular}




\begin{tabular}{|c|c|c|c|c|}
\hline 14 & $\begin{array}{l}\text { Tipos de uso de las } \\
\text { TIC en relación a } \\
\text { las redes sociales }\end{array}$ & Politómica & Cerrada & $\begin{array}{l}\text { Si su respuesta es afirmativa conteste cual seria } \\
\text { El uso principal que le doy a la red social es: } \\
\text { • } \\
\text { Compartir informacion, recursos, proyectos, } \\
\text { experiencias y comunicarme con otros } \\
\text { docentes } \\
\text { - } \quad \text { Pasar el rato, leer lo que dicen otras } \\
\text { persoans, famosos, amigos etc... } \\
\text { Contar al mundo lo que hago, donde estoy } \\
\text { etc.. cada momento de mi vida } \\
\text { Socializarme, interactuar con otros } \\
\text { Aprender y enseñar, formarme } \\
\text { personalmente y profesionalmente }\end{array}$ \\
\hline
\end{tabular}

Grilla de Valoracion

1. Uso de las TIC en la planificación

\begin{tabular}{|c|c|c|c|c|c|c|c|c|c|}
\hline \multicolumn{2}{|c|}{ Comprensión } & \multicolumn{2}{|c|}{ Pertinencia } & \multicolumn{5}{|c|}{ Importancia } & \multirow{2}{*}{$\begin{array}{l}\text { Observaciones, sugerencias, } \\
\text { correcciones }\end{array}$} \\
\hline $\mathbf{S i}$ & No & $\mathbf{S i}$ & No & 1 & 2 & 3 & 4 & 5 & \\
\hline & & & & & & & & & \\
\hline & & & & & & & & & \\
\hline
\end{tabular}

2. Uso de las TIC en proyectos pedagógicos

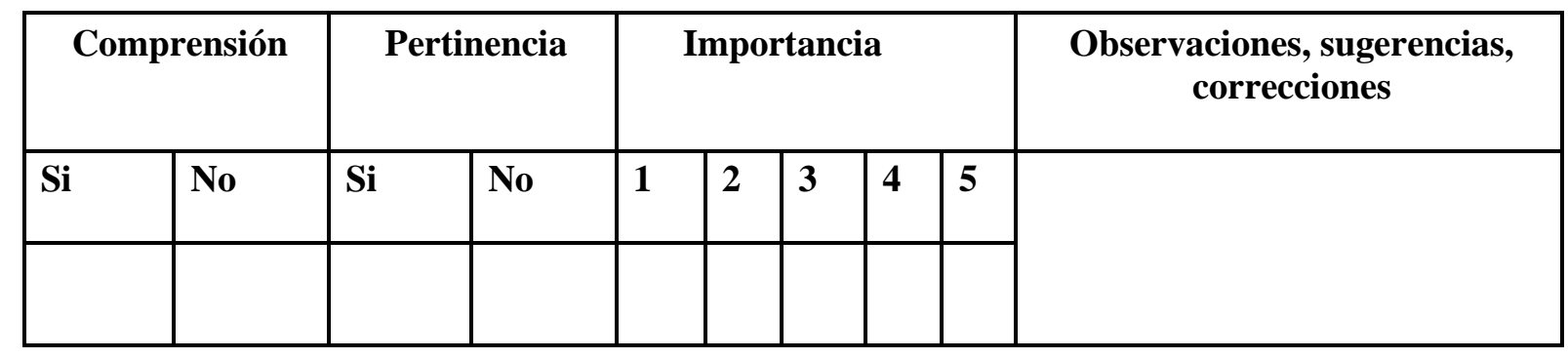

3. Usos de recursos digitales

\begin{tabular}{|l|l|l|l|l|l|l|l|l|l|}
\hline \multicolumn{2}{|c|}{ Comprensión } & \multicolumn{3}{|c|}{ Pertinencia } & \multicolumn{3}{|c|}{ Importancia } & \multicolumn{2}{c|}{$\begin{array}{c}\text { Observaciones, sugerencias, } \\
\text { correcciones }\end{array}$} \\
\cline { 1 - 5 } & No & Si & No & 1 & 2 & 3 & 4 & 5 & \\
\hline & & & & & & & & & \\
\hline
\end{tabular}


4. Tipo de recursos digitales usados

\begin{tabular}{|c|c|c|c|c|c|c|c|c|c|}
\hline \multicolumn{2}{|c|}{ Comprensión } & \multicolumn{2}{|c|}{ Pertinencia } & \multicolumn{5}{|c|}{ Importancia } & \multirow{2}{*}{$\begin{array}{c}\text { Observaciones, sugerencias, } \\
\text { correcciones }\end{array}$} \\
\hline Si & No & $\mathbf{S i}$ & No & 1 & 2 & 3 & 4 & 5 & \\
\hline & & & & & & & & & \\
\hline & & & & & & & & & \\
\hline
\end{tabular}

5. Acompañamiento para el uso de las TIC

\begin{tabular}{|l|l|l|l|l|l|l|l|l|l|}
\hline \multicolumn{2}{|c|}{ Comprensión } & \multicolumn{3}{|c|}{ Pertinencia } & \multicolumn{3}{|c|}{ Importancia } & \multicolumn{3}{c|}{$\begin{array}{c}\text { Observaciones, sugerencias, } \\
\text { correcciones }\end{array}$} \\
\cline { 1 - 3 } & No & Si & No & 1 & 2 & 3 & 4 & 5 & \\
& & & & & & & & & \\
\hline
\end{tabular}

6. Uso de las TIC para la comunicación

\begin{tabular}{|l|l|l|l|l|l|l|l|l|l|}
\hline \multicolumn{2}{|c|}{ Comprensión } & \multicolumn{3}{|c|}{ Pertinencia } & \multicolumn{3}{c|}{ Importancia } & \multicolumn{3}{c|}{$\begin{array}{c}\text { Observaciones, sugerencias, } \\
\text { correcciones }\end{array}$} \\
\cline { 1 - 6 } Si & No & Si & No & 1 & 2 & 3 & 4 & 5 & \\
& & & & & & & & & \\
\hline
\end{tabular}

7. Uso de las ti para búsqueda de información

\begin{tabular}{|l|l|l|l|l|l|l|l|l|l|}
\hline \multicolumn{2}{|c|}{ Comprensión } & \multicolumn{3}{|c|}{ Pertinencia } & \multicolumn{3}{c|}{ Importancia } & \multicolumn{3}{c|}{$\begin{array}{c}\text { Observaciones, sugerencias, } \\
\text { correcciones }\end{array}$} \\
\cline { 1 - 4 } Si & No & Si & No & 1 & 2 & 3 & 4 & 5 & \\
& & & & & & & & & \\
\hline
\end{tabular}

8. Tipos de usos en relaciona a la búsqueda de información en la red

\begin{tabular}{|c|c|c|c|c|c|c|c|c|c|}
\hline \multicolumn{2}{|c|}{ Comprensión } & \multicolumn{2}{|c|}{ Pertinencia } & \multicolumn{5}{|c|}{ Importancia } & \multirow{2}{*}{$\begin{array}{c}\text { Observaciones, sugerencias, } \\
\text { correcciones }\end{array}$} \\
\hline Si & No & $\mathbf{S i}$ & No & 1 & 2 & 3 & 4 & 5 & \\
\hline & & & & & & & & & \\
\hline & & & & & & & & & \\
\hline
\end{tabular}


9. Valoración sobre la búsqueda de información en la red

\begin{tabular}{|c|c|c|c|c|c|c|c|c|c|}
\hline \multicolumn{2}{|c|}{ Comprensión } & \multicolumn{2}{|c|}{ Pertinencia } & \multicolumn{5}{|c|}{ Importancia } & \multirow{2}{*}{$\begin{array}{c}\text { Observaciones, sugerencias, } \\
\text { correcciones }\end{array}$} \\
\hline Si & No & $\mathbf{S i}$ & No & 1 & 2 & 3 & 4 & 5 & \\
\hline & & & & & & & & & \\
\hline & & & & & & & & & \\
\hline
\end{tabular}

10. Frecuencia de uso de las TIC en la relaciona la búsqueda de información en la red

\begin{tabular}{|l|l|l|l|l|l|l|l|l|l|}
\hline \multicolumn{2}{|c|}{ Comprensión } & \multicolumn{3}{|c|}{ Pertinencia } & \multicolumn{3}{c|}{ Importancia } & \multicolumn{3}{c|}{$\begin{array}{c}\text { Observaciones, sugerencias, } \\
\text { correcciones }\end{array}$} \\
\hline Si & No & Si & No & 1 & 2 & 3 & 4 & 5 & \\
\hline & & & & & & & & & \\
\hline
\end{tabular}

11. Frecuencia de uso de las TIC en la relaciona la búsqueda de información en la red

\begin{tabular}{|l|l|l|l|l|l|l|l|l|l|}
\hline \multicolumn{2}{|c|}{ Comprensión } & \multicolumn{3}{|c|}{ Pertinencia } & \multicolumn{3}{c|}{ Importancia } & \multicolumn{3}{c|}{$\begin{array}{c}\text { Observaciones, sugerencias, } \\
\text { correcciones }\end{array}$} \\
\cline { 1 - 3 } & No & Si & No & 1 & 2 & 3 & 4 & 5 & \\
\hline & & & & & & & & & \\
\hline
\end{tabular}

12. Uso de gestores de información en la red

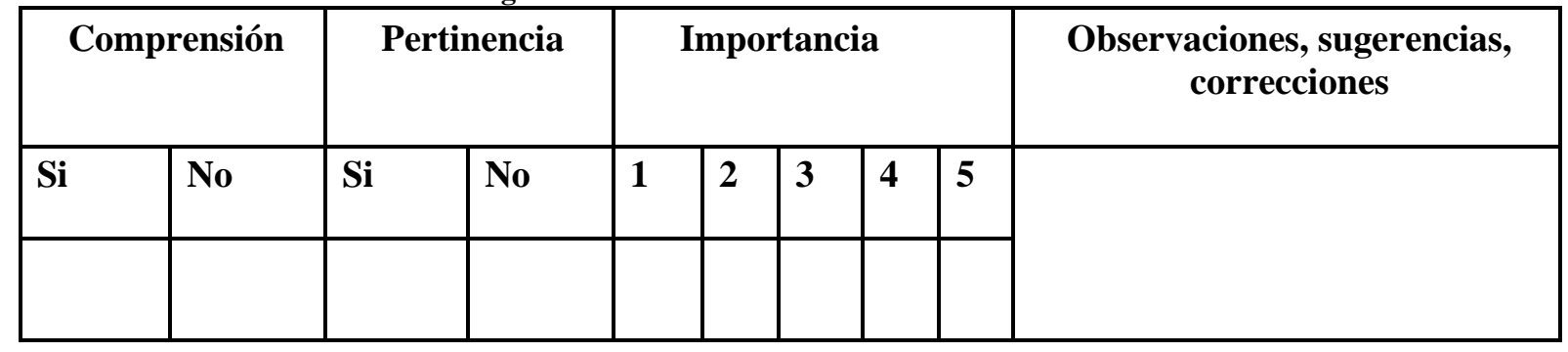

13. Uso de redes sociales

\begin{tabular}{|c|c|c|c|c|c|c|c|c|c|}
\hline \multicolumn{2}{|c|}{ Comprensión } & \multicolumn{2}{|c|}{ Pertinencia } & \multicolumn{5}{|c|}{ Importancia } & \multirow{2}{*}{$\begin{array}{c}\text { Observaciones, sugerencias, } \\
\text { correcciones }\end{array}$} \\
\hline Si & No & $\mathbf{S i}$ & No & 1 & 2 & 3 & 4 & 5 & \\
\hline & & & & & & & & & \\
\hline & & & & & & & & & \\
\hline
\end{tabular}


14. Tipos de uso de las TIC en relación a las redes sociales

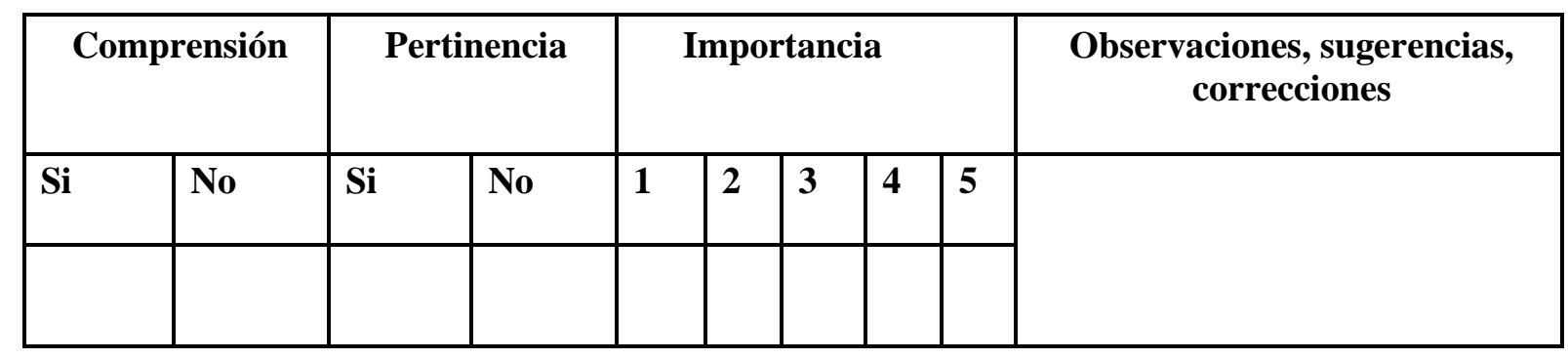

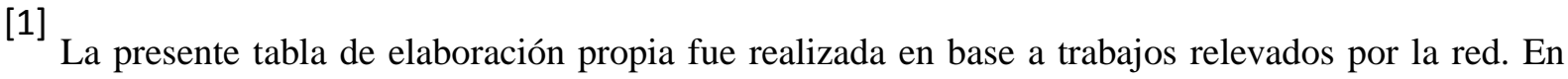
particular se tomaron en cuenta las síntesis de trabajos desarrollados por el programa conectar igualdad, UNIPE, OEI, IPE UNESCO entre otros. 
[1]

Los ámbitos de la búsqueda fueron, comenzando con el ámbito internacional, luego regional, y se realizó una búsqueda más en detalle, en la región latinoamericana del cono sur - argentina, chile, Uruguay, Perú, Paraguay.

La bibliografía en estudios de investigación y evaluación de la inclusión digital en escuelas es abundante y se encuentra una dinámica de expansión y crecimiento. Se encontraron artículos, en revistas, tesinas y estudios dirigidos al análisis, evaluación e impacto delos programas oficiales educativos de implementación del modelo 1 a 1 en los sistemas educativos (plan ceibal en Uruguay, conectar igualdad en Argentina, Enlace en chile).

[2]

Ver sección de Anexos

[3] En el ámbito de investigación relacionada con nuestro campo, es frecuente que se soliciten análisis, juicios de expertos, ensayos, evaluaciones o simplemente comentarios de colegas y personas implicadas en el uso de las TIC en los procesos de enseñanza-aprendizaje. En tal sentido, a través del Panel Internacional de Investigación en Tecnología Educativa de la Universidad de las Islas baleares (España), se ofrece el funcionamiento un servicio formalizado de jueces expertos, evaluadores, etc. que puedan ser seleccionados con criterios adecuados de aleatoriedad, adecuación, experticia, etc. en función de cada una de las demandas, al servicio de la comunidad académica relacionada con la Tecnología Educativa.

El Panel Internacional está conformada por un Comité de por varios expertos en el campo de la tecnología educativa nombrados por la junta directiva (de EDUTEC España), de modo tal, que se puedan garantizar la validez del procedimiento de selección y asimismo acreditación adecuada de la participación de dicho panel por parte de los expertos. Esta comunidad de especialistas, permiten llevar a cabo el trabajo técnico que brindan garantía a los procedimientos metodológicos de validación por expertos.

parte de los expertos

[5]

al final del trabajo puede consultarse el anexo correspondiente a la validacion a través del Panel de Expertos. 


\section{ANEXO \\ VALIDACIÓN INSTRUMENTO POR PANEL DE EXPERTOS}

En el presente apartado se presenta los diferentes aspectos valorado en el instrumento de encuesta elabora en el presente trabajo. A continuación se detallan las principales observaciones y estimación de puntajes realizado por el panel de experto ${ }^{5}$ sobre la comprensión, pertinencia e importancia de cada una de las variables y dimensiones que el instrumento diseñado: encuesta EDUTICRG v1

Dimensión 1 - (DATOS DE IDENTIFICACIÓN DEL DESTINATARIO DE LA ENCUESTA)

\begin{tabular}{|c|c|c|c|}
\hline Variables & Puntaje & observaciones & Valoración \\
\hline $\begin{array}{l}\text { Sexo; } \\
\text { Años de experiencia } \\
\text { docente; Edad } \\
\text { Formación / titulo; } \\
\text { Cantidad de horas } \\
\text { que trabaja como } \\
\text { profesor; Materias } \\
\text { que imparte }\end{array}$ & $\begin{array}{l}\text { Comprensión } 5 / 0 \\
\text { Pertinencia 5/0 } \\
\text { Importancia 24/25 }\end{array}$ & $\begin{array}{l}\text { Compuesta por } 6 \text { ítems } \\
\text { Fue valorada bien tanto la } \\
\text { comprensión y la pertinencia } \\
\text { En relación a la importancia } \\
\text { obtuvo una puntuación de } \\
0,96 \\
\text { Se sugirió agregar intervalores } \\
\text { en relaciona a lo sugerido en } \\
\text { años de experiencia, y ajustar } \\
\text { dicha escala intervalar }\end{array}$ & $\mathrm{Si}$ \\
\hline
\end{tabular}

\section{Tabla 8.- Valoración De La Dimensión 1}

Dimensión 2 (APROPIACIÓN Y VALORACIÓN INSTITUCIONAL DE LAS TIC)

Objetivo: Conocer cuál es el grado que el docente percibe sobre la importancia que la institución le otorga a las TIC.

\begin{tabular}{l|l|l|l}
\hline \multicolumn{1}{c|}{ Variables } & \multicolumn{1}{|c|}{ Puntaje } & \multicolumn{1}{c}{ Observaciones } & Valoración \\
\hline $\begin{array}{l}\text { Aporte que supone } \\
\text { la introducción de } \\
\text { las TIC en el centro } \\
\text { educativo }\end{array}$ & $\begin{array}{l}\text { Comprensión 5/0 } \\
\text { Pertinencia 5/0 } \\
\text { Importancia 19/25 } \\
(0,76)\end{array}$ & $\begin{array}{l}\text { Compuesta por 3 ítems } \\
\text { Respecto a los indicadores se } \\
\text { realizan consultas sobre } \\
\text { aspectos toóricos } \\
\text { indagados... se modificó } \\
\text { Se propone modificar } \\
\text { algunos items que supnen } \\
\text { sesgo tecnocentrico. }\end{array}$ & \\
\hline
\end{tabular}

\footnotetext{
${ }^{5}$ conformado y gestionado por el grupo de investigación en tecnología educativa de la universidad de las Islas Baleares
} 
Grado de Comprensión 4/1 satisfacción de la Pertinencia 3/2 inclusión de las TIC en el aula
Se observa ítems sobre se modificó creencias del docente..

Se reformula ítems para unificar la escala likert para todas las demás preguntas

\section{Tabla 9.- Valoración De La Dimensión 2}

Dimensión 3 (CAPACITACIÓN Y HABILIDADES TIC DEL DOCENTE)

\begin{tabular}{|c|c|c|c|}
\hline Variables & Puntaje & Observaciones & Valoración \\
\hline $\begin{array}{l}\text { Curso recibidos de } \\
\text { capacitación en TIC }\end{array}$ & $\begin{array}{l}\text { Comprensión } 5 / 0 \\
\text { Pertinencia } 5 / 0 \\
\text { Importancia 20/25 }\end{array}$ & $\begin{array}{l}\text { Se modifica el valor } 0 \text { como } \\
\text { escala }\end{array}$ & si \\
\hline $\begin{array}{l}\text { Cantidad de cursos } \\
\text { recibidos }\end{array}$ & $\begin{array}{l}\text { Comprensión } 5 / 0 \\
\text { Pertinencia } 5 / 0 \\
\text { Importancia } 23 / 25\end{array}$ & $\begin{array}{l}\text { Ítems poco relevante, se } \\
\text { reformula el aspecto } \\
\text { cuantitativo de los cursos. }\end{array}$ & no \\
\hline $\begin{array}{ll}\text { Modalidad } & \text { de } \\
\text { Capacitación } & \end{array}$ & $\begin{array}{l}\text { Comprensión } 5 / 0 \\
\text { Pertinencia } 5 / 0 \\
\text { Importancia } 23 / 25 \\
\text { Observaciones }\end{array}$ & & si \\
\hline $\begin{array}{l}\text { Temática de } \\
\text { capacitación }\end{array}$ & $\begin{array}{l}\text { Comprensión } 5 / 0 \\
\text { Pertinencia } 5 / 0 \\
\text { Importancia 22/25 }\end{array}$ & $\begin{array}{l}\text { Se sugiere Agregar temáticas } \\
\text { de carácter pedagógico }\end{array}$ & si \\
\hline $\begin{array}{ll}\text { Valoración } & \text { de } \\
\text { utilidad de la } \\
\text { capacitación para la } \\
\text { clase }\end{array}$ & $\begin{array}{l}\text { Comprensión } 4 / 1 \\
\text { Pertinencia } 4 / 1 \\
\text { Importancia 20/25 }\end{array}$ & $\begin{array}{l}\text { Se sugiere Redactar mejor el } \\
\text { ítem. puede haber problemas } \\
\text { para responder porque genera } \\
\text { confusión.. reformular la } \\
\text { redacción }\end{array}$ & si \\
\hline $\begin{array}{l}\text { Habilidades en TIC } \\
\text { del docente }\end{array}$ & $\begin{array}{l}\text { Comprensión } 5 / 0 \\
\text { Pertinencia } 5 / 0 \\
\text { Importancia } 23 / 25\end{array}$ & $\begin{array}{l}\text { En vez de escalar likert.. see } \\
\text { propone vaores por sí o no } \\
\text { en ítems } \\
\text { Se adapta pregunta a } \\
\text { instrumentos de autoinforme }\end{array}$ & si \\
\hline $\begin{array}{ll}\text { Modalidad } & \text { de } \\
\text { apropiación } & \text { de } \\
\text { habilidades TIC } & \end{array}$ & $\begin{array}{l}\text { Comprensión } 5 / 0 \\
\text { Pertinencia } 4 / 1 \\
\text { Importancia 20/25 }\end{array}$ & $\begin{array}{l}\text { Se podría reestructurar para } \\
\text { otra respuesta adicionales ... } \\
\mathrm{Ej} \text { cómo adquirió tal } \\
\text { habilidad.. }\end{array}$ & si \\
\hline $\begin{array}{l}\text { Valoración de la } \\
\text { Formación en TIC }\end{array}$ & $\begin{array}{l}\text { Comprensión } 4 / 1 \\
\text { Pertinencia } 4 / 1 \\
\text { Importancia 18/25 }\end{array}$ & $\begin{array}{l}\text { Podría haber otras } \\
\text { posibilidades de respuesta, } \\
\text { Se reformula el ítem }\end{array}$ & si \\
\hline
\end{tabular}

Tabla 10.- Valoración De La Dimensión 3 
Dimensión 4 (ACTITUDES HACIA LAS TIC --- REPRESENTACIÓN Y VALORACIÓN DE LOS DOCENTES HACIA LAS TIC Y SUS MODOS DE INCLUSIÓN)

Objetivo: Conocer el nivel de adhesión de los docentes respecto al uso de las TIC en las prácticas escolares.

\begin{tabular}{l|l|l|l}
\hline Variables & Puntaje & Observaciones & Valoración \\
\hline $\begin{array}{l}\text { Valoración que } \\
\text { supone la inclusión } \\
\text { de las TIC en la } \\
\text { clase }\end{array}$ & $\begin{array}{l}\text { Comprensión 4/1 } \\
\text { Pertinencia 4/1 } \\
\text { Importancia 20/25 }\end{array}$ & $\begin{array}{l}\text { Se reformula el itmes para } \\
\text { evitar Sesgo tecnocentrista }\end{array}$ & no \\
\hline $\begin{array}{l}\text { Actitudes } \\
\text { percepción y de } \\
\text { dificultades para la } \\
\text { inclusión TIC }\end{array}$ & $\begin{array}{l}\text { Comprensión 5/0 } \\
\text { Importancia 21/25 }\end{array}$ & $\begin{array}{l}\text { Reformular el itmes de } \\
\text { manera positiva }\end{array}$ & si \\
\hline
\end{tabular}

\section{Tabla 11.- Valoración De La Dimensión 4}

Dimensión 5 (APROPIACIÓN Y USO DE LAS TIC PARA LA PRÁCTICA PEDAGÓGICA)

Objetivo: Conocer los principales usos de las TIC y su relación con las prácticas pedagógicas orientadas a la incorporación de las TIC en el aula.

\begin{tabular}{|c|c|c|c|}
\hline Variables & Puntaje & observaciones & Valoración \\
\hline $\begin{array}{l}\text { Uso de las TIC en la } \\
\text { planificación }\end{array}$ & $\begin{array}{l}\text { Comprensión } 5 / 0 \\
\text { Pertinencia } 5 / 0 \\
\text { Importancia } 23 / 25\end{array}$ & & si \\
\hline $\begin{array}{l}\text { Uso de las TIC en } \mathrm{p} \\
\text { pedagógicos }\end{array}$ & $\begin{array}{l}\text { Comprensión } 5 / 0 \\
\text { Pertinencia } 5 / 0 \\
\text { Importancia } 23 / 25\end{array}$ & $\begin{array}{l}\text { Un experto sugiere que la } \\
\text { pregunta ya estaría } \\
\text { contestada en ítem anterior } \\
\text { se reformula para indicar si } \\
\text { utilizó en algún tipo de } \\
\text { proyecto... etc.. }\end{array}$ & si \\
\hline Usos de recursos digi & $\begin{array}{l}\text { Comprensión } 5 / 0 \\
\text { Pertinencia } 5 / 0 \\
\text { Importancia } 24 / 25\end{array}$ & & si \\
\hline $\begin{array}{l}\text { Tipo de recursos } \\
\text { digitales usados }\end{array}$ & $\begin{array}{l}\text { Comprensión } 5 / 0 \\
\text { Pertinencia } 5 / 0 \\
\text { Importancia } 23 / 25\end{array}$ & $\begin{array}{l}\text { Agregar otros... } \\
\text { Añadir objetos digitales.. } \\
\text { materiales multimedia }\end{array}$ & si \\
\hline $\begin{array}{l}\text { Acompañamiento } \\
\text { para el uso de las } \\
\text { TIC }\end{array}$ & $\begin{array}{l}\text { Comprensión } 5 / 0 \\
\text { Pertinencia } 5 / 0 \\
\text { Importancia } 22 / 25\end{array}$ & & si \\
\hline
\end{tabular}




\begin{tabular}{|c|c|c|c|}
\hline $\begin{array}{l}\text { Uso de las TIC para } \\
\text { la comunicación }\end{array}$ & $\begin{array}{l}\text { Comprensión } 5 / 0 \\
\text { Pertinencia } 5 / 0 \\
\text { Importancia } 22 / 25\end{array}$ & & si \\
\hline $\begin{array}{l}\text { Uso de las TIC para } \\
\text { búsqueda } \\
\text { información }\end{array}$ & $\begin{array}{l}\text { Comprensión } 5 / 0 \\
\text { Pertinencia 4/1 } \\
\text { Importancia 19/25 }\end{array}$ & Se activa con la otra & si \\
\hline $\begin{array}{lcc}\text { Tipos de } & \text { usos } & \text { en } \\
\text { relaciona } & \text { a } & \text { la } \\
\text { búsqueda } & & \text { de } \\
\text { información } & \text { en } & \text { la } \\
\text { red } & & \end{array}$ & $\begin{array}{l}\text { Comprensión } 5 / 0 \\
\text { Pertinencia } 5 / 0 \\
\text { Importancia } 22 / 25\end{array}$ & Ampliar opciones & si \\
\hline $\begin{array}{lrr}\text { Valoración } & \text { sobre la } \\
\text { búsqueda } & \text { de } \\
\text { información en } & \text { la } \\
\text { red } & & \end{array}$ & $\begin{array}{l}\text { Comprensión } 5 / 0 \\
\text { Pertinencia } 5 / 0 \\
\text { Importancia } 23 / 25\end{array}$ & $\begin{array}{l}\text { En vez de si o no ... ver } \\
\text { varias alternativas } \\
\text { ejemplo o tipo de acciones }\end{array}$ & si \\
\hline \begin{tabular}{lll}
\multicolumn{3}{l}{ Frecuencia de uso de } \\
las TIC en & la \\
relaciona & & la \\
búsqueda & & de \\
información & en & la \\
red & &
\end{tabular} & $\begin{array}{l}\text { Comprensión } 4 / 1 \\
\text { Pertinencia } 1 / 4 \\
\text { Importancia } 12 / 25\end{array}$ & $\begin{array}{l}\text { Puede eliminarse poniendo } \\
\text { nunca en la otra pregunta. }\end{array}$ & si \\
\hline \begin{tabular}{lll}
\multicolumn{3}{l}{ Frecuencia de uso de } \\
las TIC en & la \\
relaciona & & la \\
búsqueda & & de \\
información & en & la \\
red & &
\end{tabular} & $\begin{array}{l}\text { Comprensión } 5 / 0 \\
\text { Pertinencia } 5 / 0 \\
\text { Importancia } 22 / 25\end{array}$ & & si \\
\hline $\begin{array}{l}\text { Uso de gestores de } \\
\text { información en la } \\
\text { red }\end{array}$ & $\begin{array}{l}\text { Comprensión } 5 / 0 \\
\text { Pertinencia } 5 / 0 \\
\text { Importancia } 23 / 25\end{array}$ & $\begin{array}{l}\text { Puede eliminarse poniendo } \\
\text { nunca en la otra pregunta o } \\
\text { item }\end{array}$ & si \\
\hline $\begin{array}{l}\text { Uso de redes } \\
\text { sociales }\end{array}$ & $\begin{array}{l}\text { Comprensión } 5 / 0 \\
\text { Pertinencia } 4 / 1 \\
\text { Importancia 20/25 }\end{array}$ & $\begin{array}{l}\text { En vez de si o no .. poner } \\
\text { alternativas }\end{array}$ & si \\
\hline $\begin{array}{l}\text { Tipos de uso de las } \\
\text { TIC en relación a las } \\
\text { redes sociales }\end{array}$ & $\begin{array}{l}\text { Comprensión } 5 / 0 \\
\text { Pertinencia } 5 / 0 \\
\text { Importancia } 21 / 25\end{array}$ & & si \\
\hline
\end{tabular}

\section{Tabla 12.- Valoración De La Dimensión 5}

E5: "Añadiría algún ítem relativo a la investigación del profesorado de secundaria y las TIC; considerando que muchos están inmersos en programa planes y proyectos de calidad" 